Florida International University FIU Digital Commons

\title{
Training Through Serious Games: The Relationship Between Travel Agent Engagement, Knowledge of Cruise Products and Cruise Sales
}

Lizette Cruzie Pabon

Florida International University, lpabo002@fiu.edu

DOI: $10.25148 /$ etd.FIDC000713

Follow this and additional works at: https:// digitalcommons.fiu.edu/etd

Part of the Adult and Continuing Education and Teaching Commons, and the Curriculum and Instruction Commons

\section{Recommended Citation}

Pabon, Lizette Cruzie, "Training Through Serious Games: The Relationship Between Travel Agent Engagement, Knowledge of Cruise Products and Cruise Sales" (2016). FIU Electronic Theses and Dissertations. 2612.

https://digitalcommons.fiu.edu/etd/2612 


\section{FLORIDA INTERNATIONAL UNIVERSITY}

Miami, Florida

TRAINING THROUGH SERIOUS GAMES: THE RELATIONSHIP BETWEEN

TRAVEL AGENT ENGAGEMENT, KNOWLEDGE OF CRUISE PRODUCTS AND CRUISE SALES

A dissertation submitted in partial fulfillment of the requirements for the degree of

DOCTOR OF EDUCATION

in

CURRICULUM AND INSTRUCTION

by

Lizette C. Pabón

2016 
To: Dean Michael R. Heithaus

College of Arts, Sciences and Education

This dissertation, written by Lizette C. Pabón, and entitled Training Through Serious Games: The Relationship Between Travel Agent Engagement, Knowledge of Cruise Products and Cruise Sales, having been approved in respect to style and intellectual content, is referred to you for judgment.

We have read this dissertation and recommend that it be approved.

Hyejin Bang

Kyle Perkins

Sarah A. Mathews

Thomas G. Reio Jr., Major Professor

Date of Defense: June 28, 2016

The dissertation of Lizette C. Pabón is approved.

Dean Michael R. Heithaus

College of Arts, Sciences and Education

Andrés G. Gil

Vice President for Research and Economic Development and Dean of the University Graduate School

Florida International University, 2016 
(C) Copyright 2016 by Lizette C. Pabón

All rights reserved. 


\section{DEDICATION}

I dedicate this dissertation to my parents, my fiancé, my in-laws and my family. Without their patience, understanding, support, and most of all love, the completion of this work would not have been possible. 


\section{ACKNOWLEDGMENTS}

I wish to thank the members of my committee for their support, and patience. I would also like to thank Lee Clark and Barbara Sealund for their guidance in the area of gamification and instructional design in the business setting. 


\section{ABSTRACT OF THE DISSERTATION}

TRAINING THROUGH SERIOUS GAMES: THE RELATIONSHIP BETWEEN TRAVEL AGENT ENGAGEMENT, KNOWLEDGE OF CRUISE PRODUCTS AND CRUISE SALES

by

\section{Lizette C. Pabón}

Florida International University, 2016

Miami, Florida

Professor Thomas G. Reio Jr., Major Professor

Research is limited on the role game-based training has on the engagement of learners. The following study was conducted to further advance research on engagement and game-based training in businesses by studying the engagement of travel agents in the game.

Engagement is the manner in which a learner's cognitive and motor skills are motivated when participating in a game. Engaged learners will often push through challenging tasks and will concentrate on improving their skills due to their excitement about playing. The present study examined the engagement of travel agents as they played a serious game. The serious game, Adventures Game, was designed to provide a fun and memorable format for learning for travel agents who sell cruise tickets for a cruise line.

The focus of this study was to examine the relationship between engagement (as measured by total number of minutes playing the game) and knowledge attainment (as measured by total number of fun points) of travel agents while playing a serious game. 
In addition, to understand the relationship between engagement and total cruise sales (as measured by total number of cabins sold). Thus, this nonexperimental study investigated the relationship between engagement and knowledge attainment. A combination of linear regression analyses and correlations were used to examine this relationship. The sample consisted of travel agents $(N=309)$ who played the serious game. The study focused on data which ranged from January 1, 2012 until December 31, 2014.

The regression results supported both hypotheses proposed in this study. A strong, positive and statistically significant relationship between engagement and knowledge attainment was found. In addition, a modest, positive and statistically significant relationship between engagement and total cabin sales was found. Based on these results, further analysis was conducted, leading to finding a statistically significant relationship between knowledge attainment and total cabin sales as well.

Future research should be designed to test whether the modest link between engagement and total cabin sales is mediated by knowledge attainment. The implications of the findings demonstrate theoretical, empirical and practical relevance, particularly as it is linked to adults learning optimally in computer-mediated, workplace settings. 


\section{TABLE OF CONTENTS}

CHAPTER

PAGE

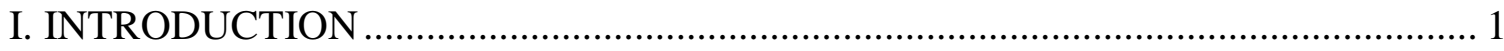

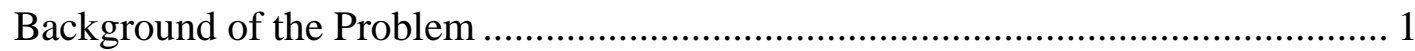

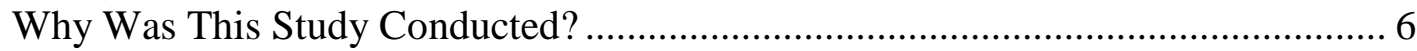

Why Was This Study Conducted at a Cruise Line?............................................... 7

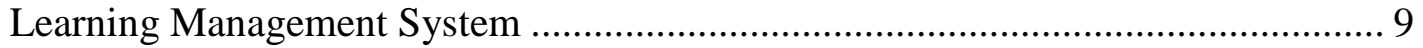

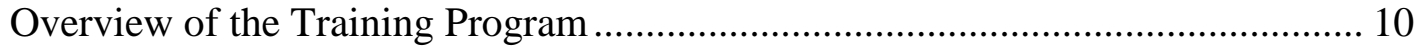

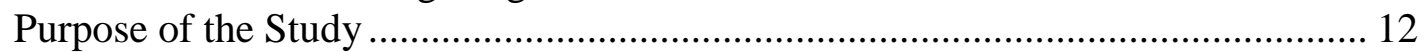

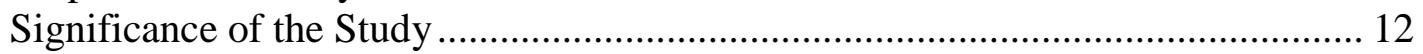

Research Questions and Hypotheses .................................................................. 12

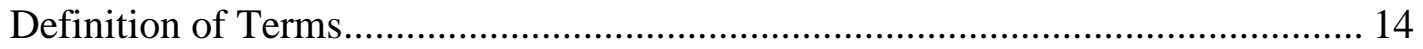

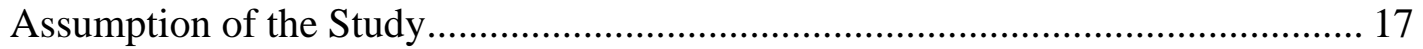

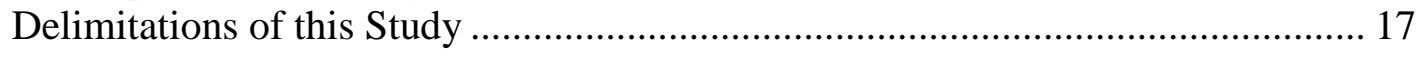

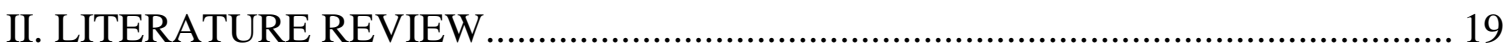

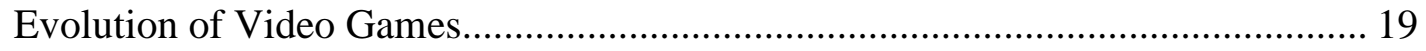

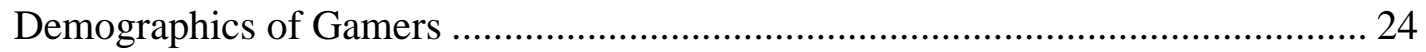

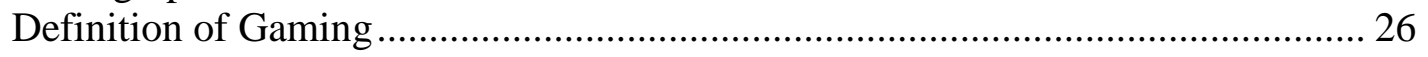

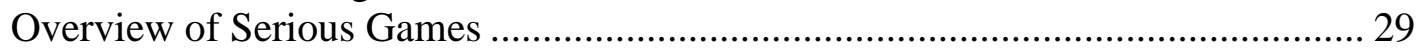

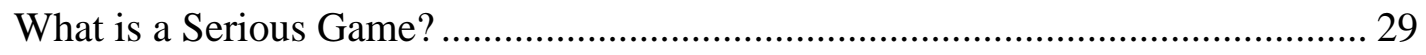

Application of Serious Games for Education and Training.................................. 34

Game-based Training Versus Face-to-Face Training ................................................ 42

Theoretical Framework for Gaming .................................................................... 43

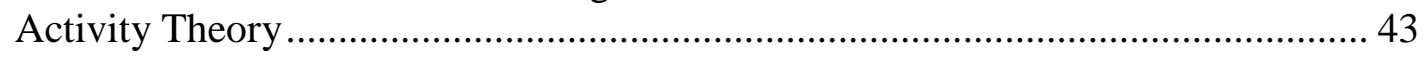

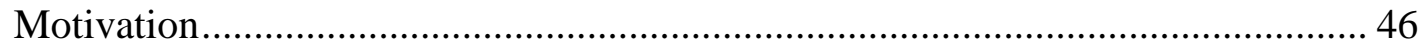

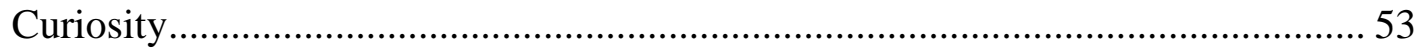

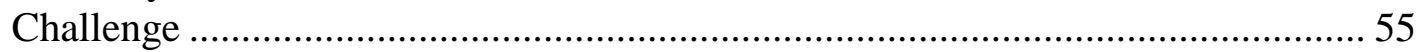

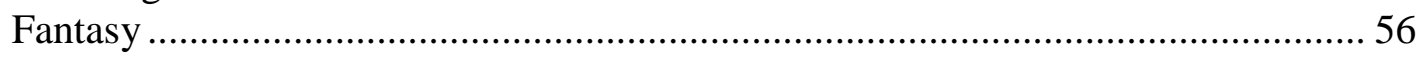

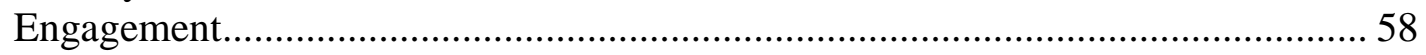

Development and Application of a Serious Game............................................. 59

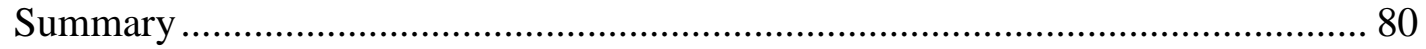

III. METHODS ............................................................................................... 81

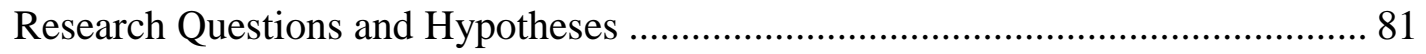

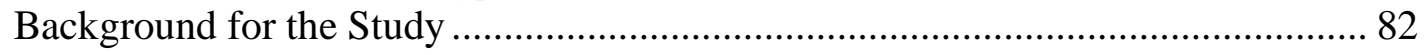

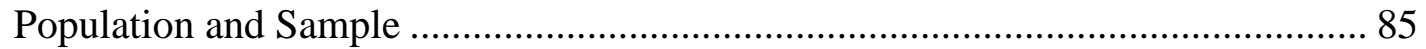

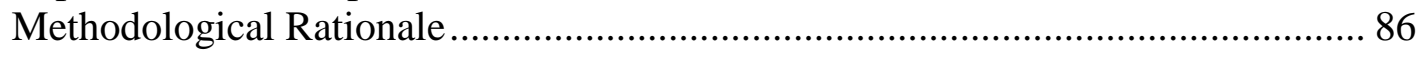

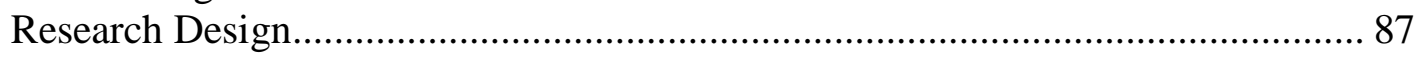

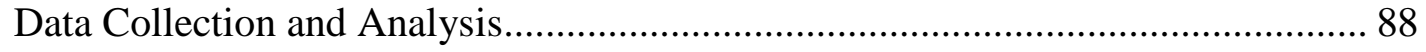

Preliminary Correlational Analyses ............................................................. 89

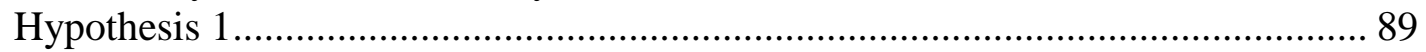

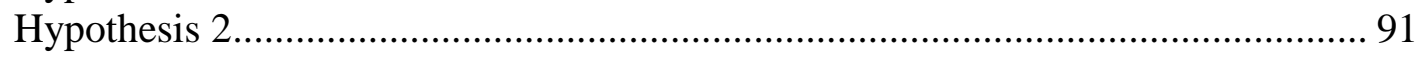




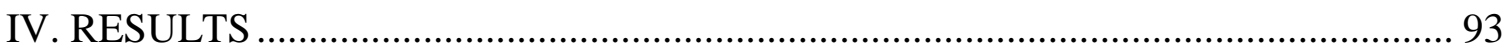

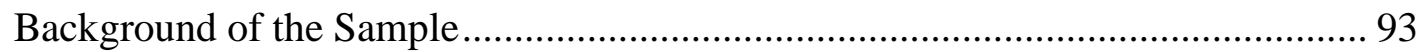

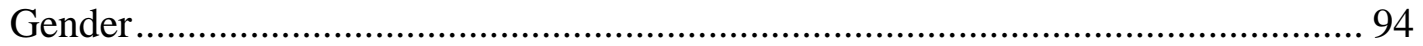

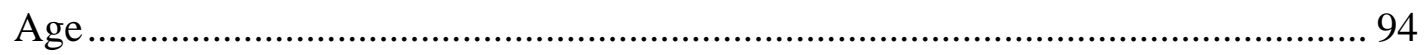

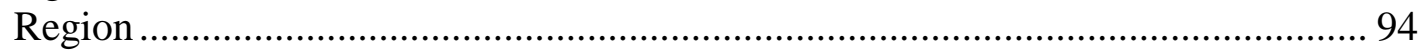

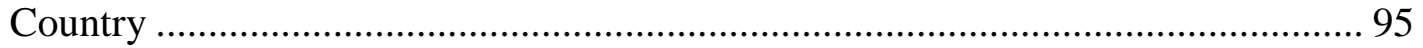

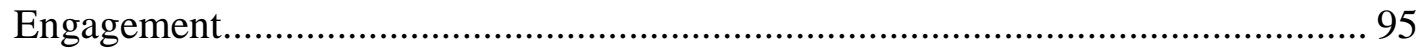

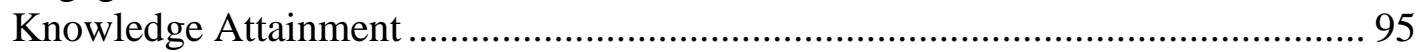

Total Cabin Sales ................................................................................................. 95

Cross Tabulation of Background Demographic Variables ........................................ 96

Examination of Hypotheses ............................................................................ 112

Preliminary Correlational Analyses ..................................................................... 112

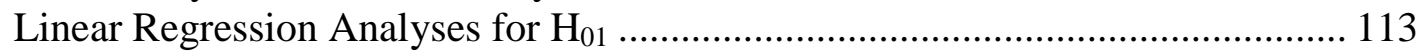

Linear Regression Analyses for $\mathrm{H}_{02}$.............................................................. 117

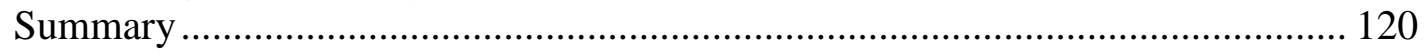

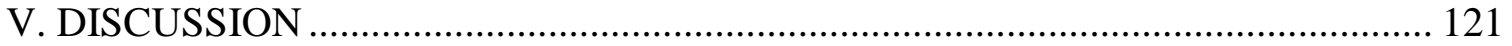

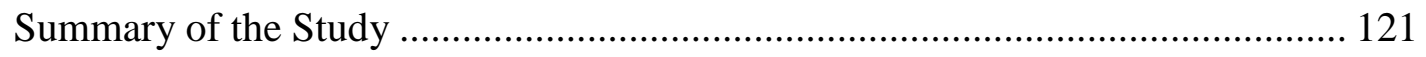

Discussion of the Results................................................................................ 123

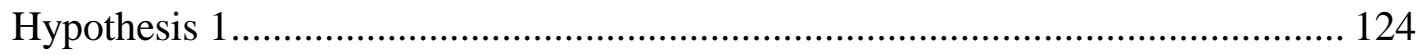

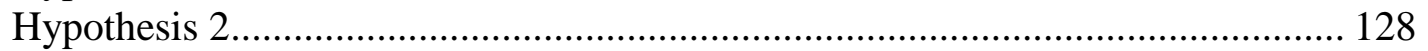

Implications for Theory, Research, and Practice .................................................... 133

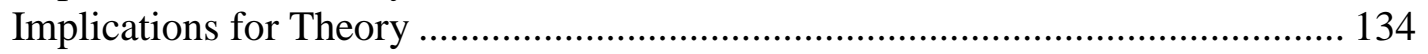

Implications for Practice .................................................................................. 138

Implications for Research ............................................................................. 140

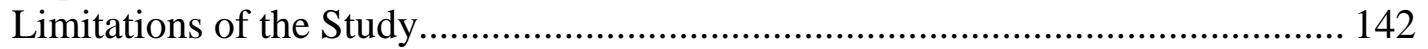

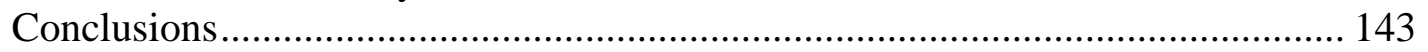

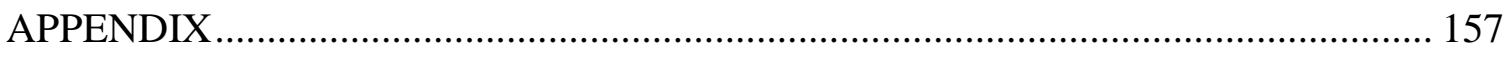

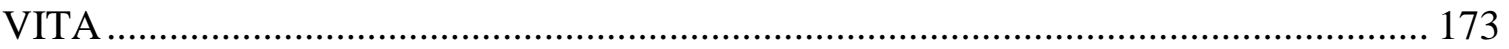




\section{LIST OF TABLES}

TABLE

PAGE

1. Demographic Variables Cross Tabulation .................................................... 98

2. One-Way ANOVA Results - Age ............................................................ 99

3. Scheffé Multiple Comparisons - Age ........................................................ 100

4. One-Way ANOVA Results - Gender ....................................................... 104

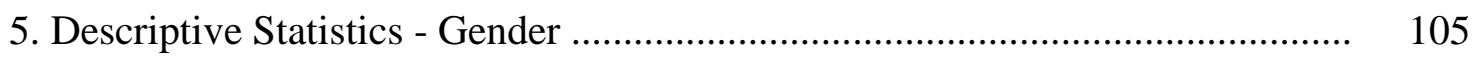

6. One-Way ANOVA Results - Region ........................................................ 106

7. Descriptive Statistics for One-Way ANOVA - Region .................................. 107

8. Descriptive Statistics for One-Way ANOVA - Country ............................... 111

9. One-Way ANOVA Results - Country ...................................................... 112

10. Preliminary Correlational Analyses ....................................................... 113

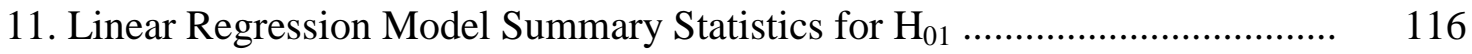

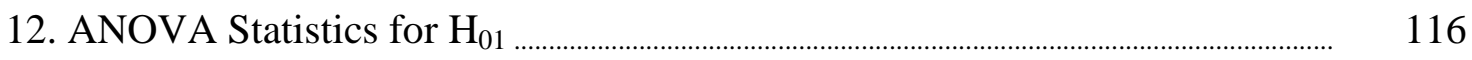

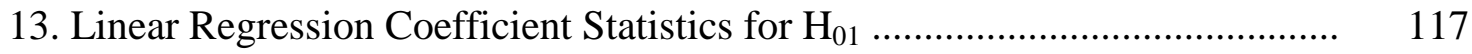

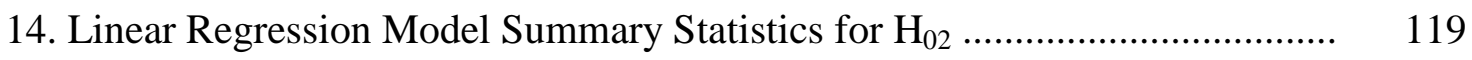

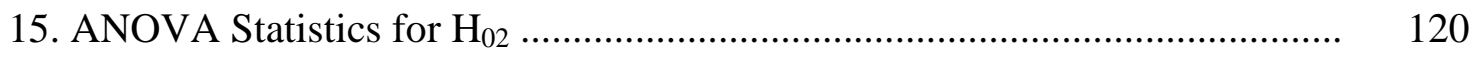

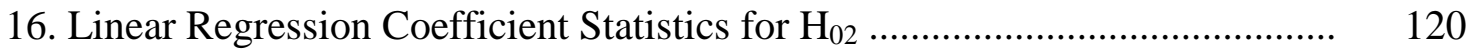




\section{LIST OF FIGURES}

$\begin{array}{ll}\text { FIGURE } & \text { PAGE }\end{array}$

1. Home page of the Passport ................................................................... 157

2. Adventures Game Page ........................................................................ 158

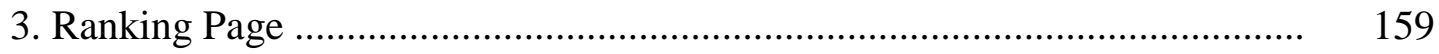

4. Adventures Game Launch Page ........................................................... $\quad 160$

5. Adventures Launch Screen ................................................................. 160

6. Adventures Avatar Screen .................................................................... 161

7. Level One - Cruise Rookie Baseball ...................................................... 161

8. Level One - Select Your Team Screen ..................................................... 162

9. Level One - Selection of Team and Description ...................................... 162

10. Level One - Cruise Rookie Selection .................................................... 163

11. Selection of your Opponents .............................................................. 163

12. Inning One - Cruise Rookie Baseball .................................................. 164

13. Inning Two - Home Run Derby ........................................................... 164

14. Level Two - Launch Page …................................................................. 165

15. Level Two - Queue for Cruisers .......................................................... 165

16. Level Two - Sample Game in Progress .................................................. 166

17. Level Three - Launch Page .................................................................. 166

18. Level Three - Begin Page and Tutorial Launch ..................................... 167

19. Level Three - Navigating the Ship …..................................................... 167

20. Level Three - Cruiser Icons ............................................................... 168 
21. Level Three - Navigating Game Questions .................................................. 168

22. Level Three - Ports of Call and Overhead Map ………………………........ 169

23. Level Three - Description and Overview of Mini-Games ............................ 169

24. Level Three - Launch Page for the Mini-Game ............................................ 170

25. Level Three - Karaoke Mini-Game .............................................................. 170

26. Level Three - Casino Mini-Game ………………......................................... 171

27. Level Three - Sample Game in Progress ……………………..................... 171

28. Game Completion Screen ………………………….................................. 172

29. Achievement Screen ............................................................................. 172 


\section{CHAPTER I}

\section{INTRODUCTION}

This study evaluated the use of a serious game to train travel agents at a large cruise line and their engagement while playing the serious game. The study assessed the travel agents' training outcomes of knowledge attainment and drive towards engagement. This introductory chapter discusses the background of the problem and the basic research question and hypotheses addressed in the study. It then provides an overview of the conceptual framework of the study that is discussed in Chapter 2, and the purpose, significance, and anticipated consequences of the study. This chapter concludes with the definitions of key terms, the assumptions, and the delimitations of the study.

\section{Background of the Problem}

Gaming is a widely used term that is defined in numerous ways. Knapp (2012) defined a game as, "a system in which players engage in an abstract challenge, defined by rules, interactivity, and feedback, that results in a quantifiable outcome often eliciting an emotional reaction" (p. 7). Using this definition, games provided evidence for components that are essential in promoting engaged learning environments.

Games have provided a motivating environment conducive to learning (Subrahmanyam \& Greenfield, 1994). Researchers have suggested that gaming was a new means to teach (de Freitas, 2006). Since the inception of commercial off-the-shelf games, they were primarily used for entertainment and enjoyment purposes. Research has supported the idea that there was an interaction between play and learning. Research has suggested that there were important components necessary in a game to enhance learning, visualization, experimentation, and creativity of play (Betz, 1995). The first 
component, visualization has been demonstrated to be essential to enhancing diversity and developing problem solving skills for learners (Hooper \& Rieber, 1995). Games have enhanced the players ability to react quickly and explore the environment visible on the screen. Games have also influenced the players ability to formulate ideas and compete with other users in the game (Leutner, 1993).

Games have enhanced skill development of every day needs, such as developing confidence, taking risks, and improving communication skills (Federation of American Scientists, 2006). Using a game for training has encouraged flexibility and enhanced the employee's love for gaming. Games have been used for vocational and educational training purposes (Federation of American Scientists, 2006). Reeves, Malone, and O'Driscoll (2006), shared findings of a report completed on the use of the game, World of Warcraft, in promoting leadership skills amongst business professionals,

Leadership in online games offers a sneak preview of tomorrow's business world. In broad terms, that environment can be expected to feature the fluid workforces, the self-organized and collaborative work activities, and the decentralized, nonhierarchical leadership that typify games. In more specific terms, we found several distinctive characteristics of leadership in online games that suggest some of the qualities tomorrow's business leaders will need in order to achieve success. Some of these characteristics included risk taking and the ability to work quickly and efficiently.

As presented above serious games have created a fun environment that enhanced leadership and skill development amongst users. Simulations have been used for providing professional development credits and as an introduction to potential vocational 
careers (Squire, 2005). As Squire (2005) demonstrated in his research, games have enhanced motivation and aided learners in developing high level and complex skills. Games have built upon previous experience to enhance learning. In turn, this has lead to the development of problem solving and critical thinking skills (Squire, 2005).

Over the years, educational games have evolved into what is currently known as "serious games". Serious games have been traditionally used in the classroom or for training purposes. Michael and Chen (2006) defined the term serious game as, "a game in which education (in its various forms) is the primary goal, rather than entertainment" (p. 17). Serious games demonstrate a wide range of opportunities for educational and training applications.

Serious games were initially used in a number of sectors including health care, and the business arena (Federation of American Scientists, 2006). The healthcare sector followed in the footsteps of the military and used serious games for training medical practitioners. The simulations have been used to provide medical practitioners realistic role-play rather than traditional modes of teaching. Training simulations have illustrated clear and well defined learning objectives with no fixed answers (Federation of American Scientists, 2006).

Serious games are used to enhance the learning experience for students. Marinho (2012) noted that serious games have been used to create an environment conducive to enhancing skills such as problem solving, collaboration, emotional intelligence and encouraging communication amongst players. The Federation of American Scientists (2006) reinforced this idea with their description of the role of serious games and their ability to, "Teach higher order thinking skills such as strategic thinking, interpretive 
analysis, problem solving, plan formulation and the ability to rapid change" (p. 6). As evident here games have provided support on multiple levels for a learner and have been a great tool for training or teaching purposes.

Serious games are available in 3-D virtual formats, which provided realistic visualizations for the learner (Federation of American Scientists, 2006). For example, the U.S. Army has used serious games to train soldiers for combat by providing a visual representation of the actual warfare environment without causing physical harm to anyone. Serious games have provided a safe space for training since they are visually realistic and are able to provide an immersive environment that is cost-effective (Federation of American Scientists, 2006). The military has been able to provide realistic visuals of the battlefield and place the learner into the field without causing them physical harm.

Over the past few years, game developers capitalized on the ultimate potential of using games for education and training. For example, games like Where in the World is Carmen San Diego? and Oregon Trail were used to educate learners in geography (Sitzmann, 2011). Serious games have been one of the most popular games used for simulation training. As previously noted in Micheal and Chen’s (2006) definition of serious games, they were designed for the purpose of educating learners. Sitzmann (2011) provides another definition for serious games by stating that serious games are a type of instruction that provide a virtual and simulated environment that encourages the learner to develop decision making skills. Malone (1981) noted that serious games provided an environment where the learner was fully immersed in the game and lost themselves while playing; therefore, increasing their intrinsic motivation. 
Slagle (2006) noted that video games were seen as very popular for adults. Over $40 \%$ of adults play games regularly; therefore, emphasizing the importance of harnessing the motivation of learners that results from playing a video game and using it towards improving the learning and training experience (Garris, Ahlers, \& Driskell, 2002). Cold Stone Creamery harnessed this idea by creating a game for the purpose of training new employees. The design of the game consisted of a virtual Cold Stone Creamery Store to replicate an actual ice store in action. The goal of the game was to train new employees on the techniques and skills needed to address customer service issues and serving ice cream to customers using portion control (Jana, 2006). The employee was required to balance serving the customer quickly and serving the appropriate amount of ice cream, while making a profit for the company. Within the first week of dissemination, over 8,000 employees ( $30 \%$ of the workforce) played the game without being required to play. Corporate trainers in the Cold Stone Creamery organization suspected that players would continue to play the serious game, because of its entertainment aspect, while also enhancing their skill development; even though there was not research or results to support this assumption (Jana, 2006).

Similarly, Canon used a simulation game to train their employees (Jana, 2006). The game focused on training staff on the techniques needed to conduct copy machine repairs. The game was developed with a virtual environment replicating a board game. A board game is a game that contains pieces that are moved or placed on a pre-marked surface such as a board and followed a set of rules to play. Some examples of board games are chess, checkers, Monopoly, etc. The employee was required to drag and drop parts into the correct location on the copy machine. When an incorrect location was 
selected, a light would flash on the screen and a buzzer would sound. Jana (2006) noted that employees who were trained using the serious game exhibited a 5-8\% increase in their training assessment scores compared to those who used traditional training methods.

Engagement is a key indicator to academic success, motivation, and continual progress in a task (Rozendaal, Braat, \& Wensveen, 2010). Engagement is the manner in which a learner's cognitive and motor skills are motivated when participating in a game (Rozendaal et al., 2010). The learner experiences positive motivation to continue playing as an act of engagement. Engaged learners push through challenging tasks and concentrate on improving their skills due to their excitement about playing. Engaged learners are likely to demonstrate positive attributes such as enthusiasm, optimism, curiosity, and interest (Rozendaal et al., 2010). Maximizing the players' engagement, requires for equilibrium to exist between the players' interest and the level of challenge exhibited by playing the game (Hoffman \& Nadelson, 2010). For example, if the game is too easy for the learner, engagement decreases. On the other hand, if the game offers the optimal level of challenge, then engagement is increased (Hoffman \& Nadelson, 2010). The present study examined the relationship between engagement and knowledge attainment of travel agents as they played a serious game.

\section{Why Was This Study Conducted?}

Research is limited on the role of engagement in game-based training and the business impact of gaming. The study was conducted to expand current research on engagement and game-based training in businesses by investigating engagement and knowledge attainment of travel agents who played the serious game. Currently, there is limited research on using game-based training to train travel agents in the cruise line 
industry. The researcher saw the opportunity to expand current research on this topic and understand the role of game-based training in the travel industry.

\section{Why Was This Study Conducted at a Cruise Line?}

The following cruise line was selected because they were the first cruise line to develop a serious game and the travel industry had not previously used a serious game for training purposes. In addition, they are the world's largest cruise line and would be able to provide an example for competitors to follow in their path. In addition, there was limited research surrounding gamification in the cruising industry. Gamification is the idea of applying game mechanics and game design techniques to engage and motivate players as they fulfill the goals outlined within the game. The study can provide guidance for future research and the potential advancement of game-based training in the cruising industry.

A cruise line decided to conduct this study, because they wish to understand the relationship between engagement and knowledge attainment of travel professionals who completed their trainings. Prior to this program, travel agents participated in a traditional certificate program, for which there are limited data on the completion status of participants. The traditional certificate program consisted of travel agents completing 10 courses to attain the Bachelors degree, 10 courses and a Seminar at Sea or Live Event for the Masters of Memories Degree, and 10 courses and 2 or more Live Events for the PhD Degree. Each item was self reported by the travel agent and verified by the department administering the certificate. Travel agents receive a certificate for completing each degree. In addition, the cruise line was unable to determine the engagement of learners. Management only knew that $10 \%$ of active travel agents affiliated with the cruise line 
completed the certificate program. Because of the lack of tracking, the cruise line developed a training site (Learning Management System: LMS) and expanded their training program to include a serious game.

On the basis of the attributes detailed here, a large cruise line designed a serious game. The game was designed with the intention to increase engagement of travel agents through a fun and entertaining environment. In collaboration with Sealund Innovative Associates, the serious game was designed using game design and gamification techniques. A key component of the game was that when a player answered a question, that player received immediate feedback (Sealund, 2012). In the game, the learner received a response of correct or incorrect immediately after answering a question. The learner, after finishing the level returned to the LMS and reviewed a tutorial on the question topic that he/she answered incorrectly. Game questions were updated on a monthly basis to reflect new tutorials that were added to the LMS. The learner, reinforced their learning through this action and repeatedly tested their knowledge.

To address flow, the game was designed with three levels each with two sublevels. The three levels allowed the player the ability to select the level of difficulty. The user selected from Easy, Easy 2, Medium, Medium 2, Hard, and Hard 2. Each level began with an optional tutorial to guide the user on how to play each level and complete it successfully. At the beginning of the game the player was presented with a cartoon and an introduction to the game. The tutorial at the beginning of each level, provided instruction to the player on navigating the game and successfully completing the level.

To incorporate motivation in the game, a passport was added to allow the learner to see which stamps he/she had attained while playing the game. The stamps were 
various awards the player received for accomplishments in the game. In addition, continual feedback was incorporated allowing the player to see how he/she was progressing within the game. At the top of the screen was a goal bar that allowed the player to see the total fun points he/she had achieved and what was needed to complete the level. Fun points are points that are attained throughout the game for answering a question correctly, the speed of answering a question, and successfully completing the home run derby and mini games.

The last component that was incorporated was interaction. The player interacted with objects in the game. For example, during the speed booking level the player interacted with cruise rookies to book them on a cruise. In addition, in the cruising level the player interacted with cruise rookies to learn about the experiences onboard. These items provided guidance and structure to the game. A well-organized game promoted interaction between the learner and the video game (Juul, 2005). As seen in the game, activities such as the home run derby, interactive game questions after each movement of a cruiser, simulated cruising experience, and an interactive speed booking level, each provided interaction between the content and initiated various levels of information processing by the player (Sealund, 2012).

\section{Learning Management System}

In conjunction with the serious game, the cruise line deployed a series of eLearning tutorials via Taleo’s Oracle Learning Management System (LMS). Through the assistance of Taleo Oracle, the cruise line released an LMS called Passport. The cruise line conducted a soft launch on October 5, 2012 and a full launch of the LMS on January 2, 2013. The serious game was housed in the Taleo Oracle Learn Center, which was 
managed by a member of the cruise lines trade team. Prior to the development of the LMS, the cruise line did not have a software application to track and administer training to their travel agents. The management team decided that they needed to be able track and report on their training programs; therefore, an LMS was developed. An LMS is a software application typically used for the administration, documentation, tracking, reporting and delivery of e-learning training programs.

Corporate training departments use an LMS to deliver online training and manage registration for training events. The cruise line used the LMS to track enrollment and completion of e-learning training, live events and virtual training events. The LMS was designed to allow agents to select individual path of learning without any restrictions. Agents were able to select an e-learning training (job aid, FAQ, tutorial, video, or game) from one of the nine portals available on the home page of the LMS. New training was added each month. The LMS was used to manage and host the Adventures Game.

\section{Overview of the Training Program}

The largest and world’s leading cruise line has been training over 80,000 travel agents for many years through the combination of online and instructor led trainings. Training results were satisfactory; however, they were limited in showing travel agents’ continuing engagement in their learning. As noted by Clark,

When we began the redesign of our learning delivery system, we reflect on what our past system did not do. ... One of the major shortcomings was that it did not drive engagement, meaning that it was a "one-and-done"type program. Once the travel agent completed the program, he or she had no reason to re-engage with 
either the training or with us. Ongoing engagement became a key objective in what we wanted to build (as cited iWinchester, 2013, p. 39).

Based upon the research presented in this introduction, the present study examined the relationship between engagement and knowledge attainment of travel agents as they played a serious game. The serious game, Adventures Game, was designed to provide a fun and memorable format for learning for travel agents who sell cruises for the cruise line. There were three primary goals in designing the serious game: (a) Engagement/fun, (b) Familiarize agents with ships and destinations, and (c) Familiarize agents with the cruise lines policies and procedures. This game was designed to teach higher order thinking skills in a fun and engaging format without the learner realizing they were engaged while learning at the same time.

The cruise line partnered with Sealund Innovative Associates, a Tampa based developer of innovative training solutions. The innovative training solution organization has been a leader since 1985 with implementing e-learning and game-based solutions with leading agencies in the government, military and health care industry. Sealund Innovative Associates designed the Adventures Game for the cruise line. Prior to selecting this organization the cruise line completed a RFP process where they received bids from two large gaming organizations, Game On Learning! and Sealund Innovative Associates. The cruise line had a team of six individuals who reviewed the proposals and selected the organization that would design the serious game. The cruise line decided to partner with this organization due to their extensive experience of designing serious and simulation games for a variety of fields(including, the military, education and health 
care). In addition, the cruise line appreciated that the organization was located within four hours of their headquarters, making it easier to meet in person if needed.

\section{Purpose of the Study}

The purpose of the study was to examine the relationship between engagement and knowledge attainment of travel agents who played a serious game. Is there a relationship between playing a serious game and engagement of travel agents? Is there a relationship between travel agent engagement and cruise sales? These questions are examined further in the subsequent chapters.

\section{Significance of the Study}

This research study was important in understanding travel agent engagement and knowledge attainment. Currently, this is the only cruise line that had used a serious game to train travel professionals about the cruise industry. The information provided through this study may provide insight into the learning, development, and training of travel professionals in the future. In addition, this study can aid in understanding how gamebased training can be applied to the educational setting and assist in understanding gender differences with game-based training.

\section{Research Questions and Hypotheses}

The research study focused on the following two research questions.

Research Question One. Is there a relationship between engagement (total number of minutes playing the game) of travel agents who play the Adventures Game (a serious game designed with three levels that allows the travel agent to attain fun points) and their knowledge attainment (total number of fun points earned)? 
Null Hypothesis $\left(H_{01}\right)$ for Research Question One. There is no relationship between engagement (as measured by number of minutes playing the game) of travel agents playing the Adventures Game and knowledge attainment (as measured by the total number of fun points).

Alternative Hypothesis One $\left(H_{1}\right)$ for Research Question One. There is a positive relationship between engagement (as measured by number of minutes playing the game) of travel agents playing the Adventures Game and knowledge attainment (as measured by the total number of fun points).

Research Question Two. Is there a relationship between engagement and playing serious games on the agent's total cruise sales?

Null Hypothesis Two $\left(\mathrm{H}_{02}\right)$ for Research Question Two. There is no relationship between engagement (as measured by total number of minutes playing the game) of a travel agent who plays the serious game and their total cruise sales (as measured by the total number of cabins sold).

Alternative Hypothesis Two $\left(\mathrm{H}_{2}\right)$ for Research Question Two. There is a positive relationship between engagement (as measured by total number of minutes playing the game) of a travel agent who plays the serious game and their total cruise sales (as measured by the total number of cabins sold).

The general context of this study focused on the cruise industry. The data for this study, were collected from the cruise line's data base for those participants who played a game-based training program. 


\section{Definition of Terms}

The following terms are defined in order for readers to understand common terminology used throughout this study:

Avatar is an image of that represents an individual in a serious game.

Challenge is the ability of the learner to gain control over the environment.

Computer Game is a range of games which can be recorded on cassette or disc for use in a home computer, that are played by manipulating a mouse, joystick, or the keys on the keyboard of a computer in response to the graphics on the screen.

Console Video Games are individual devices that create a video signal or image to display a game which can be played.

Curiosity is the strong desire of a player to learn a new skill or gain new knowledge. Digital Game is a "system in which players engage in an artificial conflict, defined by rules, that results in a quantifiable outcome" (Salen and Zimmerman, 2003).

Engagement is a "predictive of academic proficiency, motivation, and task persistence, with the balance between learner interest and task demands determining the strength of that engagement" (Hoffman \& Nadelson, 2010). Engagement in this study is measured by the total number of minutes playing the game.

Fantasy is an environment that "evokes mental images of physical or social situations not actually present” (p.240). Garris et al. (2002) asserted that including "imaginary or fantasy context, themes, or characters” and providing “optimal level of informational complexity” can make computer games motivational (p. 447).

Flow is described by Csikszentmihalyi (1990) as the order in which an individual performs a task. In a game, this relates to the pattern of action that occurs by the player. 
Fun points were the points attained by the player while playing the Adventures Game. These points were attained through answering questions correctly and quickly, completing mini-games successfully and completing the home run derby. Knowledge attainment was measured by the total number of fun points the travel agent received in the serious game by playing.

Games were fun engaging activities usually used purely for entertainment, but they may also allow people to gain exposure to a particular set of tools, motions, or ideas. All games were played in a virtual world structured by specific rules, feedback mechanisms, and requisite tools to support them. Games were defined as, "one or more players compete or cooperate for pay-off according to a set of rules or . . . a setting in which participants make choices, implement those options and receive consequences of those decisions as an effort to achieve given objective,” (Vogel et al., 2006, p.231). Game Based Learning (GBL) is a form of gaming that using learning objectives to direct game play, and engage learners to solve the problem.

Gamification is defined by Knapp (2012) as "a careful and considered application of game thinking to solving problems and encouraging learning using all the elements of games that are appropriate" (p. 16).

Goals were clear and concise statements written in SMART format to guide the direction of the game and identify learning outcomes. SMART format is known as Specific (target a specific area for improvement), Measurable (Contains an indicator that demonstrates progress), Attainable (Goal is in-line with company goals), Realistic (Results-based) and Time-Bound (Trackable) 
Handheld Video Games were those games designed to be played using a handheld device such as Nintendo Gameboy, PDAs and mobile devices.

Learning Management System (LMS) is a web-based software application such as Moodle, Webct 6.0 or Blackboard, which are used to plan, implement and evaluate a learning program.

Massively Multi-player Online Games (MMOGs) were highly graphical 2- or 3-D videogames played online, allowing individuals, through their self-created digital characters or "avatars," to interact not only with the gaming software (the designed environment of the game and the computer controlled characters within it) but with other players' avatars as well. These virtual worlds were persistent social and material worlds, loosely structured by open-ended (fantasy) narratives, where players are largely free to do as they please - slay ogres, siege castles, barter goods in town, or shake the fruit out of trees (Steinkuehler, 2004, p. 521).

Multi-User Dungeons (MUDs) are a multiplayer online game which incorporates role playing, interactive fiction, and online chats within the game for players to use to interact with each other while playing. Massively Multiplayer Online Role-Playing Games (MMORPGs) are large multi-user online games that use an avatar to interact with the other players.

Serious game is a game that was designed with an educational purpose and to promote behavior change and not for entertainment purposes. In this study, the Adventures game is an example of a serious game. 
Simulation is the imitation of a real-life experience such as replicating soldier experience in war or administering an IV for a patient by a nurse. In this study, the Adventures game has components such as the cruise ship and travel agent office that simulate real-life experiences for a travel agent.

Travel agent is a person engaged in selling and arranging transportation, accommodations, tours, cruises or trips for travelers.

Video game is an electronic game played by manipulating moving figures on a display screen, most commonly played on a hand held device such as a mobile phone, an IPad, or a Nintendo DS.

Virtual worlds are multiplayer 3-D social environments that provide a space for playing.

\section{Assumption of the Study}

Engagement and knowledge of the field are essential components to acquire cruise sales. these components have a direct relationship with the bottom line for a cruise line. The more engaged travel professionals are with the particular cruise line, the more likely they would recommend a cruise with that particular company. In addition, increasing their knowledge of the cruise line and their products would make the travel professional more confident and provide them the tools to make a sale. Therefore, this study can potentially improve the future of training for travel professionals worldwide, as well as provide guidance for training offered by travel agencies and other cruise lines for travel professionals.

\section{Delimitations of this Study}

This study was designed to examine travel agent engagement as they played the Adventures game. One of the delimitations of this study was that the data collected were 
limited to game participation data that was collected by a single large cruise line. All travel agents who participated and played the game were based in the United States and Canada. Each of the agents were provided the option to play and were not given a specific time frame in which to play. 


\section{CHAPTER II}

\section{LITERATURE REVIEW}

This chapter begins with an introduction to the evolution of video games. Second an overview of the demographics of gamers followed by an examination of the literature surrounding defining games. Fourth, an overview of the literature around serious games followed by an examination of the theoretical framework for gaming. This chapter concludes with an examination of the serious game used by participants in this study.

\section{Evolution of Video Games}

Video games have a long standing history ranging as far back as to the late 1940s (Sellers, 2001). Video games made their debut in January 1947 when Thomas Goldsmith, Jr and Estle Ray Mann designed a patent for a cathode ray tube amusement device used in flight simulations (Sellers, 2001). The device was used to simulate the action of firing air-borne targets (Sellers, 2001). This device provided players the opportunity to simulate military behaviors and develop skills necessary for being successful in the military. Gaming further evolved with the creation of a popular board game in a digital format, tic-tac-toe. In 1952, A.S. Douglas created a graphic version of tic-tac-toe known as $O X O$ (Sellers, 2001).

The evolution of video games emerged due to the integration and presence of computers during this time period (Sellers, 2001). The first generation of video games focused on computer games. Computer games were available in many formats and continued to evolve from the 1950s to the present (Sellers, 2001). During this time period, many computer games were created on mainframe computers. Mouse in the Maze was a computer game designed during the period of 1959 to 1961 (Sellers, 2001). 
As gaming continued to evolve into a popular activity, digital and computer gaming became more prominent. In 1958, another popular game was developed to simulate playing tennis. Tennis for Two was created by William Higinbotham and used an oscilloscope and analog computer (Sellers, 2001). In 1962, Steve Russell designed the first video game that was used specifically for computer use, SpaceWar (Sellers, 2001). Spacewar was considered one of the first influential computer games created. Spacewar was designed with the purpose of simulating the behavior of firing missiles while within a space craft (Sellers, 2001). This game was designed with the purpose of having multiple players playing against each other while attempting to complete the space mission. On the other hand, in 1967 Ralph Baer designed the first video game for use on the television. The television based video game was known as Chase (Sellers, 2001).

The second generation of video games focused on console games. In the late 1960s, there was a movement towards the development of the first home-based console games. Ralph Baer and his associates designed the first home-based console game system (Sellers, 2001). The development of the device was from 1966-1968, with Brown Box being the first prototype released (Sellers, 2001). In 1972, Magnavox Odyssey another console game was released in the United States of America (Sellers, 2001). In 1971, coin-operated video games were developed, such as the popular pin ball machine seen in arcade facilities (Sellers, 2001). Stanford University had the first coin-operated game, Galaxy Game, in their facilities (Sellers, 2001).

In the 1970s, there was a progression into University main frame games (Forster, 2005). Main frame computer games consisted of two types of devices: Plato System and DECUS. Plato System was run by the Control Data Corporation and created at the 
University of Illinois (Forster, 2005). DECUS were computer devices created by the Digital Equipment Corporation (DEC). Don Daglow created a computer baseball game on a DEC PDP-10 mainframe (Forster, 2005). Further on in 1987, in a joint venture with Eddie Dombrower they designed Earl Weaver Baseball (Forster, 2005).

There was a series of three console devices that dominated the second generation of video games (Forster, 2005). Atari was known as a Video Computer System. Atari was a ROM cartridge-based console and was released in 1977 (Forster, 2005). In 1980, the second device known as Intellivision was released by Mattel (Forster, 2005). This device had more robust graphics than their competitor Atari, making it the most popular second generation gaming device based upon demand. In 1982, the third device known as the Colecco Vision arrived in the spread of games available and was even more prominent than the other three console games available (Forster, 2005). The market for console games soon after crashed due to an overcrowded market (Forster, 2005).

The third generation of games emerged with the presence of color arcade games and the creation of home-based computer games. In 1978, the arcade industry made a powerful impression by the release of Space Invaders by Taito (Forster, 2005). Pac-Man was one of the first color arcade games in the industry. Pac-Man was most popular during the time frame of 1979 to 1980 (Forster, 2005). Following the crash of console games, home-based computer games were popular (Forster, 2005). In the 1980s, there was a trend towards purchasing a home computer, leading to the creation of home-based computer games. Some of the popular games developed were Star Trek, Space Invaders, 
Frogger, Pac-Man and Donkey Kong (Forster, 2005). Home-based computer games were also disseminated via floppy disks, cassette tapes, and/or ROM cartridges that could be purchased at an entertainment store or via the mail (Forster, 2005).

The video gaming industry continued to evolve with the re-emergence of previous devices. In 1985, the video game console market resurged with the creation of the Nintendo Entertainment System (NES) (Forster, 2005). One of the first popular games of NES was Super Mario Bros. It was an instant success. In 1986, The Legend of Zelda series was released with The Legend of Zelda was the first game within the series (Forster, 2005). In the same year, the Dragon Quest series was released with Dragon Quest, which was the first game in the series (Forster, 2005). The 1990s presented a time period of innovation and evolution with video gaming. It was a decade of transition from faster graphics to 3-D graphics and included several genres of video games including first-person shooter, real-time strategy, and MMO (Forster, 2005). In 1989, handheld gaming was popular due to the release of Game Boy. In the 1990s, the use of arcade games was declining due to the crash and the creation of home-based game consoles (Forster, 2005).

Before the end of the decade, the fourth generation of gaming evolved with the emergence of the graphical Multi-User Dungeons (MUDs). They were also commonly known as the first Massively Multiplayer Online Role-Playing Games (MMORPGs). MUDs is known as a multiplayer online game, which incorporates role playing, interactive fiction, and online chats within the game for players to use to interact with each other while playing (Forester, 2005). MMORPGs are large multi-user online games that use an avatar to interact with the other players. Some common MUDs were Ultima 
Online and Ever Quest (Forster, 2005). An example of an MMORPG was Runescape, which was designed by Jagex (Forster, 2005). Maxis continued the trend with publishing its series of SIM games, SimCity, SimEarth, SimCity 2000, SimAnt, and SimTower (Forster, 2005).

In 1989, Nintendo released the first handheld console game, the Game Boy (Forster, 2005). Tetris is a popular puzzle game which was included in the device (Forster, 2005). During this same time period other handhelds emerged, including the Sega Game Gear and Atari Lynx. The Mega Drive/Genesis emerged during this year as well. However, in 1991 Nintendo responded with its own next generation system, Super NES (SNES) (Forster, 2005). SNES and Genesis both released Mortal Kombat, which was considered one of the most popular console game of its time (Forster, 2005). In 1994, three new consoles were released Sega Saturn, PlayStation, and PC-FX. PlayStation was well received and sold out immediately (Forster, 2005).

The fifth generation led to the growth of 3-D digital games (Forster, 2005). Some examples of popular 3-D games were Super Mario 64, Crash Bandicoot and Nights into Dreams. 3-D digital games became the main focus in this era, especially with the decreased creation of video game cartridges and the increased use of CDs to disseminate digital games. Soon after was the creation of the sixth generation of video games. This generation focused on creating the first groupings of online digital games and the further emergence of gaming consoles. Microsoft developed a lead with the creation of gaming consoles. Dreamcast launched in 1998, which was the first console developed for online play. Sony released the Sony Play Station 2 and Nintendo released Nintendo Game 
Cube. Windows continued the trend with the creation of the Xbox (Forster, 2005). As well as popular online games and gaming sites were used by many individuals to engage and interact with other players worldwide, such as SIMHQ (Forster, 2005).

\section{Demographics of Gamers}

Gaming has a long standing history and has evolved into many formats. A majority of individuals has experienced playing a video, online or computer game. Games tend to be addictive, because of their ability to grab the learners' attention and keep them entertained for long periods of time (Aarseth, 2001, February, 2004;

Eskelinen, 2001, 2004; Juul, 2001). Gaming was seen as a popular activity performed by youth and adults alike. The Entertainment Software Association (2012) stated that, Computer and video games have reached a critical mass. Today, nearly every device with screen plays games, providing interactive entertainment experiences for a wide and diverse population. The creativity of our developers and publishers produces an ever-expanding variety of games to choose from in different formats and across all platforms. Their innovations drive consumer demand for our products, solidifying our industry's position as one of the strongest and most cutting-edge sectors in the U.S. economy. (p. 2)

Gaming provided a creative environment where players felt engaged and had an opportunity to have fun. Gaming was more popular than one might think. As noted by the Siwek, in the United States $\$ 15.4$ billion dollars was spent purchasing video and computer games (Entertainment Software Association, 2014). In 51\% of U.S. households there was at least one gaming console, PC or smart phone used for gaming purposes and there was an average of two gamers in their home (Entertainment Software 
Association, 2014). As described by the Entertainment Software Association (2014), gaming was prominent in 1 out of 2 homes. Games were played using varying devices such as an iPad, a computer, or a hand held device, making gaming easily accessible to all users.

Research has shown that there were many misconceptions about which age groups were the most frequent game players. The demographics of gamers have changed drastically over the years. As addressed by Allaire, "People of all ages play video games. There is no longer a 'stereotype game player,' but instead a game player can be your grandparent, your boss, or even your professor" (Entertainment Software Association, 2014, p. 4). The average age of a typical gamer was approximately 31 years old. The age range of gamers varied from 29\% being under 18 years old, 32\% between the ages of 18-35, and 39\% being 36 and older (Entertainment Software Association, 2014). In addition, it was perceived that males made up the majority of gamers. However, based upon these statistics there were only $4 \%$ more of males that played games compared to females, demonstrating that males only have a slight variance over females (Entertainment Software Association, 2014). As we seen from the demographics, gamers were typically adult males. Gamers typically played games for the purpose of enjoyment and fun. Games provided players the opportunity to engage in skill enhancement activities, to compete with other players, and to develop strategy for winning the game. Research conducted earlier on the demographics of gamers indicated that the average age of the most frequent game purchaser was 35 years (Entertainment Software Association, 2014). Evident again within the population of frequent game purchasers, there was a small difference between males (52\%) and females (48\%) (Entertainment 
Software Association, 2014). On average 44\% of game players believed that computer and video games gave them the most value for their money, compared to purchasing DVDs, CDs or going to see a movie (Entertainment Software Association, 2014). Gamers were using a mobile device or smart phone to play more frequently than in the past. $44 \%$ of gamers played games on their smart phones and 33\% played games on their handheld device (Entertainment Software Association, 2014). The average number of years a gamer has played games was approximately 14 years, with adult gamers playing for an average of 16 years (Entertainment Software Association, 2014). Males played for an average of 18 years compared to females who played for an average of 13 years (Entertainment Software Association, 2014).

The Entertainment Software Association (2014) demonstrated with these statistics that gaming is seen through the eyes of everyone, as an engaging and challenging environment that is enticing and exhilarating. Games were played by both males and females alike and within all age categories. In addition, though males game at a higher rate than females, there was only a small difference. This demonstrates that gaming is popular with all types of individuals and all age groups.

\section{Definition of Gaming}

Researchers had a difficult time in defining the term gaming (Wittgenstein, 1958). The challenge with defining games stemmed from the many uses of the term, "For example, we use the term 'game' for non-play activities such as simulation games and the stock market, and for activities that have real world consequences such as gambling" (Murray, 2006, p. 187). Games take many forms ranging from win-lose based games to 
role-playing games. For example, a baseball or cross word puzzle game have a win-lose structure whereas, MMORPGs typically provided opportunities for role-playing using avatars or simulation (Salen \& Zimmerman, 2003; Murray, 2006).

Tomasello (2000) used his research in human cognition to shed light on why individuals are engaged in games. He states that humans might be hardwired to play games, because of our desire to explore the world that we live in. Games allowed individuals to expand their response methods and created new cognitive patterns to apply in different situations. Games encouraged an individual to perform tasks that they typically saw as tedious and boring. For example, in a game a player could be asked to match and sort products. A player might spend an hour doing this task within the game and be fully engaged. However, if they were given a similar task in real life, they would find it boring and tedious. Games encouraged intrinsic enjoyment.

Murray (1997) has shown that games have similar elements that are present within Joint Attentional Scenes. Joint attention is a social-communicative skill in which two individuals, typically a child and an adult, where they use gestures to share their attention to an object. Joint Attentional Scenes have multiple objects, such as intentional and active communication, available that the player focused their attention on (Murray, 1997). Games exhibited and reinforced the attributes of attentional scenes. Tomasello (2000) provided an overview of the core adaptive benefits of games. Games provided an understanding of the player and objects within the game, the capability to demonstrate one's own point of view, and the ability to teach and learn providing an opportunity for development (Tomasello, 2000). 
Games provided a venue for players to work collaboratively leading to an increase in overall performance. In addition, games provided a space where participants can critique and evaluate behaviors of their peers in the gaming environment (Tomasello, 2000). Games provided structured rules for the player, where they were able to interact socially while following specific behaviors. Murray (1997) noted that "The rules of games allow social groups to focus questions of what is allowed, disallowed, fair, and unfair. Gaming involves a pleasure in inventing, establishing, recognizing, and reproducing patterns of behavior and object manipulation” (p. 197). The rules provided direction for the player in being successful in winning or completing a task. Games provided the framework for the development of mastery skills, through social interaction, practice, and reenacting behaviors. Players learned through performing a task and seeing the task performed. Playing games provided an environment for this type of behavior to occur. This type of behavior was also commonly known as spectatorship (Tomasello, 2000).

Gaming provides an environment for social orientation and interaction (Tomasello, 2000). Players participated in team activity, followed the leader, addressed conflict, and exchanged skills together while playing. Games also included win-lose behaviors and encouraged the learner to compete with their peers (Prensky, 2001). Games also demonstrated non-play situations where the player found joy in participating in an activity that they found compelling (Murray, 1997). Games continued to evolve and provided a venue for exploration and expression with new technologies within the cohesive systems and continued to allow the player to directly focus on various forms of activities. 


\section{Overview of Serious Games}

As discussed in the previous section, gaming has been around since the 1940s and continues to be prominent in our society today. Video gaming was traditionally seen as for entertainment purposes. However, in the last century there was a transition from entertainment into educational purposes. The next segment describes the evolution of serious games and their use for educational and training purposes.

\section{What is a Serious Game?}

Serious games have evolved through the transition of video games into the classroom and were used for the purpose of training. Michael and Chen (2006) define the term serious games as a game designed for the purpose of training or educating an individual, rather than for the purpose of entertainment. Serious games provided a wide range of opportunities for educational and training applications, ranging from medicine to defense training. Games were used for role-based learning and educational games were defined as, "applications using the characteristics of video and computer games to create engaging and immersive learning experiences for delivering specified learning goals, outcomes and experiences" (de Freitas, 2006, p. 10). Serious games were used to enhance the learning experience for the student.

Zyda (2005) provided another definition of serious games, “a mental contest, played with a computer in accordance with specific rules, that uses entertainment to further government or corporate training, education, health, public policy, and strategic communication objectives” (p. 26). Zyda's (2005) definition of serious games brings light to a prominent terminology used in the gaming world, known as simulations. Simulations were seen as systems that replicated real or hypothetical processes (Zyda, 
2005). Simulation-based learning was typically used to replicate real life situations and were used widely in hospital-based training, military training, teaching interviewing skills, and sales. Simulation training was first used in military training and still remains prominent (Zyda, 2005).

Over the past few years, games were developed into comprehensive and complex communities and learning environments (Prensky, 2006). In addition, games evolved into Massive Multiplayer Online Games (MMOGs), which allow for communication and engagement from the United States to Europe and to other parts of the world (Magnussen \& Misfeldt, 2004). Games were used as a safe space, where collaboration and interaction amongst multiple players occur frequently with individuals living all over the world. Digital games such as Sega Genesis, Nintendo, etc were traditionally used by children and adolescents (Magnussen \& Misfeldt, 2004).

Steinkuehler (2004) demonstrated in his review of the literature that video games transitioned from MUDs to MMOGs and the digital games available today in society. Games were a virtual space that were conducive to engagement and collaboration. Turkle (1995) provided a clear description of how MMOGs were used for collaboration, Playing one's character(s) and living in [these virtual worlds] becomes an important part of daily life. Since much of the excitement of the game depends on having personal relationships and being part of [the] community's developing politics and projects, it is hard to participate just a little. (p. 184) 
Based upon this description, games contained avatars to provide a physical representation of individuals in the game. In addition, avatars were used to help in telling a story. MMOGs provided a space for engagement and an opportunity for building relationships (Turkle, 1995).

Games were traditionally used for non-entertainment purposes (Steinkuehler, 2004). Over time scholars investigated the purpose and provided potential uses for games, as a growing interest in using games for educational purposes developed. Serious games such as MMOGs provided an environment similar to what the learner would experience in their real life experiences. Steinkuehler (2004) described the use of MMOGs as the following,

MMOGs are highly graphical 2- or 3-D videogames played online, allowing individuals, through their self-created digital characters or 'avatars,' to interact not only with the gaming software (the designed environment of the game and the computer controlled characters within it) but with other players' avatars as well. These virtual worlds are persistent social and material worlds, loosely structured by open-ended (fantasy) narratives, where players are largely free to do as they please - slay ogres, siege castles, barter goods in town, or shake the fruit out of trees. (p. 521)

Steinkuehler (2004) indicated that MMOGs provided a safe gaming environment that allowed players to navigate the game as they please through the use of a flexible environment, fantasy rich stories and narration throughout the game. For example, in the Star Wars Galaxies game participants were able to share stories and strategies at the virtual rebel outpost or local cantina with fellow peers who exist worldwide (Kolbert, 
2001). Players took on the role of a hero or villain depending upon their interest through playing MMOGs. Players were able to immerse themselves into mini-communities within the game and provided opportunities for exploration (Steinkuehler, 2004).

MMOGs were popular games for players (Herz \& Macedonia, 2002). Gamers were able to achieve milestones by working through various levels and obstacles within the game. Players were able to use an avatar to assume various roles and develop character identities throughout the game (Herz \& Macedonia, 2002). MMOGs provided opportunities for sharing ideas and challenging their peers as they progress through the game (Herz \& Macedonia, 2002). MMOGs allowed the player to develop character, create relationships with their peers, and assume various roles (Knight, 2003).

MMOGs were conducive to fostering growth and development amongst players. As noted by Bonk and Dennen (2005) "when playing a game, learning should be both frustrating and life enhancing. For games where there are rewards for longevity, lifeenhancing events are crucial. The player cannot be passive, but must be a participant" (p. 8). Bonk and Dennen (2005) indicated that through the use of engaging and active games, players developed expertise and learned how to deal with challenges that can be applied to real life experiences. Gamers developed a sense of belonging and feeling like active participants. For the player to be engaged and to develop further, it is essential that they were active players and have gained an understanding of the value of the game (Bonk \& Dennen, 2005).

The primary purpose of a serious game is to provide an environment where learners were engaged while attaining knowledge and skills (Shute, Ventura, Bauer, \& Zapata-Rivera, 2009). The first serious game developed by the U.S. Army was America's 
Army 3, which replicated the experience of being a member of the U.S. Army. On the other spectrum were games designed for the purpose of entertainment, such as Dance Revolution or Dinner Dash. The purpose of these games were to provide an individual down time and the opportunity to play casually (Shute et al., 2009).

Research demonstrated the potential of serious games for learning through describing them as edutainment and educational games. Denis and Jouvelot (2005), noted that the difference between edutainment and educational games was that educational games focused on engaging the learner through interactivity, whereas edutainment games were more linear in approach. Traditionally, educational games required the learner to exhibit high order thinking and participate in problem solving activities and tasks.

Educational games contain the following primary characteristics, such as goals, rules, competition, time, reward structures and feedback (Kapp, 2012, Prensky, 2001). Games contain goals which provided measurable outcomes and a purpose for playing the game. Learners were able to apply various techniques to meet the goal. Motivation is enhanced through the presence of clear goals and learning objectives. When motivation is present, it impacts the engagement of the learner and encourages them to continue playing and be successful in completing the game. To obtain optimal gaming experience of the learner, the gamer needed to feel fully immersed and engaged in the learning process. In addition, the learner needed to have internal motivation rather external motivation to further enhance their gaming experience (Shute et al, 2009). For example, the Adventure game contained a play bar on the top of the screen that indicated the players' progress and reminded them of the fun points needed in order to complete the level and successfully advance through the game. 
Games contain a set number of rules. These rules provide direction as to the number of players, number of points a player can attain, and actions allowed when playing the game. Rules are essential to the overall function of a game. They guided the players' actions and aided in managing the structure of the game. At the beginning of each level of the Adventures game, the player was presented with the rules of the level and a tutorial explained the rules of play for the completing the level. Games also provided a challenging component. The challenge was exhibited through the conflict that lies between two players. For example, in the Adventures game there was a timer that was within the game that works towards motivating the player to work faster. Time was another component of games. Time was considered a motivator for player activity. Games such as the Adventures game contained a timer in the top right hand corner of the screen which increased the stress level of the individual playing and motivated them to advance through the game quicker. Games also incorporated rewards to motivate and engage learners. Many players love to win and to show off that they obtained the highest score. In the Adventures game, players received badges within their passport demonstrating the thresholds they achieved in the game and were added to the leader board that was present for all players to view. Lastly, feedback was an essential component of games. In a game the player was provided immediate and real-time feedback on their progress towards completing the game. The feedback assisted in encouraging proper behavior and actions within the game.

\section{Application of Serious Games for Education and Training}

Educational purpose. Games were recently used for the purpose of training or teaching. Initially they were used for the purpose of enjoyment. Gee (2003) stated that 
games have many beneficial attributes including the following, for example, allowed for the transfer of knowledge and skills to real life experiences. Games allowed for the practice of behavior, that when played multiple times lead to mastery and over learning (Gee, 2003). Gee (2003) also pointed out in his research that learning outside of school is out pacing learning inside schools. Lastly, the mastery attained within the game ultimately leads to automated behavior and was stored in the player's memory. Games provided a challenging environment, where the player was pushed to master a skill through trial and error (Gee, 2003).

The concept discussed here by Gee (2003) is also known as deliberate practice. Deliberate practice is described by Ericsson and his colleagues (1993) as a structured activity in which a learner engages in to improve their overall performance with a particular task. Deliberate practice exhibits different tendencies than what is visible from simply working, playing or repeating a task or skills. This type of practice requires concerted effort from the learner and is not always considered enjoyable. When a learner engages in deliberate practice the focus is to improve their level of performance.

Another benefit of gaming was that games provide instant feedback for the learner. Learners are encouraged to engage in decision making and explore options through playing (Kirriemuir, 2002). Games, such as the one designed by a large cruise line in South Florida, provide varying levels of difficultly as the player progresses throughout the game. As learners progressed through the game, they were required to master each level in order to progress into the next level. Advancement was based upon mastery. The learner was unable to proceed to the medium or hard level without 
previously mastering the easy or easy 2 levels. This pattern encouraged learners to increase their knowledge and encouraged them to not give up until they were successful at mastering the game (Kirriemuir, 2002).

Prensky (2001) provided another reason for using gaming as an educational tool. Games provided an engaging and interactive environment conducive to the learner having fun. Games also provided immediate feedback and an immersive virtually stimulating environment similar to the traditional environment (Mitchell \& Savill-Smith, 2004). Paraskeva, Mysirlaki, and Papagianni (2010) stated that games were capable of being used as an educational tool when they provided varying levels of difficulty to be able to adapt to the varying types of learners and their previous knowledge of the material. In addition, the presence of goals and learning objectives was able to provide direction to the learner. As evident here, Prensky (2001) and Paraskeva et al. (2010) were in alignment on their assessment of the use of games for educational purposes. It was obvious that games have clear objectives with intended outcomes that are beneficial for assessing knowledge and skill attainment in the learning environment.

Klawe (1994) stated that games encouraged an increase in intrinsic motivation of complacent learners, who found learning boring or lacked confidence. Games were designed to increase cognition and higher-order processing, leading to the development of strategic and complex skills (Mitchell and Savill-Smith, 2004). Researchers were wondering if gaming can be considered engaging enough for players. In order to examine this idea, they took into consideration a number of factors such as how often games were played, the association of players with the avatars within the game, and the 
type of games that were typically played by players. Researchers also examined the role gaming had on academic performance, increasing self-esteem, and self-efficacy (Klawe, 1994).

Simulation training purpose. Games were used for the purpose of simulation training within the military and medical fields (Perla, 1990). The use of simulations and gaming for the purpose of training soldiers stems from a long standing history that was present since the Roman Empire. Commanders in the military used sand tables with abstract icons to replicate the role of soldiers and units within battle, which allowed soldiers to get a glimpse of a traditional battlefield (Perla, 1990).

The previous simulation described was designed for training soldiers to practice simulating how they would respond to various situations within the battlefield without being in a real life situation (Perla, 1990). This experience allowed the soldiers to determine how they would react and respond to a particular situation. This is important since soldiers were faced with difficult situations and challenging environments, where they would need to think on their feet quickly. Gaming provided a safe space to practice and develop the skills necessary to be successful in a battlefield (Perla, 1990).

In the same vein, leaders and other members of the platoon used historical perspective and previous experiences to test new approaches. They competed with fellow team members making the activity engaging and fun (Perla, 1990). The same approach was used by the United States Naval War College in the late 19th Century to determine the best manner to defend themselves against the invasion of the New York Harbor. Perla (1990) also noted that a similar model was used to simulate the approach 
for addressing the invasion of Poland and used by the Japanese to address the Pearl Harbor attacks. War games were training simulations that showed soldiers the art of warfare (Perla, 1990).

Simulation training transformed significantly over the past few years (Perla, 1990). Our journey first began with home-based computers and graphic cards that allowed for the design of more economical and user friendly simulations. In the 1990s, military games such as like Simulator Networking (SIMNET) and Modular Semiautomated Forces (ModSAF) emerged. In addition, in the entertainment arena games such as Steel Panthers and Close Combat emerged with a strong military focus. During this time period, researchers questioned the validity of using simulations to prepare military personal for battle. There was concern that the military simulation games would not accurately portray a battlefield and would not appropriately prepare the solider for war. There was also concern that the focus of the player would be based upon the appeal of the game, rather than on getting prepared for battle. These concerns were evident in both the military arena and also amongst the medical profession, who in the same light use simulations to train their medical and nursing professionals (Perla, 1990).

Benefits of simulation training. Over the years research has proven that amidst the concerns, simulation training was in fact beneficial for training military personal and medical professionals on the complex skills necessary for their roles. Technology evolved leading to medical professionals using more advance equipment when dealing with patient needs and conducting surgeries (Lane, 2001). Therefore, simulations were effective in minimizing the impact of the advancement of technology and assisted in training these professionals in these advanced skills. Simulations contained a 3-D engine 
that provided users attractive and accurate visualizations of an activity such as a battlefield (Lane, 2001). Simulations were easy to use and provided a clear menu system, which make it easy for a gamer to come in and begin playing without prior experience with the game (Lane, 2001).

Simulations provided an environment that is similar to real life experiences making the environment conducive for learning (Gredler, 1996; Lane, 2001). The gaming environment was also challenging, encouraged gamers to expand their knowledge expertise and pushed them to challenge themselves. Simulations were designed in a manner in which the game automatically adjusted the level of play dependent upon the expertise of the learner. Therefore, tailoring the experience based upon the needs of the player. The simulation environment allowed for players to share ideas and concerns with other gamers, building a network of communication. Lastly, simulations were constantly changing and becoming enhanced to make the space new and engaging for the gamer daily (Gredler, 1996; Lane, 2001).

As evident in military games, simulations were widely used to include strategy, sports, war, puzzles, educational, and computer role playing games (Ju \& Wagner, 1997). Sawyer (2002) reaffirmed previous research completed on the use of military simulations by providing an overview of the advantages of simulations and games. Simulations created an environment conducive to developing strategic thinking. Simulations used technology that was readily available and easy to use for players. They were able to access the game without having to purchase additional hardware. Lastly, simulations provided an environment where the narrative and story can integrate both fictional and non-fictional events with in the game (Sawyer, 2002). 
Malone (1981) stated that games provided motivation for the gamer to achieve the goal or task at hand. Malone (1981) also noted that achieving a goal was the most important factor of a game. By having this motivation to achieve the goal of the game, the player's self-esteem was increased. Through the game, players developed skills and shared strategies with their peers to achieve the goal outlined within the game (Sawyer, 2002). Players had a major role in the game, they were able to impact the outcome of the game. Players had control over the direction of the game, based upon their skills and how they work towards achieving the goal. Serious games were designed to also be engaging, interactive, fun, and to be played repeatedly (Sawyer, 2002). Simulations and games were beneficial components to the learning environment. A learner through playing was able to learn skills such as running a war team, running their own business, or completing a process (Rickard \& Oblinger, 2004).

There were various types of simulations such as branching, game-based simulations, and business school spreadsheets (Dessouky, Verma, Bailey, \& Rickel, 2001). Branching simulations direct players on a distinct path with various points where their path ways can be led into another direction. The player determined the direction of the path. For example, branching simulations were used to provide direction to an individual on addressing customer concerns. Dependent upon the concern presented the individual would be directed down a different path way. The second type was business school spreadsheets that assessed sales and pricing (Dessouky et al., 2001). This type was beneficial for business individuals. The third type was game-based simulations similar to the one used for this study and games such as game shows (Dessouky et al., 
2001). These types of games focused on the art of practice and skill development. They were also provided an engaging space with goals, digital graphics, and character development.

The descriptions of the types of simulations used were applied to the work done by the military. Because of the changing face of technology the military decided to explore the use of online gaming to train military personal. The military chose to design MMOGs that allowed for a large network of players. MMOGs mirrored the skills needed by military personal to be successful in a war zone (Alberts, Garstka \& Stein, 1999). Therefore, MMOGs were consistently used by the military to prepare them for warfare because of their ability to replicate warfare environments for training purposes. Alberts et al (1999) describe "network centric warfare environments" as a space, where there was a connection between the knowledge exchanged and the location in which the transfer occurred and these items were linked.

Massively Multi-player Online Games have provided an engaging virtual environment where players were integrated and were able to share and collaborate together throughout the game. Alberts et al. (1999) emphasizes the importance of collaboration and the ability to empower the players to develop a degree of synchronization. Players were given the opportunity to play for many months or years and were able to take part in many roles. By playing frequently they were able to reflect on their experiences in the many roles and used those experiences to determine how they would react in a real-life situation (Harmon, 2003). The act of debriefing or reflecting on the gaming experience was important in impacting and increasing change for the future 
(Prensky, 2001). Simulations encouraged decision making and problem solving of the player which was a crucial task for military personal.

\section{Game-based Training Versus Face-to-Face Training}

Researchers have shown that game-based training can be more effective than traditional face-to-face training. Game-based training incorporates a highly motivating environment that maintains the learner actively engaged (Trybus, 2014). In addition, game-based training contains the following benefits: a learning environment tailored to the individual learner, provides immediate feedback to the learner, offers transfer of learning to a real-world environment and assesses learners on knowledge attained. However, traditional face-to-face training tends to be a passive training that focuses on teaching a set of facts, and then evaluates the learner on their recollection of what they were taught (Trybus, 2014).

Traditional face-to-face training does not allow the learner the opportunity to practice the knowledge attainment in a real-life environment or situation (Trybus, 2014). Therefore, the knowledge and skills attained remain untested by the learner. In the traditional face-to-face environment learners disengage quickly due to the lack of opportunity to practice the skills attained. Game-based training provides the opportunity to apply and practice the skills attained at a low-risk to individuals involved (Trybus, 2014). Learners need effective and interactive learning experiences that illicit motivation and engagement throughout the entire learning process. Therefore, for the purpose of this study, it was decided to focus on a game-based training program. 


\section{Theoretical Framework for Gaming}

Although video games are not designed with a particular theoretical framework in mind, there are some theories that can be applied to gaming and understanding the engagement of learners.

\section{Activity Theory}

One of the components of evaluating the impact of gaming on education was activity theory. Activity theory focused on the connection between the players' consciousness and their actual activities performed (Kaptelinin, Kuutti, \& Bannon, 1995). The key principle of Activity Theory comes from a Marxism point of view as to the idea that individuals live in an objective reality that shapes how they view their world (Kaptelinin et al., 1995). The theory emphasized the evolution of the player's development of individuality while playing. Kaptelinin and his colleagues (1995) provided an overview of the hierarchical structure of activity as it relates to activity theory. He stated that, "the unit of analysis is an activity directed at an object which motivates activity, giving it a specific direction. Activities are composed of goal-directed actions that must be undertaken to fulfill the object" (Kaptelinin et al., 1995; p. 1). The basic premise of activity theory looked at the following attributes, the structure of the activity, internalization/externalization of the activity performed, tool mediation, and development (Kaptelinin et al., 1995).

Activity theory stated that when a player performed a task, it was typically automatic and involved their consciousness (Kaptelinin et al., 1995). Learners put thought into why and how they were going to perform a task. This theory differentiated between internal and external activities. Internal activities were those seen as mental 
processes. External activities were those which occur through an interaction with the environment. Activity theory stated that internal and external activities were understood by evaluating their impact based upon each other. Internalization was the translation of external activities into internal activities. Internalization dealt with practicing a skill without performing the task on a real object, such as using a simulation to learn how to care for a patient.

Activity Theory used tools that were created and re-imagined through the development of the activity (Kaptelinin et al., 1995). These tools impacted the manner in which individuals interacted with reality. For example, when external activities were shaped they in turn impacted internal activities and vice a versa. There were two types of tools emphasized by Vygotsky (as referenced in Kaptelinin et al., 1995), technical and psychological tools. Technical tools were those items used to manipulate a particular object. Psychological tools were those used by an individual to influence others. Tools were applied in the context of the activity theory to show that the tools one uses were influenced by the social and cultural context in which they were being applied.

Activity theory lends itself to the idea of social learning. Gaming research examined the educational potential of computer games. However, there was limited research on the use of Activity Theory to explain the interaction of players with the game. (Oliver \& Pelletier, 2005). Recently due to the increase in use of MMOGs, there was an increased awareness of the social dimensions of learning that occur within the game (Ducheneaut \& Moore, 2004). Since social interaction was the primary focus within gaming, it can be assumed that social interaction occurs on two levels, player-game interaction and player-player interaction (Kaptelinin et al., 1995). The player developed 
an association with the game due to character development and the immersive nature of the game. The player also builds cohesion with other players through the opportunities available in the game to share ideas and challenges (Kaptelinin et al., 1995).

Ducheneaut and Moore (2004) also took the liberty to examine social learning in MMOG games and determined that there were three types of learning, small group selforganization, instrumental coordination and sociability. According to Ducheneaut and Moore (2004), gamers developed social skills through the interactions and the collaboration in groups within the game. Gamers developed a team within the game. After the team was developed, their social skills grew from group organization to instrumental coordination. Instrumental coordination focused on achieving the same goals and objectives in the game. Group players interacted with each other through social play, where they engaged in small talk with their peers. As noted by Ducheneaut et al. (2004), social play was prominent in simulations and serious games. Gamers engaged in social play through the use of the chatting tools and used the additional collaboration opportunities available throughout the game.

Players needed to feel a part of a community and engage, which was a key feature of activity theory. Activity theory was a theoretical framework that allows researchers to explain human social activity. Farangal (2012) stated that games fulfill the overall need of gamers, "games that challenge players to tackle real-world problems, such as poverty, hunger and climate change, through planetary-scale collaboration and investigate how these games are transforming the way we lead our real lives, and how they can be used to increase our resilience and well-being” (p. 1038). Gaming provided the opportunity for 
social interaction and learning as described in the activity theory. Gaming provided the learner the ability to develop their investigative skills and enhance their life skills through play.

Games contain traits such as clear goals, rules of engagement, a feedback system to motivate gamers. As reinforced by McGonigal (2011), “Compared with games, reality is too easy. Games challenge us with voluntary obstacles and help us put our personal strengths to better use" (p. 22) and "Compared with games, reality is unproductive. Games give us a clearer mission and more satisfying, hands-on work” (p. 55). Games provided the opportunity for engagement and involvement by the player. The activity theory helped to explain how social interaction and play impacted the gaming experience. This theory was applicable to any type of serious game especially the Adventures game that was designed by a large cruise line in South Florida. This serious game provided opportunities for engagement and social interaction amongst players. The player learned how to be fully engaged in the booking process and gained experience as a guest, as they navigated the opportunities available on the ship.

\section{Motivation}

A key component to designing a serious game was providing game elements that increased the motivation of the learner. Motivation of the learner directly impacted the engagement of the learner. Motivation components were learning objectives/goals and reward structures. The first element that was included in the game was clear goals and learning objectives (Malone, 1980). Learning objectives gave the player direction in how to successfully complete the game. One item that was important to keep in mind was that learning objectives outlined in the game should be meaningful for the player. 
For example, game designers tend to create fantasy relevance for the player. This allowed the learner to explore their imagination comfortably (Millians, 1999). In turn this stimulated the learners' behavior and maintained their engagement (Vockell, 2004).

To make learning motivating and appealing for learners, it's important to present the material to them in one of the following ways, as an imaginary context which was familiar to them or in a fantasy context which was emotionally appealing for the learner (Malone \& Lepper, 1987). Creating such environments that stimulated learners to become absorbed in a fantasy world allowed the player to be motivated and engaged in activities (Cordova, 1993). Research suggests that embedding material in a fantasy context enhances learning more than in a traditional learning environment (Cordova, 1993).

Traditionally, computer games were played alone or with a peer through the face to face or online format (Malone, 1980). Well-designed games were considered fun and intrinsically motivating. These types of games had an optimal level of challenge, were goal-oriented, contained clear learning objectives, provided continual feedback, encouraged curiosity of the player and provided fantasy elements (Malone, 1980). Games provided an intrinsically motivating environment, provided players options and control over the features in the game, were interactive and allowed the learner to engage with competition (Malone \& Lepper, 1987; Snider, 2003; Waal, 1995).

Malone and Lepper (1987) in their research discussed the effects of using games in an educational environment to increase a student's motivation and learning. In their research, they identified a number of conflicting views on using games to 
increase motivation. Some researchers felt that adding game elements would only increase motivation for a short period of time, but wouldn’t have a long term impact ((Malone \& Lepper, 1987).

Some researchers felt that once the learner returned to the traditional learning format they would find the material boring and lead to more negative effects. However, Garris et al. (2002) provided another perspective through his analysis of a study by Ricci et al. (1996) where gaming was incorporated into the classroom and it increased the motivation of the learners and lead to a greater attention span of the learner. Lesgold (1982) emphasized the importance of computer-based educational games in impacting young adults and children's enjoyment, attention, and concentration when learning. As with other researchers, they indicated the negative perspective as well stated that in some cases computer-based educational games diminished learning and the attention of youth when in an educational environment. The reality was that learning was changing and youth were now raised surrounded by technology. Therefore, education would never be the same and it forced educators to think of other ways to engage learners (DeaterDeckard, Chang, \& Evans, 2013; Lesgold, 1982).

Papastergiou \& Solomonidou (2005) study evaluated two educational applications that focused on increasing memory. Each application had similar learning objectives and learning materials in which the only difference was that one application was a game. Each participant was assigned to one of two groups (A or B), where group A (LearnMem1) used a gaming approach, and group B (LearnMem2) used a non-gaming approach (Papastergiou, 2009). Based upon varying observations throughout the study, 
researchers assessed that participants in Group A were enthusiastic about the gaming approach (Papastergiou \& Solomonidou, 2005; Papastergiou, 2009). Participants in Group A were more engaged in the task at hand and reached the varying levels to achieve the highest score possible. The lab was quiet except for outburst of excitement when varying levels of achievement were reached (Papastergiou \& Solomonidou, 2005; Papastergiou, 2009). Group B participants were interested in the non-gaming activity, but seemed as if they were less engaged and less attentive. Those participants in Group B also showed willingness and interest in using the educational website. After reviewing the feedback questionnaire, it was evident that both groups had positive feelings towards the overall experience. However, Group A participants found their learning more engaging than Group B participants (Papastergiou \& Solomonidou, 2005; Papastergiou, 2009).

Intrinsic motivation revolved around the player having a need to be rewarded (Malone \& Lepper, 1987). External motivation stemmed from the player wanting to receive an external reward, such as praise from their peers or recognition. Malone and Lepper (1987) in their research stated that in order to create engaging games the player needed to have intrinsic and external motivation components. An example of incorporating intrinsic and external motivation components was providing a reward system for the learner with the game (Malone \& Lepper, 1987). To increase motivation and encourage engagement, a passport was added to the Adventures Game to allow the learner to see which stamps they have attained as they navigate the game. The stamps were various awards they received for accomplishments in the game. 


\section{Flow}

Csikszentmihalyi (1990) was the creator of the concept flow, which he described as engagement in a particular activity. He expanded on the idea of flow by describing the characteristics necessary to produce this experience. In order to produce flow the game should contain: clear learning objectives and rules; allow for autonomy amongst learners; provide continual feedback on progress throughout the game; provided an environment where the player can focus and remove distraction (Csikszentimihalyi, 1990).

Csikszentmihalyi (1990) described flow as the direction and pattern of activity that are transmitted over time. The concept of flow involves the idea of play. The idea of play was around since the inception of civilization. Huizinga (1949) stated that in every walk of life we were exposed to play. Play was done during leisure time and was not seen as a task. Huizinga (1949) stated that play was considered as an optional activity that was completed outside of the ordinary life in an imaginary space. He noted that play was a crucial component to gaming. When each of the elements to gaming was integrated (play, goals, flow, feedback, etc) the player feels fully immersed in the learning experience. They had a gaming experience that consisted of fun, engaging and enjoyable elements. They became completely immersed in to the game that they forget about everything else in their surroundings while playing, otherwise, known as focused attention (Csikszentmihalyi, 1990).

Within the same lines as Csikszentimihalyi (1988 \& 1990), Malone and Lepper (1987) indicated that games should provide control and a challenging environment for the player. In this instance, control was viewed through providing continual feedback. In addition, provided the gamer a choice on the difficulty level of the game they wished to 
play allows them to feel involved in the process. Lastly, allowing a means for the learner to attain points in the game for surpassing a level gave them a sense of thrill and accomplishment (Malone \& Lepper, 1987).

Sweetser and Wyeth (2005) further expanded on the idea of flow by combining the concept with usability into a theoretical model of enjoyment called GameFlow. They believed that player enjoyment was similar in concept to flow; therefore, enjoyment (or flow) is a standard for design and evaluating games. GameFlow contained the following elements of flow, such as immersion, clarity of goal, autonomy, feedback, concentration, challenge, and player interaction. As first identified by Csikszentimihalyi (1993) games, such as GameFlow, contained clear learning objectives to illicit autonomy and provided feedback to the player. To illicit flow games provided a challenging and immersive environment. Through the use of these elements the player felt a deep connection to the game and provided an opportunity for social interaction (Csikszentimihalyi, 1993).

Douglas and Hargadon (2000) in their research used schema theory to define the terms engagement and immersion. Schema theory is the manner in which knowledge is organized, represented and used. Typically in a schema, knowledge is organized into chunks of information also known as units. One's desire to be engaged in a task ranges from being able to gain perspective from the schema outside of what was seen before us. Our enjoyment in engagement stems from being able to work with in a series of schemas. Whereas, the pleasure of being immersed in the game related to being integrated into the flow of schema. Douglas and Hargadon (2000) stated in their research that immersion relates to recognition/comprehension, and engagement to problem-solving. 
Douglas and Hargadon (2000) acknowledged the pattern of engagement and immersion by noting that players experience flow through engaging in a game or a complex object over a sustained period of time. The game must contain flow in order to be engaging for the player, otherwise their desire to continue playing would be shortlived. Challenge was an important component to increasing engagement and flow. A challenge within a game focused on the goals presented and the varying outcomes that emerged as a result of the challenge presented (Douglas \& Hargadon, 2000).

Games provided the appropriate level of challenge and work towards creating skill development (Sweetser \& Wyeth, 2005). The game contained elements of flow to facilitate higher order thinking and improve the user's experience while playing. Games contained clear goals including sub-goals as appropriate. Challenge was integrated into the level of difficulty in the game. When the player was provided an adequate level of challenge the gamer had a positive experience and felt engaged providing a balance with player skill and the game difficulty (Kiili, 2005a). For this study, the researcher used a game called IT-Emperor to express this idea as it relates to gaming (Kiili, 2005b).

Tiger (2000) emphasized the importance of pleasure in engaging the player. Narrative goes hand in hand with engagement. The story line provided the "why" for the game, giving the player background and motivation to become involved (Sweetser, 2006). Games provided the player the chance to compete or cooperate with peers. Players engaged with each other through social interaction and engaged in pleasure (Sweetser \& Wyeth, 2005). These factors engaged the sensory pleasures of a player and sparked their motivation to learn due to their interactions with others (Kiili, 2005a). This study used a series of interviews and surveys to access pleasure and flow. 
Cikszentmihalyi (1988 \& 1990) found that the experience of flow encompasses key factors, such as the activity, concentration, the challenge to player skills, control, clear goal, feedback, and immersion.

\section{Curiosity}

In understanding engagement it was important to gain insight into curiosity. As play and curiosity both play a role in engagement. Reio and colleagues (2006) defined curiosity as, "a desire to acquire new [information and] knowledge and new sensory experience that motivates exploratory behavior" (p. 75). Curiosity was a two pronged approach in encouraging information seeking and sensation-seeking as it relates to exploratory behavior. Researchers such as Piaget noted that curiosity and exploratory behavior impacted knowledge attainment in learners (Reio et al., 2006).

Malone and Lepper (1987) explained that curiosity can be stimulated by making individuals think that their existing knowledge lacks one or more of these three characteristics: completeness, consistency, and parsimony. In a game, mystery was able to evoke curiosity. For example, adventure themes, or including activities in fantasy contexts were able to stimulate curiosity. Curiosity was the result of a knowledge gap (Malone \& Lepper, 1987).

Malone (1981) provided insight into the impact of curiosity in motivating learners and gamers alike. Key components of motivation are the ability of the game to illicit and sustain a player's curiosity. Based upon current research curiosity was known to encourage exploratory behavior through enhancing the development of social, emotional, spiritual and physical characteristics of the individual (Reio et al., 2006). Curiosity was described by Berlyne (1954, 1960 \& 1966) as consisting of four elements: novelty, 
complexity, surprise, and incongruity. Curiosity was peaked when the player attempted to understand the uniqueness of the game and determine a solution. In turn by playing the game the player was engaged, because their interest was piqued.

One of the components of curiosity was novelty. Novelty is defined as an object or game that was new or original. Reio \& Wiswell (2000) through their review of Reeve's (1992) work on epistemic curiosity, provided insight into the link between intrinsic motivation and curiosity. Reio and Wiswell (2000) reflected on the link between intrinsic motivation and novelty by noting that when a player finds an activity to be interesting, they become excited and their intrinsic motivation in turn increases. However, if they don't feel excited about the game or task, they would move on to another task.

Novelty impacts the overall experience the player has within the game, due to the newness of the game, exploring their curiosity and play provoking activities exhibited within the game. Let's take a moment and imagine if we were a child. As a child, on special occasions, you were often given a new toy (Berlyne, 1954, 1960 \& 1966). When you received the new toy, you immediately gravitated to the new toy and left your old ones behind. You immediately started to play with the toy to figure out what it did and how to play with the new toy. The same is true with a new game. The gamer was excited, full of joy and can't wait to start to play (Malone, 1981). The gamer used their curiosity to explore the game and play provoking activities to engage themselves within the game.

Complexity, surprise, and incongruity go hand in hand with each other. There was an optimal level of information complexity that a player can have at a particular time 
(Berlyne, 1966). Complexity deals with the level of difficulty or challenge a gamer can engage with during a game. There should be an optimal level of challenge to peak their curiosity and engage the learner. As noted by Berlyne (1966) the primary factor to produce curiosity was conceptual conflict which was seen as, "conflict between incompatible attitudes or ideas evoked by a stimulus situation" (Malone, 1981, p. 338). Conceptual conflict is the struggle elicited when a gamer was engaged with a stimulus in a game and it leads to varying and conflicting ideas. This can be seen by evaluating the response of an individual when they are told man can walk on water. There is initially disbelief until the person sees someone doing this and then becomes curious as the prospects of other things occurring (Malone, 1981).

In addition, to curiosity playing a role in motivation there were structural features that were important as well. Banet (1979) identified a number of structural features such as skilled performance, challenge, and fantasy. Games encouraged the development of skills through the interaction of objects and with other players. Challenge forces the player to push past their comfort zone. Games should also engage the gamer's curiosity and creative side. Lastly, games should track the player’s progress through monitoring their responses and reaction time (Banet, 1979).

\section{Challenge}

A number of theorists emphasized the importance of challenge in intrinsic motivation. Challenge played a role in engagement exhibited by the learner when playing the game. Csikszentmihalyi (1975 \& 1988) extended their analysis by describing what he felt were the most important structural features of intrinsically motivating activities. Csikszentmihalyi (1975 \& 1988) described intrinsically motivating activities as 
follows: 1. Players should have the ability to increase or decrease the level of difficulty to match their skill level. This is evident in the learning game, players are able to select their level of difficulty at each level within the game. 2 . The game designer should separate the stimuli that interact within the environment to make the game user friendly. 3. There should be clear criteria for determining your progress and success during the game (Csikszentmihalyi, 1975 \& 1988).

Gamers in the learning game had a goal bar that tells them their total points and demonstrated how many more points they needed to beat the level (Csikszentmihalyi, 1975 \& 1988). In addition, they had a passport that filled with stamps to demonstrate their successes during the game. 4 . The game also provided continual feedback. During the learning game, players received feedback when answering a question (correct or incorrect), when playing the baseball derby, or navigating through the ship. 5. Lastly, the game should contain an optimal level of challenge. The challenge should be difficult enough that it engages the learner but not so difficult that they get turned off and frustrated while playing (Csikszentmihalyi, 1975 \& 1988). The goal was to use just the right amount of challenge to make the task difficult, but also maintained the learner engaged.

\section{Fantasy}

In the creation of serious games, designers used fantasy to increase motivation and engage learners. Gaming environments used themes or fantasies to allow the player to immerse themselves in the learning environment (Malone \& Lepper, 1987). Many children's games also included essential fantasy elements (e.g., "cowboys and Indians", "playing house"). Even though these theories of fantasy dealt primarily with the fantasies 
people produced (as in dreams or imaginary play), their proponents would presumably argue that similar processes were involved in determining the fantasies people found appealing in external environments (Malone \& Lepper, 1987).

Malone and Lepper (1987) defined fantasy as an environment that "evokes mental images of physical or social situations not actually present” (p.240). Garris et al. (2002) reinforce Malone and Lepper's ideas by stating that the integration of imagination and fantasy made a game motivational for the player. The player was able to interact with the environment as if it was reality and fully immerse themself into the virtual space. The player's needs were met through the interconnection with their imagination. Players were able to satisfy those inner desires of being successful or gaining power by portraying their fantasies in a game (Cordova, 1993; Malone \& Lepper, 1987). Gee (2003) emphasized these ideas by stating that games allowed players to be able to develop their own identity in a virtual space. Games allowed the player to develop whatever type of character they would like to have and provided variable options for the player to select an avatar that would fulfill their fantasy (Gee, 2003).

According to Myers (1990), fantasy was one of the many components necessary to maintain the player engaged and motivated.. Fantasy was considered intrinsic and extrinsic in nature (Malone \& Lepper, 1987). In extrinsic fantasy, the information or material to be learned was related directly to the fantasy. In intrinsic fantasy, the relationship was not related to the two items. It was believed that these two types of fantasy have a lasting impact on the content and learners' motivation towards learning (Malone \& Lepper, 1987). Malone and Lepper (1987) stated that "fantasies should provide appropriate metaphors or analogies for the material presented for learning” (p. 
249). In addition, Malone and Lepper (1987) indicated that goals within the game that related to fantasy needed to reinforce the content in the game and assist with meeting the suggested outcomes. In short, fantasies or imagination elicited by the learner would integrate well with the goals of the game and complement their success. Fantasy was created using characters that were familiar to the gamer and allowed the learner to fulfill their emotional needs in order to remain engaged and motivated in the game (Malone \& Lepper, 1987).

\section{Engagement}

When considering engagement, imagine a child that recently received a new video game (Chaiklin, 2003). They might be sitting in the living room playing the video game, until they were able to beat the level and/or completed the entire game. The gamer was fully immersed in the game and lost focus on anything else happening in their surroundings while playing. They would often times forget what was occurring around them and be lost within the realm of the game. This type of behavior is known as engagement. Engagement is the ability of an activity or game to grab the attention and sustain the learner's attention (Chaiklin, 2003).

Engagement was shown to impact academic performance and proficiency (Chaiklin, 2003). Engagement was mediated based on the level of challenge exhibited by the game and intrinsic motivation of the player. For example, if a task was too simple for a learner, their engagement decreased. If the task offered optimal level of difficulty for the learner, they remained engaged and their skills were enhanced (Chaiklin, 2003). In addition, the level of flow and game elements such as fantasy or themes that were included in the game, can impact the engagement of a learner. 
Measuring engagement included cognitive, behavioral, and affective components (Skinner \& Belmont, 1993). Cognitive engagement focused on the player's attention level and short term and working memory. Behavioral engagement dealt with motor reaction time of the player focusing in on his/her speed and accuracy of fine and gross motor skills. Motor reaction time was accessed through evaluating the player's responses to objects on the screen (Skinner \& Belmont, 1993). Affective engagement focused on the motivation and experiences associated with engagement. Experiences consisted of positive emotions (excitement, happiness) and negative emotion (frustration, irritation, anxiety) (Posner \& Rothbart, 2007). Affective engagement was measured from the expressions and experiences of the player (i.e. facial expressions while playing).

\section{Development and Application of a Serious Game}

Based upon current research and trends in the industry, the cruise line decided to design a serious game to train travel agents on the cruise booking process. The serious game was designed in collaboration with Sealund Innovative Associates. For over thirty years, Sealund Innovative Associates was a leader in designing, developing and deploying eLearning solutions. They collaborated with many organizations and businesses to enhance learning using technologies such as a serious game, scenario-based training, virtual learning environments, and simulations.

With the combination of the management team at the cruise line and Sealund Innovative Associates, they determined the purpose and goals for the game. The purpose of the game was to increase engagement of travel agents in the training programs offered by the cruise line. The Adventures Serious Game was initially designed with the following three goals in mind, 1. Create an engaging and fun learning environment, 2. 
Familiarize agents with the cruise lines current ships and destinations/itineraries provided by each ship, 3. Familiarize agents with the cruise lines policies and procedures (Sealund, 2012). The serious game was designed to engage travel agents with the cruise line in a fun format and encouraged travel agents to return frequently to play the game. The serious game was designed with three different levels: Level 1 - Baseball, Level 2 Speed Booking, and Level 3 - Cruising.

Sealund (2012) used a Quality Assurance Methodology to ensure the accuracy and effectiveness of the serious game throughout the analysis, design, development, evaluation, production, and implementation phases. During the analysis phase, the designer clarified the instructional challenges, learning objectives, learning environment and existing knowledge of the learner. The design phase dealt with integrating the items identified in the analysis phase and incorporated the assessment instruments, exercises and subject matter analysis, in addition, incorporated systematic and specific components of the instructional design process. Systematic means a logical, orderly method of identifying, developing and evaluating a set of planned strategies targeted for attaining the project's goals. Specific means each element of the instructional design plan needed to be executed with attention to details, also known as fidelity.

In the development phase, instructional designers created and assembled content as outlined in the design phase. It is common for an instructional designer to create a storyboard to outline the development process. In this phase there were frequent revisions and evaluations conducted to provide appropriate feedback on the training or game designed. The implementation phase developed procedures for training facilitators and learners. Training facilitators covered the course curriculum, learning outcomes, 
method of delivery, and testing procedures. Preparation for learners included training them on new tools (software or hardware) and student registration. Implementation included evaluation of the design. The evaluation phase consisted of two parts: formative and summative.

The Sealund Quality Assurance Methodology ensured the aesthetics and the functional integrity of the serious game. The QA team was comprised of highly-skilled QA specialists. The team was governed by the QA Manager, who ensures that each specialist performs a specific review, at the appropriate level, and following Sealund's standards and the methodologies of the cruise line as well (Sealund, 2012).

Foundation content for the serious game was based on the content provided from the cruise lines resources that were available to travel partners, including the Cruise Rookies presentation and GoCCL.com. Content in the game was updated on a monthly basis to ensure content was up to date with current booking procedures and policies. The cruise line decided to partner with Sealund due to their long standing history of designing and implementing interactive and engaging games. Sealund emphasized the use of proven best practices, including well-documented methodologies for all phases of design, development and deployment. Major corporations and organizations relied on Sealund to provide custom innovative training solutions for global systems conversions, application training support, conceptual training, and diverse training requirements with an emphasis on schedule and budget. Sealund's creativity and innovation designed into its client solutions provided highly engaging training that produces greater learner retention and application to job performance. 
Through the collaboration with Sealund, the cruise line was able to design a serious game using engaging graphics and interactions (Sealund, 2012). The game was packaged in SCORM format to allow for easy upload into the LMS. This format allowed for the game activity to be tracked and monitored within the LMS. Images of the game and the launch screens are available in the Appendix and were referenced throughout the dissertation.

The learner launched the game from the homepage of the Taleo's Oracle Learn Center (Figure 1, See Appendix) (Passport, 2012; Sealund, 2012). Upon clicking the image for the game a description page detailing the two adventures games appeared (Figure 2, See Appendix). The learner clicked the image of the adventures game and then was directed to the ranking page. The ranking page appears, where the learner was able to view his/her monthly and yearly total ranking in comparison to other learners in the system from this leader board (Figure 3, See Appendix). From the ranking page, the learner was able to launch the game by selecting "Launch Game" (Passport, 2012; Sealund, 2012) (Figure 3, See Appendix). On the next page, the learner was able to select "Click here to Play" which directed them to the play screen (Figure 4, See Appendix). The three levels of the serious game were connected via a main screen. When the player first accessed the serious game to play, he/she initially viewed a main screen (Figure 5, See Appendix). From the main screen the player was able to continue a previously uncompleted attempt of the serious game and/or start a new game. When the player began the game from the beginning, the introductory page for Carnival Adventures game appeared. The player then needed to select "Continue" to start the game (Figure 5, See Appendix). The game began with a brief Adventures cartoon, 
describing the adventure the player would travel through to eliminate the villains of fun: gloom, monotony, and boredom (Figure 6, See Appendix). The cartoon was added to the game to provide an engaging and fun component to the storyline of the game. To proceed with playing the game, the player needed to then select "Continue" (Passport, 2012; Sealund, 2012) (Figure 6, See Appendix). If the player was returning to a previous game, he/she was directed to where he/she left off from the previous game. For example, if the agent finished the last game after completing level one he/she would then start the game at level 2.

After proceeding through the cartoon and launching the game, the level one game screen appeared (Figure 7, See Appendix) (Passport, 2012; Sealund, 2012). From this screen the player started a brand new game or continued a currently saved game. If a player had saved a game and he/she wanted to play a new game, the player was warned that starting a new game would erase the progress of the player's current game. The player was only able to have one game saved at a time. The player started the game by selecting the level of difficulty of the game from the level 1 launch page (Figure 7, See Appendix). If the player had not previously completed the easy level, the buttons from medium and hard were grayed out (Figure 7, See Appendix). They must complete the easy level of difficulty prior to progressing to a harder level (Figured 7, See Appendix) (Passport, 2012; Sealund, 2012).

The first level of the social game was cruise rookie's baseball called "C. Baseball." When selecting to play C. Baseball, the player was presented with the mentor who provided instructions at the beginning of the game as well as interesting facts throughout the game. The player first selected the team they wanted to play against 
(Figure 8, See Appendix). The different teams were based on the different classes of ships at the cruise line (Figure 8, See Appendix) (Passport, 2012; Sealund, 2012). Each of these ships were found in one of the many classes of ships within the cruise line. A brief description was provided of the ship/team that were selected (Passport, 2012; Sealund, 2012) (Figure 9, See Appendix).

After the player selected the team/ship, the player then selected three cards from a deck of cards (Passport, 2012; Sealund, 2012) (Figure 10, See Appendix). Each card the player selected represented a different type of cruise rookie. The cruise rookies they selected were their pitchers during this segment of the game. Cruise rookie selections could be the Snubs (a middle class family, who only has one big vacation per year, and was looking for freedom to explore and have adventure), Hankee-Pankees (a newly-wed couple, new to cruising, looking for privacy and treasuring their special occasion together), and Red Socks (an affinity group looking for a vacation that has something for everyone in the group to do and allows for enough time to explore each port of call) (Passport, 2012; Sealund, 2012) (Figure 11, See Appendix). There were additional rookies available that can be selected in this process.

The cruise rookies asked the player questions and the player was required to answer the questions correctly to progress in the game (Passport, 2012; Sealund, 2012). For each question the player answered correctly, the player's stamina meter would increase. The player's stamina meter would increase based upon a combination of answering the question correct and a silent timer that kept track of how long the player took to answer the question (Figure 12, See Appendix). After the player answered the questions, the player was given an opportunity to play baseball in the style of a home-run 
derby (Figure 13, See Appendix). The player's stamina meter that was built up during the question and answer portion of the game gave the batter power. The bat was used to hit the baseball during the homerun derby. The player was given a specific number of baseballs to hit based upon the number of questions they answered correctly (Passport, 2012; Sealund, 2012).

When the player hits the baseball, the player received a home run (Passport, 2012; Sealund, 2012). The player was able to see how far he/she hit the baseball which was calculated using two items a combination of how accurate the baseball was hit and how much stamina the player had. The farther the baseball was hit, the more fun points the player received. Before the player plays home-run derby portion of C. Baseball, he/she first had to answer questions related to cruise rookies. The player earned a baseball for each question answered correctly. The player started with three baseballs. Each question that was answered correctly assisted in powering up the player's stamina meter. Each question was multiple choice with up to four responses. The player was required to answer six questions; two questions per rookie (Passport, 2012; Sealund, 2012) (Figure 13, See Appendix).

After the questions were answered correctly, the player was presented with a baseball game in the style of a home-run derby (Figure 13, See Appendix) (Passport, 2012; Sealund, 2012). During the home-run derby portion of the game, the pitcher pitched a ball at the player. A marker appeared as a target of where the ball was to appear similar to the strike zone in a traditional baseball game. The player used their 
mouse to click on the marker at the right time to send the ball out of the park. The ball was always a home run as long as it was selected on target (Figure 13, See Appendix) (Passport, 2012; Sealund, 2012).

For each question answered correctly, the player earned 50 fun points, which were points assigned to the player for answering a question correctly or completing a level quickly (Passport, 2012; Sealund, 2012). For each ball hit out of the park, 100 fun points were earned. There were bonus fun points as well based upon the stamina meter. The higher the stamina meter the farther the ball had the potential to go. For every foot beyond 400, two bonus fun points were added. To beat the level on the easy difficulty, the player was required to answer three of the cruise rookie questions correctly. To beat the level on the medium difficulty, the player was required to answer four of the cruise rookie questions correctly. To beat the level on the hard difficulty, the player was required to answer all of the cruise rookie questions correctly (Passport, 2012; Sealund, 2012).

Every question asked has a hidden timer associated with it. The faster a question was answered the more points that were added to the stamina meter, as bonus points in the baseball section (Passport, 2012; Sealund, 2012). During each level, the player was able to attain various achievements. The following was a list of possible achievements that were earned during Level 1: Double Play (Level completed on easy); Triple play (Level completed on medium); Home run (Level completed on hard); Shutout (Every question answered correctly on easy); Grand Slam (Every question answered correctly on medium); Perfect Game (Every question answered correctly on hard); Hitting Streak (Three baseballs hit in a row); No-hitter (No baseballs hit in the baseball game); Out of 
the Park (All nine balls are hit in a row); and Baseball Platinum (Earned every achievement possible in C. Baseball) (Passport, 2012; Sealund, 2012).

Level 2 of the game, was entitled Speed Booking (Figure 14, See Appendix). The player began the game by selecting the level of difficult, easy, medium, and hard, in which they wish to play (Passport, 2012; Sealund, 2012). Medium and hard only appeared, if they previously completed the easy level in its entirety. Otherwise they were only given have the option of easy. During this level, the player simulates being a travel partner that navigates answering questions for groups that were interested in booking a cruise. When selecting to play Speed Booking, the player was presented with a mentor who was available to provide instructions at the beginning of the game as well as interesting facts throughout the game (Passport, 2012; Sealund, 2012).

The player was given four desks at which they could place potential travelers (Passport, 2012; Sealund, 2012) (Figure 15, See Appendix). When the level begins, travelers appeared in a line on the left hand side of the screen (Figure 16, See Appendix). Speed booking began with four different cruise group types sitting at four different desks and the player in the center of the room. Eventually one of the groups raised their hand. This indicated that the groups had a question that the player needed to respond to them in a timely manner. When a group raised their hand, the player needed to click on the desk. The character representing the player then walked over to the desk to allow the agent to answer the group's question. The player needed to drag the travelers to an open desk. When the desks were full, the line would continue to build. If travelers waited too long in the line, they would leave and would not book their cruise. The player was only able to answer questions for travelers who were sitting at the desks. Each group of travelers 
asked between one and three questions that were relevant to that group. The player knew that a group was ready to ask a question because the group raised their hands. In addition, a talk bubble appeared and the desk glowed (Passport, 2012; Sealund, 2012) (Figure 16, See Appendix).

When the player selected a desk, his/her character moved to that particular desk (Passport, 2012; Sealund, 2012) (Figure 16, See Appendix). After the player clicked on the desk and their character walked over to the desk, a question appeared along with a timer. The player then needed to address the travelers' questions in a reasonable amount of time. If the player responded to their questions quick enough and answered all of their questions correctly, the group then booked their cruise and the amount of money that the player earned for this level increased. Each question was worth $\$ 100.00$ and an extra dollar was earned for each second that was left on the timer. As a result of answering the question incorrectly, the player earned no points and the group was unhappy and left immediately. The faster the player answered the questions, the happier the group was and the more money they spent overall (for example, they booked a balcony instead of an interior cabin) (Passport, 2012; Sealund, 2012) (Figure 16, See Appendix).

If the group was waiting a long period of time in the queue, the group alerted the player that they were getting close to leaving by placing an exclamation point above their head (Passport, 2012; Sealund, 2012) (Figure 15, See Appendix). The faster the exclamation point shook, the closer the group was to leaving. The game play continued until every possible question that were available was answered or no more groups remained. At the end, the players were presented with their final score and if they beat the level. Each dollar earned equaled two Fun Points (Passport, 2012; Sealund, 2012). 
To beat the level on the easy difficulty, the player needed to earn at least $\$ 1000.00$ (Passport, 2012; Sealund, 2012). There were a total of 15 groups. There was a possibility of $\$ 1500.00$ from questions. To beat the level on the medium difficulty, the player needed to earn at least $\$ 2000.00$. There were a total of 25 groups. There was a possibility of $\$ 2500.00$ from answering questions. To beat the level on the hard difficulty, the player needed to earn at least $\$ 3000.00$. There was a total of 30 groups. There was a possibility of $\$ 3000.00$ from questions. For each question asked there was a timer associated with it. The amount of time available to answer the question was dependent upon the question and the amount of time needed to answer the question (Passport, 2012; Sealund, 2012).

The following was a list of possible achievements that a player earned during this level: Novice (Level completed on easy); Skipper (Level completed on medium); Captain (Level completed on hard); Rookie (Every question answered corrected on easy); Pro (Every question answered corrected on medium); All-star (Every question answered corrected on hard); Mover and Shaker (\$500.00 earned on easy); Bright Future (\$1,500.00 earned on easy); Lookin' Good (\$1,000.00 earned on medium); Money Maker (\$2,500.00 earned on medium); Deep Pockets (\$2000.00 earned on hard); Winning! (\$3,500.00 earned on hard); Lots of Knowledge (Answered 5 questions in a row correctly on easy) ;Know it all (Answered 7 questions in a row correctly on medium); Can't touch this! (Answered 10 questions in a row correctly on hard); Go back to school, now! (Answered 5 questions in a row incorrectly on any mode); Satisfied clients (Level completed on easy and no group left because they waited in line too long); Very satisfied clients (Level completed on medium and no group left because they waited in line too 
long); Very, very satisfied clients (Level completed on hard and no group left because they waited in line too long); and Speed Booking Platinum (Earned every achievement possible in Speed Booking) (Passport, 2012; Sealund, 2012).

There were three different levels of game play for this level: easy, medium, and hard (Passport, 2012; Sealund, 2012) (Figure 17, See Appendix). Once the player completed the easy level of difficulty there were provided the opportunity to play the medium level of difficulty. The same was true for the next level of difficulty after completing easy and medium, the hard option was now available for play for the player. Each difficulty level would play the exact same way but the player would have to answer each of the groups' questions faster and would be required to earn more money from booking groups on cruises (Passport, 2012; Sealund, 2012).

The questions posted were concerning the cruise lines products, GoCCL (booking engine), and policies and procedures (Passport, 2012; Sealund, 2012). Questions in this level were updated on a monthly basis to reflect new e-learning tutorials added to the LMS. This allowed the agents to be up to date on new topics related to booking their guest. As noted previously, the player attained fun points for answering each question correctly during the speed booking process (Sealund, 2012). To beat the level, the player needed to attain enough fun points. If the player did not attain enough fun points they were required to try the level again until they successfully completed the level. The player was able to monitor their score by viewing the score on the top right hand side of the screen. A progress bar appeared indicating how close the player was to reaching their goal of beating the level. The progress bar also indicated the total number of fun points the player achieved within that particular level. When the green bar was full the player 
was able to progress to the next level because they had enough fun points. The player must surpass the goal for the level in order to progress, otherwise they were required to play the level again from the beginning (Sealund, 2012).

Level 3 of the game was entitled Cruising!. During this level, the agent booked the group and they were now going to cruise (Passport, 2012; Sealund, 2012) (Figure 17, See Appendix). The player begins the game by selecting the level of difficulty, Easy, Easy 2, Medium, Medium 2, Hard, or Hard 2, in which they wish to play the game. The player must complete the easy or medium levels in order to progress to the hard level. The player was now going to manage a series of cruisers in a fast-paced ship environment. When selecting to play cruising, the player was presented with the mentor who provided instructions at the beginning of the game as well as interesting facts throughout the game (Figure 18, See Appendix). The locations on the ship were represented by icons on the cruise ship (Figure 20, See Appendix). The travelers were miniature drawings of the character. Within this level, each cruiser was spread out throughout the ship in various locations. The player needed to move the cruisers around based upon the location the cruiser identified as their next place (Passport, 2012; Sealund, 2012). As the cruisers were moved around, the player would be asked questions concerning the ship and cruising environment (Figure 21, See Appendix). This level provided the player the opportunity to learn about the cruising experience, activities onboard the ship, and experience ship life.

During this level, the player was presented an image of the ship (Passport, 2012; Sealund, 2012). However, only a third of the ship was visible at one time (Figure 19, See Appendix). The player needed to select a section of the ship to move to the next location. 
The player was able to change which portion of the ship they were viewing by rolling their mouse over a smaller icon of the ship. The portion of the ship they were currently viewing was presented in color. The portion of the ship the player was not viewing was grayed out. If the player rolls over one of the darkened sections, the ship would transition to that portion of the ship. On the left hand screen in the blue menu box, cruisers appeared (Figures $20 \& 21$, See Appendix). This was an indication that the cruisers were ready to be moved to another part of the ship. Only three cruisers appear at a time on the blue menu bar. If additional cruisers were ready to be moved, the player would see an exclamation point with the number of cruisers (Passport, 2012; Sealund, 2012). The goal was to keep the happiness meter of each of the traveler's high.

On the right side of the screen, the player would have a bar which would fill up with different traveler's heads and a call out bubble of the new location that particular traveler's heads and a call out bubble of the new location that particular traveler would like to go now (Passport, 2012; Sealund, 2012). In this bar the player would be able to see where on the ship the traveler was currently at, the traveler's current happiness meter, and the call out bubble of where the traveler would like to go next. Only five travelers would be placed into this bar at a time. If more than five travelers were ready to change their location, an exclamation mark would appear behind the fifth traveler waiting to move with a number of how many other travelers were waiting to move (Passport, 2012; Sealund, 2012).

One of the icons was an image of where the cruisers wished to move to in the ship, i.e. the pool, the spa, the mini golf area, etc (Figures 22 \& 23, See Appendix) (Passport, 2012; Sealund, 2012). Above the cruiser was a series of hearts. Each cruiser 
begins the game with three hearts. The hearts represented the cruisers level of happiness. The quicker the player moved the cruiser, the higher their level of happiness. In addition, the more fun points the player attained. Each time the player does not move the cruiser quickly, the cruiser began to lose hearts decreasing their level of happiness. The last icon was a small ship, which represents the current location of the cruiser on the ship. To move the cruiser, they needed to find the cruiser on the ship, click on the cruiser, and hold their left mouse down and drag the cruiser to the new location (Passport, 2012; Sealund, 2012). The following locations were available on the Cruising Game: Waterslide, mini-golf, running, spa, internet location, horseback riding, casino, nightlife location, sports bar, comedy club, relaxing on the deck, staterooms, dolphin swim, parasailing, and safari (Passport, 2012; Sealund, 2012) (Figures 22 \& 23, See Appendix).

Throughout the game, the player was asked a question once the cruiser moved to a new location (Sealund, 2012) (Figure 21, See Appendix). The player was required to answer the question in order to proceed and to move another cruiser. For answering the question correctly, the player attained 100 fun points that were added to their total level score. The player gained 25 fun points every 20 seconds for each group that had a high happiness meter. The player gained 10 fun points every 20 seconds for each group that had a medium happiness meter. The player gained no points for groups who had low happiness meters. As with a traditional ship, the ship would dock in various ports of calls or destinations (Figure 22, See Appendix). Within the main screen on the lower right hand corner there was an image of an overhead map with an icon that represents the port where the ship had arrived. When an icon appeared on the overhead map, the cruiser 
selected the port of call as their new location (Figures 22 \& 27, See Appendix). When the ship left the port, the cruiser was automatically placed back on the ship to ensure no cruiser was left behind (Sealund, 2012).

In some instances the movement to a new location initiated a mini-game (Passport, 2012; Sealund, 2012) (Figures 23 \& 24, See Appendix). Based on the itinerary the player was selected previously, players entered into different modes. For example, if a player was going on an excursion they would play a mini-game based on the type of excursion that was booked. Mini-games consisted of a slots machine casino game (Figure 26, See Appendix), horseback riding excursion, or a karaoke game (Figure 25, See Appendix). Mini-games were incorporated throughout the ship, providing the player the opportunity to attain additional fun points. Examples of mini-games that were incorporated were: 1 . Slot machine casino game, where the player goes to the casino and plays the slots. Players attained fun points for successfully answering the questions and playing the slots. 2. Horse racing game, where the player answered various questions to get their horse to win a horse race on a beach. 3. Karaoke game, where the player answers various questions about the amenities on board the ship while standing in the comedy club (Passport, 2012; Sealund, 2012).

These mini-games required the player to answer questions about shore excursions, night life on-board the ship, and/or amenities on-board the ship (Passport, 2012; Sealund, 2012). To beat the level, the player needed to attain enough fun points. If the player does not attain enough fun points, he/she was required to try the level again until they successfully completed the level. The player monitored their score by viewing the score on the top right hand side of the screen. A progress bar was available to demonstrate how 
close the player was to reaching their goal of beating the level. When the green bar was full the player was able to progress to the next level due to having enough fun points (Passport, 2012; Sealund, 2012).

Throughout level 3, the player was given an interface that included: a pause button, a save button, and the player's score for the current game (Sealund, 2012) (Figure 27, See Appendix). The main screen of the game was a zoomed out scene of the ship. The ship had indicators on it which represented the different members of the group. Each of the members of the player's group started in their stateroom. In the stateroom, the player was given access to a clickable "brochure" that the player can click on to learn more about the ship (Sealund, 2012).

At this point the player begins selecting activities for the members of the group to complete (Passport, 2012; Sealund, 2012). This may include going to the following locations, pool, internet café, ocean plaza, adult only serenity area, casino, night club, Punchliner Comedy Club, one of the production shows, karaoke, Cloud 9 Spa, play minigolf, eat, or walking around the ship. Each of the locations were places on the ship that a guest would experience on one of the 24 Fun Ships. The locations were strategically located to simulate the actual location of the space on the ship. For example, the Lido Pool would appear on Deck 11 and the Cloud 9 Spa would appear on Deck 12. It is the player's job to keep each member of the group satisfied and having fun. If their fun meter drops too low, it was because the player has brought them to a part of the ship that they didn’t want to go or they were at a location for too long. The player was given indicators of where the members of the groups wanted to go. As time passes, the player received points based on how the members of the group were enjoying their time. 
Additionally, based on where the player puts a member of the group, a question may appear. If the player answered the question correctly, points were added to their score (Passport, 2012; Sealund, 2012). Throughout the level each player was eligible to attain various achievements (Figure 27, See Appendix) such as: Deckhand (Level completed on easy); Sailor (Level completed on medium); Conqueror of the Seven Seas (Level completed on hard); Knowledgeable (Every question answered correctly on easy); You've done well, Grasshopper (Every question answered correctly on medium); The GoCCL.com website comes to you when it needs help (Every question answered correctly on hard); You hit the high notes! (Answered three questions in a row in the karaoke mini-game); Hail to the King, King of the slots (Hit every possible jackpot during the casino mini-game); You must be a jockey! (Completed the horseback riding mini-game without hitting any obstacle); One with the ship you are (Completed any round of the ship without any traveler's happiness meter falling one notch); and Cruising Platinum (Earned on all Cruising achievements).

Once the player completed all three levels they were presented with a congratulations and completion screen (Passport, 2012; Sealund, 2012) (Figure 28, See Appendix). The screen displayed the player's score and indicated that the score was submitted to the leader board and saved. In addition, the player was given three buttons to select from, passport, play again, or close. The passport button took them to their passport, where they attained passport stamps for achieving various levels throughout the game (Figure 29). For example, for attaining a double play in level 1, they received a double play stamp. The play again button encouraged the player to play again and make greater advances through another level of difficulty. The close button was used to exit 
the game and return to the Learning Management System. The close button also allowed the LMS to record that the player ended the game and their duration of play in the game (Passport, 2012; Sealund, 2012).

One item to note was that at the beginning of each level a tutorial was displayed (Sealund, 2012). The tutorial provided the player the opportunity to practice the skills they needed to progress through the level and attain a maximum amount of fun points. The player had the option of skipping the tutorial if they wish to immediately progress into the game (Sealund, 2012).

Within each level the player accumulated fun points. Fun points were saved after the completion of each level. The fun points were translated into reward points at the value of 100,000 fun points to equal 100 reward points. The reward points were able to be redeemed in the Travel Agents Reward Program. The rewards program was used in all activities completed by travel agents that were active with the cruise line. The reward points were redeemed for prizes such as an IPad, gift cards, cruise cash, and other incentives.

The serious game designed by the large cruise line provided a brief overview and a simulated real-life experience to the life of being a travel agent (Passport, 2012;

Sealund, 2012). Level one provided the travel agent the opportunity to learn about how to sell and market to various groups. Some of the topics covered were asking the right questions, building relationships, closing the sale, identifying groups, and tailoring the cruise to the individual booking. One of the greatest challenges for a travel agent was identifying the right fit for a group. For example, one knows that an elderly person would not want to travel on a cruise during spring break but would be interested in the 
winter because it was not as hot. Within level one the travel agent was able to learn about the group and also about the cruise rookies which was a hot market for cruising (Passport, 2012; Sealund, 2012).

Level two provided the travel agent the opportunity to learn about the booking engine and policies and procedures (Passport, 2012; Sealund, 2012). In order to be an effective agent, they needed to know what were the policies and procedures associated with booking. For example, knowing the special rate codes for early saver booking or fun seeker and the policies associated with them. Each rate code had different terms and conditions that impacted the guest if they needed to cancel or move their trip to another time. A player was also able to learn about various policies impacting the booking process. The speed booking allowed the agent to learn faster techniques to booking by understanding the ins and outs of the booking engine. For example, the agent was presented questions about adding cruise cash, booking an individual into a group, making a payment, printing and sending a confirmation, to name a few. Each of these were tasks frequently performed by the agent in order to make a smooth booking process for the guest (Passport, 2012; Sealund, 2012).

Level three provided the agent the ability to understand the cruising experience (Passport, 2012; Sealund, 2012). The agent was able to learn what the guest would experience while on-board the ship. This was very important. A guest wants to know what type of experience they would have. They also wanted to know what amenities are available on their ship. The cruise line has 24 cruise ships. The questions posed here 
covers each of the ships and were updated frequently to reflect new additions, such as Fun Ship 2.0 enhancements to keep the agent up to date on the features being added to the Fun Ship near them (Passport, 2012; Sealund, 2012).

The Adventures Game was designed to be integrated into the Learning Management System (LMS) of the cruise line using a SCORM package. The LMS records the number of fun points and duration of time playing after each level of completion. If the learner does not complete the level the fun points attained at that time are not recorded by the LMS. If a learner walks away from playing the game, the LMS will time out after minutes of inactivity. This was implemented to ensure a player does not leave the window open for a long duration of time without playing. The player can exit the game by selecting the close button. If they wish to pause the game to return to play later (but not later than 15 minutes), they can select the pause button.

There were some limitations to the technology platform that host the Adventures game. The LMS does not record each instance of entry individually, number of instances play and incomplete instances of play. In addition, the system does not display data such as number of fun points and duration of time based upon each individual level. Instead, the system records a cumulative duration of time and total fun points. This limitation only allows the researcher to be able to analyze the data based upon cumulative data rather than at each individual interval.

The serious game designed by a large cruise line provides an engaging and interactive environment that encouraged the learner to participate in other activities. Based upon data collected by the cruise line, they were 2,800 out of 5,500 travel agents who have accessed the LMS and have also played the game (Passport, 2013). Over 20 of 
our top players, have greater than 100,000 fun points (Passport, 2013). On average, travel agents play the video game 10 hours per week (Passport, 2013). The use of the game has led to 25,000 educational opportunities being completed by travel agents (Passport, 2013).

\section{Summary}

In summary, the researcher provided an overview of the evolution of gaming and the use of game-based training in various environments, undergirded by theoretical and empirical evidence. The researcher also provided an overview of the design of the Adventures game and the collaboration between the cruise line and Sealund Innovative Associates to create a serious game. Lastly, the researcher discusses the design process for developing the serious game and the game elements included to create a simulated real-life experience of being a travel agent. 


\section{CHAPTER III}

\section{METHODS}

This chapter details the methods and design that were developed to address the research questions for this study and describes the participants, instruments, data collection procedures, and data analysis techniques. This study examined the use of a serious game, defined as a game with an educational purpose as well as to promote behavior change and not used just for entertainment purposes, to train travel agents at a large cruise line. The study assessed the travel agents' training outcomes of knowledge attainment and engagement.

\section{Research Questions and Hypotheses}

As previously discussed the research study was based upon two research questions.

Research Question One. Is there a relationship between engagement (total number of minutes playing the game) of travel agents who play the Adventures Game (a serious game designed with three levels that allows the travel agent to attain fun points) and their knowledge attainment (total number of fun points earned)?

Null Hypothesis $\left(\mathrm{H}_{01}\right)$ for Research Question One. There is no relationship between engagement (as measured by number of minutes playing the game) of travel agents playing the Adventures Game and knowledge attainment (as measured by the total number of fun points).

Alternative Hypothesis One $\left(H_{1}\right)$ for Research Question One. There is a positive relationship between engagement (as measured by number of minutes playing the game) 
of travel agents playing the Adventures Game and knowledge attainment (as measured by the total number of fun points).

Research Question Two. Is there a relationship between engagement and playing serious games on the agent's total cruise sales (as measured by total cabin sales)?

Null Hypothesis Two $\left(\mathrm{H}_{02}\right)$ for Research Question Two. There is no relationship between engagement (as measured by total number of minutes playing the game) of a travel agent who plays the serious game and their total cruise sales.

Alternative Hypothesis Two $\left(\mathrm{H}_{2}\right)$ for Research Question Two. There is a positive relationship between engagement (as measured by total number of minutes playing the game) of a travel agent who plays the serious game and their total cruise sales (as measured by total cabin sales).

\section{Background for the Study}

The following study was based upon a game-based training program. Games over the years have been used for the purpose of training. Researchers have shown that games were a medium that can be used as to demonstrate the connection between learning, work and relationships (Juul, 2005). Games were traditionally seen for the entertainment of users; however, over time the purpose of games have evolved in many other ways and were currently being used in academia, public health, government, businesses, and simulation-based training (Juul, 2005).

Research has showed that playing serious games was beneficial for learning purposes, such as providing travel agents the knowledge necessary to book a guest on a cruise (Csikszentmihaly, 1979; Kiili, 2005ab). The following segment provides an overview on how games assist in learning. In addition, the benefit of using a serious 
game, Adventures game, on training travel agents on the skills and knowledge need to book a guest on a cruise. Computer-based games and video games assisted players in attaining the knowledge necessary to book a guest, make sales, market or increase productivity through the use of simulation and interactivity.

There is clear evidence through the use of gaming elements and theories that games are effective in promoting engagement and learning in players (Sridharan, Hrishikesh \& Raj, n.d.). The reality is that games tap into the best qualities of a learner, motivating them, creating a collaborative environment, and taping into their inner competitive side when a challenge is presented (Sridharan et al., n.d.). Gaming encourages the player to be enthusiastic about gaining new knowledge through their interactions with other players in the virtual environment (Sridharan et al., n.d.). Deterding, Dixon, Khaled, and Nacke (2011) described the role of gamification and stated that games provide a more enjoyable and engaging environment versus those components that do not incorporate gaming. Gamification also yielded player involvement and provides motivation to address challenges presented their way (Kohl, 2013).

Jonassen (1988) and Keller (1979) both argued that a well-designed game should promote confidence in the learner and lead him/her to success. The manner in which games fulfilled this duty was by encouraging intrinsic motivation in learners and promoting retention of material. As described by Cameron and Dwyer (2005), “instructional gaming has the intrinsic ability to develop the learners' confidence in determining their own destiny. Additional research has shown that as the learner's selfconcept improves, cognitive learning also increases” (p. 244). The retention ultimately 
leads to sustained knowledge and transfer of information to other skills and tasks. A game with clearly defined goals and high levels of interactivity instills these attributes needed to be considered a successful game.

Engagement is demonstrated when the motivation of a learner was piqued when positive experiences grab and sustain the players' cognitive and motor competencies (Chaiklin, 2003). Engaged learners demonstrate involvement in educational activities through their behavior such as excitement and playing for hours. When given the opportunity, they initiated the desire to play, tried their best and focused on the game to learn new skills and master new knowledge. When a game was too easy, engagement tended to decrease (Chaiklin, 2003).

Engagement states include cognitive, behavioral, and affective components (Skinner \& Belmont, 1993). Behavioral engagement was represented when a stimulus was presented and the speed and accuracy of fine and motor movements were measured. When a player was engaged in an activity, the dopamine passage way in their brain was activated due to the stimuli presented to them at that moment. In addition, their motor cortex was activated when they were engaged (Skinner \& Belmont, 1993).

Motor reaction time was measured directly using the game device, based on how quickly the student responded to stimuli on the screen (Posner, 1978). The speed of correct actions such as cursor moves and screen touches were a tool used to measure reaction time; on the other hand, the number of incorrect touches was used to interpret reaction time and motor control. In addition, sustained attentive behavior was used to understand level of behavioral engagement of the player with the game (Posner, 1978). 
Engagement incorporated various elements such as affective engagement (Posner \& Rothbart, 2007). Affective engagement focused on the motivation associated with engagement and the emotions associated with it. Emotions were positive, excitement, joy, happiness, or can be negative, annoyance, frustration or irritation. The player's emotional state while playing the game impacted their desire to play and further engagement into the game (Posner \& Rothbart). Affective engagement was important in determining the player's behaviors that were impactful when they were playing the game. Affective engagement emotions consisted of positive emotions (e.g., excitement, happiness) and negative emotions (e.g., frustration, irritation, anxiety) (Posner \& Rothbart). Each of these potentially impacted the user's experience while playing the game and were evaluated to provide the best user experience possible when playing.

\section{Population and Sample}

The target population for this study was 20,000 travel professionals located throughout the United States of America who sell cruises and are employed by a North American travel agency (Passport, 2013). Travel agents' ages typically range from 2180, with a majority of agents falling between the age ranges of 51-70 (Rice, 2013). Thirty-eight percent of travel agents are home-based agents and over 50\% work for a travel agency (U.S. Department of Labor, 2014). Forty-two percent of travel professionals have completed college and 24\% have completed some college (U.S. Department of Labor, 2014). In this research, all travel agents (over 20,000) who did business with the cruise line were provided the opportunity to play the game; thus, none of the travel agents were excluded from playing the game. When the game was launched in 2012, a press release and email communication was sent to travel agents in the U.S. 
and Canada, who were listed within the cruise lines trade marketing email database to encourage them to play.

For the purpose of this study, the researcher focused on the sample of travel agents who played the serious game $(N=309)$. Initially, the data base had 2,298 agents who had played the game. After further review of the data, the researcher removed from the data set users who had no fun points, no cabin sales and less than a minute of play in the game. In addition, 40 outliers ( $\pm 3 S D$ or more from mean) were removed. Tabachnick and Fidell (1996) have recommended removing outliers when they exceed $1 \%$ of the sample, as was the case in this research (1.74\%). The study focused on data ranging from January 1, 2012 until December 31, 2014. In 2012, the cruise line reported that over 289 of its top players had more than 50,000 fun points (Passport, 2013). Fun points, as described earlier, were the credits received throughout the game for answering questions and advancing through particular thresholds. This sample of travel agents tended to play an average of 10 hours per week (Passport, 2013). Travel agents were able to play the game during working hours or on their own free time at home. Some agents were also home-based and had flexible schedules allowing them to play more frequently.

\section{Methodological Rationale}

For the following study, data were collected by the cruise line during a 2-year time period. Because the researcher was unable to control for random assignment or manipulate the variables, the researcher conducted a nonexperimental, correlational study. By choosing a nonexperimental correlational study, the researcher was unable therefore to assess cause-effect relationships. 
On the basis of the extant research that links learner engagement, knowledge attainment and performance (e.g., Cameron \& Dwyer, 2005 \& Sridharan et al., n.d.), the researcher investigated the relationships among the following variables: engagement, knowledge attainment and total cruise sales. Engagement was measured by the duration of time the travel agent played the game. Knowledge attainment was measured by the total number of fun points the travel agent received by playing the Adventures game. Fun points were selected for this measure because for the learner to receive fun points in the game, the learner had to answer the questions correctly and quickly. The more questions they answered correctly and the faster they were to respond to each question, the higher the number of fun points they attained. Lastly, the researcher also wanted to examine the relationship between engagement and total cruise sales. The variables engagement and total cruise sales were used to evaluate this relationship. Total cruise sales was provided through data collected by the cruise line over the 2-year time period previously identified in this study and was measured by total cabins sold.

\section{Research Design}

The following study used a nonexperimental design as outlined by Trochim (2005). Trochim (2005) noted that a nonexperimental design focuses on a statistical relationship between two or more variables; however, it does not allow for the manipulation of an independent variable and/or random assignment of the participants as we would see in experimental research designs Nonexperimental designs can take two forms: correlational research and quasi-experimental research. In this study, the researcher was unable to manipulate the subjects because they were not employed by the cruise line and were employed by an outside agency. In addition, the subjects opted into 
participating in the training offerings and were not required to participate. Because the researcher was unable to control or manipulate the subjects in the study or conduct random assignment, the researcher focused on a correlational study. When conducting a correlational study, the researcher measures and assesses the relationship between the variables of interest. In this type of study, the researcher was unable to control for extraneous variables as well. Linear regression analyses were also used to make predictions based upon the linear relationships between the dependent variables (i.e., knowledge attainment and cabin sales) as they relate to the independent variable (i.e., engagement).

\section{Data Collection and Analysis}

The general context of this study was focused on the cruising industry. The data for this study were collected from participants who played a game-based training program. The goal of the study was to understand how engaged the travel agents were with the cruise lines' game-based training and the degree to which they learned, and its possible link to total cabin sales (measure of learning performance). The three primary goals outlined by the cruise line for the design of the game correlated with the research questions outlined in the study. Both the goals and the research questions focused on understanding engagement and knowledge attainment. The research questions outlined in the study measured the outcomes that were outlined in the goals of the game. The following research study examined two research questions. 


\section{Preliminary Correlational Analyses}

Preliminary analyses was completed using the Pearson correlation coefficient $(r)$ to evaluate the strength and direction of the relationship between knowledge attainment (as measured by total fun points) and total cabin sales (as measured by cabins sold). The strength of the particular relationship was expressed by a correlation coefficient, which can range between -1.0 to 1.0 . If the two variables are directly or positively correlated, the correlation coefficient would be positive (Kuzma \& Bohnenblust, 2001; Springer, 2010). If the correlation coefficient value is exactly 1.0, the two variables were perfectly positively correlated (Kuzma \& Bohnenblust, 2001; Springer, 2010). A negative correlation coefficient means that the variables were inversely correlated. A correlation coefficient of exactly - 1.0 would mean that the variables were perfectly negatively correlated. A correlation coefficient of 0 (or close to 0 ) means that there was no relationship between the variables (Kuzma \& Bohnenblust, 2001; Springer, 2010).

\section{Hypothesis 1}

This hypothesis tested the relationship between engagement and knowledge attainment. To be a successful travel agent, they needed to attain the knowledge necessary to book a guest. Travel agents needed to understand marketing and selling to cruise rookies, booking guests using the GoCCL booking engine, and the cruising experience such as products available onboard and various types of ships available. The Adventures Game included all of these components.

Throughout the game, the travel agent answered questions pertaining to the booking process and cruising experience. Each question answered correctly yielded a set 
number of fun points. The number of fun points attained varied depending upon the rate and accuracy of answering the questions presented throughout the game.

Fun points are a direct measure of knowledge acquired because the agent needed to answer the question correctly and quickly to attain the maximum number of fun points. Therefore, the agent must have acquired the knowledge to answer it correctly. Consequently, knowledge attained was measured by the total number of fun points the travel agent attained by playing the serious game. Engagement, on the other hand, was measured based upon the duration of time the travel agent played the Adventures game.

The data collected from the cruise line was available on a LMS through a series of reports and the server that housed the extraction reports for the game and files that were loaded onto the LMS. The data collected for this hypothesis were compiled from the extraction report and updated daily from the Adventures Game on the server, which houses all content loaded onto the LMS. The LMS was an online website where the training materials were housed and tracked for all travel agents. All of the training materials and registrations for the live events were housed in the LMS. Travel agents registered and created a user account within the LMS. The LMS required that the travel agent to enter demographic information, travel agency name, personal identifying information (date of birth and driver's license/passport information for registration for live events onboard the ships) and travel agent certification number (IATA and CLIA) to create an account. IATA was known as The International Air Transport Association, which is a trade association of the world's airlines. CLIA was the Cruise Lines International Association. Both IATA and CLIA were certifications travel agents can receive to be recognized worldwide. Each agent was required to only maintain one user 
account; any duplicate accounts were removed. The user account tracks all trainings the agents completed and activities within the LMS.

The data were housed on the server containing the following information: username, user's last name, agency name, and total fun points. The data were on a text file that can be downloaded from the Server by date. The data were loaded daily in the evening and simultaneously appears on the leader board located on the main page of the game in the LMS for the travel agent to see their current standing. The text files from the date range of January 1, 2012 until December 31, 2014 were downloaded from the Filezilla Server. The data were compiled and then loaded into SPSS 22.0 and analyzed.

To evaluate a relationship between two variables, the researcher used a linear regression analysis to examine the relationship between the two variables, independent (Engagement) and dependent variable (Knowledge attainment). The goal was to understand the relationship between engagement (total number of minutes playing the game) and knowledge attainment (total number of fun points). In a linear regression, the dependent variable is known as the criterion variable and the independent variable is known as the predictor variable. When testing this hypothesis, the criterion variable was knowledge attainment and predictor variable was engagement as measured by total of minutes played.

\section{Hypothesis 2}

For Hypothesis 2, the researcher assessed the relationship between engagement in playing the Adventures game and cruise sales over a 2-year period (noted as cabin sales). Cruise sales were compiled by the individual travel agent by month. The data were 
analyzed using a linear regression analysis to determine the relationship between the engagement (independent variable) of those who played the Adventures game and cruise sales (dependent variable).

\section{Summary}

A nonexperimental research design was used to address the two research questions and two research hypotheses outlined in the study. A combination of linear regression analyses and Pearson product-moment correlation coefficient techniques were used to assess the relationships presented. 


\section{CHAPTER IV}

\section{RESULTS}

This chapter presents the results of the study and is organized into three main sections: background of the sample, examination of the hypotheses, and brief summary of the chapter. To test the hypotheses, regression analyses were used to test the hypothesized model of travel agent engagement, knowledge attainment and total cruise sales.

\section{Background of the Sample}

Three hundred and nine travel agents participated in this study representing $7.44 \%$ $(N=2,298)$ of those travel agents who had at least opened the game. Initially, the data base had 2,298 agents who had at least opened the serious game. All travel agents who had access to the Learning Management System (LMS) were given the opportunity to play the game. The researcher found that a large number of agents $(N=1,949)$ seemed to open the game out of curiosity and the quick desire to understand what the game entailed. Those travel agents who were still interested in playing the game, however, proceeded through to completing the first level of the game. The remainder opted to close the game before completing the first level of the game. Therefore, their total number of fun points was zero or their total number of minutes playing the game showed as zero. The researcher removed the 1,949 individuals that had no fun points, no cabin sales or less than a minute of play in the game. In addition, 40 outliers were removed, resulting in the final sample of 309. The participant's background, i.e., gender, age, country, region are examined in the following sections based upon the data provided in the data set. 


\section{Gender}

The sample was $88.0 \%$ female $(n=273)$ and $11.7 \%(n=36)$ male. All participants reported their gender.

Age

A frequency analysis of age indicated that $1.6 \%(n=5)$ of the respondents reported belonging to the 21-30 years old group, $12.3 \%(n=38)$ to the $31-40$ years old group, $21.4 \%(n=66)$ to the $41-50$ years old group, $29.1 \%(n=90)$ to the $51-60$ years old group, $19.4 \%(n=60)$ to the $61-70$ years old group, $1.9 \%(n=6)$ to the $71-80$ years old group; 14.2\% $(n=44)$ of respondents did not report their age.

\section{Region}

A frequency analysis of region indicated that $10.4 \%(n=32)$ of the respondents reported belonging to the Northeast region, $14.6 \%(n=45)$ to the Midwest region, $54.4 \%$ ( $n=168)$ to the South region, $11 \%(n=34)$ to the West region, and finally $9.7 \%(n=30)$ to the Canada region. The regions examined here consisted of New England (Connecticut, Maine, Massachusetts, New Hampshire, Rhode Island, Vermont, New Jersey, New York, and Pennsylvania), Midwest (Illinois, Indiana, Michigan, Ohio, Wisconsin, Iowa, Kansas, Minnesota, Missouri, Nebraska, North Dakota, and South Dakota), South (Delaware, Florida, Georgia, Maryland, North Carolina, South Carolina, Virginia, Washington D.C., West Virginia, Alabama, Kentucky, Mississippi, Puerto Rico, Tennessee, Arkansas, Louisiana, Oklahoma, and Texas), and West (Arizona, Colorado, Idaho, Montana, Nevada, New Mexico, Utah, Wyoming, Alaska, California, Hawaii, Oregon, and Washington). 


\section{Country}

A frequency analysis of the country each agent was from was completed indicated $90.3 \%(n=279)$ of the participants were from the US; 9.7\% $(n=30)$ reported they were from Canada.

\section{Engagement}

A frequency analysis of the engagement of travel agents by quartile was completed indicated $24.9 \%(n=77)$ of the participants had 1-3,380 minutes of play, $24.9 \%(n=77)$ had $3,382-7,278$ minutes of play, $24.9 \%(n=77)$ had $7,279-17,507$ minutes of play, and $24.9 \%(n=77)$ had $17,508-45,000$ minutes of play.

\section{Knowledge Attainment}

A frequency analysis of the knowledge attainment (total number of fun points attained) of travel agents was completed by quartile and indicated $24.9 \%(n=77)$ of the participants had 1-5,420 total fun points, $24.9 \%(n=77)$ had 5,421 - 12,462 total fun points, $25.2 \%(n=78)$ had $12,463-25,069$ total fun points, and 24.9\% $(n=77)$ had 25,070 - 76,000 total fun points.

\section{Total Cabin Sales}

A frequency analysis of total cabin sales of travel agents by quartile was completed and indicated $24.3 \%(n=75)$ of the participants had 1 - 31 total cabin sales, 25.6\% $(n=79)$ had $32-107$ total cabin sales, 24.9\% $(n=77)$ had 108 - 334 total cabin sales, and 24.9\% $(n=77)$ had $335-2,684$ total cabin sales. 


\section{Data Transformation}

Careful examination of the engagement, knowledge and cabin sales variables revealed that each of the variables were moderately to substantially positively skewed. In situations like these, Tabachnick and Fidell (1996) have recommended transforming the data to normality via a log transformation with the formula NEWX $=\mathrm{LG10}(\mathrm{X})$ to improve interpretations. Before the log transformations, the research variables’ means, SDs and skewness statistics were respectively, engagement $(M=12,371.73 ; S D=$ 12,558.0; skewness $=1.84)$, knowledge $(M=18,073.18$; $S D=16315.60$; skewness $=$ 1.63), and cabin sales $(M=273.45 ; S D=107.50$; skewness $=3.02)$. After the log transformation, the skewness statistics improved markedly to: engagement $(M=3.88 ; S D$ $=.46$; skewness $=-.41)$, knowledge $(M=4.10 ; S D=.37$; skewness $=.26)$, and cabin sales $(M=1.98 ; S D=.74$; skewness $=-.46)$. Thus, all subsequent analyses employ the transformed data.

\section{Cross Tabulation of Background Demographic Variables}

Cross tabulation analyses of the demographic variables were examined to assess the relationship between two nominal variables and determine meaningful relations that might exist using nonparametric statistics. Chi-square analysis is commonly used by researchers to help in drawing conclusions about a population from a sample and provide evidence regarding the generalizability of findings to a broader population (Creswell, 2005; Shannon \& Davenport, 2001). The chi-square procedure is the most commonly used statistic to test the null hypothesis and demonstrate if the two nominal variables are not related or if they are related (Shannon \& Davenport, 2001). The chi-square procedure is used to compare observed cell frequencies with what you would expect if the two 
variables were not related (Hinkle et al., 2003). It is expected that as the difference between observed and expected frequencies increase, so will the chi-square statistic. The chi-square statistic follows a known distribution; therefore, it is possible to determine the extent to which a specific chi-square would occur by chance (Hinkle et al., 2003). This is expressed in the form of a significance level ( $p$ value). As chi-square values increase, the probability of chance decreases. Should the probability of a result occurring by chance be equal to or less than the significance level ( $p$ value), the null hypothesis should be rejected and it would be safe to conclude that a relationship exists between the variables (Hinkle et al., 2003; Shannon \& Davenport, 2001). Each of these showed a statistically non-significant finding. In plainer language, there was evidence that the different combinations of nominal variables were not related.

Four variable combinations were evaluated: age and region, age and country, gender and region, and gender and country (see Table one). Each of these variables was evaluated to ensure they were not related. The significance level ( $p$ value) reported for the Pearson chi-square for Age and Region was .569. A value of .569 is high, meaning that one would expect the observed and expected frequencies to differ as much as they do by chance about 56 times out of 100 . In other words, it is very likely that these frequencies differ by chance and that there is no relationship between age and region. Therefore, this is considered a statistically non-significant finding. The same is true for the variable combinations of age and country $(p=.533)$, gender and region $(p=.464)$ and gender and country $(p=.324)$. Each of these showed a statistically non-significant finding. 
Table 1

Demographic Variable Cross Tabulation

\begin{tabular}{lccc}
\hline Variable Combination & $\chi^{2}$ Value & $d f$ & $p$ \\
\hline Age and Region & 22.176 & 24 & .569 \\
Age and Country & 5.082 & 6 & .533 \\
Gender and Region & 3.591 & 4 & .464 \\
Gender and Country & .972 & 1 & .324 \\
\hline
\end{tabular}

Additionally, the researcher conducted a one-way Analysis of Variance (one-way ANOVA) to test for possible group mean differences. ANOVA can be used to make comparisons between individuals in different groups or within the same group. Table 2 provides the information for the variable age as it relates to each of the study variables (engagement, total cabin sales, and knowledge attainment). The reported $F$ ratio is 1.556 , having a probability of .160 for engagement. The reported $F$ ratio is 1.187 , having a probability of .139 for knowledge attainment. The ANOVAs for age and engagement ( $p$ $\left.=.160, \eta^{2}=.03\right)$ and age and knowledge attainment $\left(p=.313, \eta^{2}=.02\right)$, showed statistically non-significant results. The reported $F$ ratio is 2.441 , having a probability of .026 for total cabin sales. The ANOVA result for age and total cabin sales $\left(p=.026, \eta^{2}=\right.$ .05), however, showed statistically significant results. After further analysis using Scheffé post hoc analysis, results indicated statistically non-significant results for age and total cabin sales (see Table 3). 
Table 2

One-Way ANOVA Results - Age

\begin{tabular}{|c|c|c|c|c|c|c|c|}
\hline & & $\begin{array}{l}\text { Sum of } \\
\text { Squares }\end{array}$ & $d f$ & $\begin{array}{c}\text { Mean } \\
\text { Square }\end{array}$ & $F$ & Sig. & $\eta^{2}$ \\
\hline \multirow{3}{*}{ Engagement } & Between Groups & 1.960 & 6 & .327 & 1.556 & .160 & .03 \\
\hline & Within Groups & 63.189 & 301 & .210 & & & \\
\hline & Total & 65.148 & 307 & & & & \\
\hline \multirow{3}{*}{$\begin{array}{l}\text { Total Cabin } \\
\text { Sales }\end{array}$} & Between Groups & 7.760 & 6 & 1.293 & 2.441 & .026 & .05 \\
\hline & Within Groups & 159.470 & 301 & .530 & & & \\
\hline & Total & 167.230 & 307 & & & & \\
\hline \multirow{3}{*}{$\begin{array}{l}\text { Knowledge } \\
\text { Attainment }\end{array}$} & Between Groups & .966 & 6 & .161 & 1.187 & .313 & .02 \\
\hline & Within Groups & 40.930 & 302 & .136 & & & \\
\hline & Total & 41.896 & 308 & & & & \\
\hline
\end{tabular}


Table 3

Scheffé Multiple Comparisons - Age

\begin{tabular}{|c|c|c|c|c|c|c|c|}
\hline \multirow[t]{2}{*}{ Dependent Variable } & \multirow[t]{2}{*}{ (I) Age } & \multirow[t]{2}{*}{ (J) Age } & \multirow[t]{2}{*}{ Mean Difference (I-J) } & \multirow[t]{2}{*}{ Std. Error } & \multirow[t]{2}{*}{ Sig. } & \multicolumn{2}{|c|}{$95 \% \mathrm{CI}$} \\
\hline & & & & & & Lower & Upper \\
\hline \multirow{19}{*}{ Engagement } & \multirow{5}{*}{ Ages 21-30 } & Ages 31-40 & .08915 & .21797 & 1.000 & -.6898 & .8681 \\
\hline & & Ages 41-50 & -.07239 & .21252 & 1.000 & -.8319 & .6871 \\
\hline & & Ages 51-60 & -.04828 & .21058 & 1.000 & -.8009 & .7043 \\
\hline & & Ages 61-70 & -.18044 & .21327 & .994 & -.9426 & .5818 \\
\hline & & Ages 71-80 & -.06109 & .27744 & 1.000 & -1.0526 & .9305 \\
\hline & \multirow{5}{*}{ Ages 31-40 } & Ages 21-30 & -.08915 & .21797 & 1.000 & -.8681 & .6898 \\
\hline & & Ages 41-50 & -.16154 & .09330 & .809 & -.4950 & .1719 \\
\hline & & Ages 51-60 & -.13744 & .08879 & .879 & -.4548 & .1799 \\
\hline & & Ages 61-70 & -.26960 & .09499 & .238 & -.6091 & .0699 \\
\hline & & Ages 71-80 & -.15024 & .20128 & .997 & -.8696 & .5691 \\
\hline & \multirow{5}{*}{ Ages 41-50 } & Ages 21-30 & .07239 & .21252 & 1.000 & -.6871 & .8319 \\
\hline & & Ages 31-40 & .16154 & .09330 & .809 & -.1719 & .4950 \\
\hline & & Ages 51-60 & .02411 & .07443 & 1.000 & -.2419 & .2901 \\
\hline & & Ages 61-70 & -.10805 & .08173 & .941 & -.4001 & .1840 \\
\hline & & Ages 71-80 & .01130 & .19537 & 1.000 & -.6869 & .7095 \\
\hline & \multirow{4}{*}{ Ages 51-60 } & Ages 21-30 & .04828 & .21058 & 1.000 & -.7043 & .8009 \\
\hline & & Ages 31-40 & .13744 & .08879 & .879 & -.1799 & .4548 \\
\hline & & Ages 41-50 & -.02411 & .07443 & 1.000 & -.2901 & .2419 \\
\hline & & Ages 61-70 & -.13216 & .07653 & .810 & -.4057 & .1414 \\
\hline
\end{tabular}




\begin{tabular}{|c|c|c|c|c|c|c|c|}
\hline & & Ages 71-80 & -.01280 & .19325 & 1.000 & -.7035 & 6779 \\
\hline & \multirow{5}{*}{ Ages 61-70 } & Ages 21-30 & .18044 & .21327 & .994 & -.5818 & .9426 \\
\hline & & Ages 31-40 & .26960 & .09499 & .238 & -.0699 & .6091 \\
\hline & & Ages 41-50 & .10805 & .08173 & .941 & -.1840 & .4001 \\
\hline & & Ages 51-60 & .13216 & .07653 & .810 & -.1414 & .4057 \\
\hline & & Ages 71-80 & .11936 & .19618 & .999 & -.5818 & .8205 \\
\hline & \multirow{5}{*}{ Ages 71-80 } & Ages 21-30 & .06109 & .27744 & 1.000 & -.9305 & 1.0526 \\
\hline & & Ages 31-40 & .15024 & .20128 & .997 & -.5691 & .8696 \\
\hline & & Ages $41-50$ & -.01130 & .19537 & 1.000 & -.7095 & .6869 \\
\hline & & Ages 51-60 & .01280 & .19325 & 1.000 & -.6779 & .7035 \\
\hline & & Ages 61-70 & -.11936 & .19618 & .999 & -.8205 & .5818 \\
\hline \multirow{14}{*}{$\begin{array}{l}\text { Knowledge } \\
\text { Attainment }\end{array}$} & \multirow{5}{*}{ Ages 21-30 } & Ages 31-40 & .00553 & .17514 & 1.000 & -.6204 & .6314 \\
\hline & & Ages 41-50 & -.01732 & .17076 & 1.000 & -.6276 & .5929 \\
\hline & & Ages 51-60 & .03239 & .16915 & 1.000 & -.5721 & .6369 \\
\hline & & Ages 61-70 & -.11306 & .17136 & .999 & -.7255 & .4994 \\
\hline & & Ages 71-80 & .13850 & .22292 & .999 & -.6582 & .9352 \\
\hline & \multirow{5}{*}{ Ages 31-40 } & Ages 21-30 & -.00553 & .17514 & 1.000 & -.6314 & .6204 \\
\hline & & Ages 41-50 & -.02285 & .07497 & 1.000 & -.2908 & .2451 \\
\hline & & Ages 51-60 & .02685 & .07122 & 1.000 & -.2277 & .2814 \\
\hline & & Ages 61-70 & -.11859 & .07632 & .877 & -.3914 & .1542 \\
\hline & & Ages 71-80 & .13297 & .16173 & .995 & -.4450 & .7109 \\
\hline & \multirow{4}{*}{ Ages $41-50$} & Ages 21-30 & .01732 & .17076 & 1.000 & -.5929 & .6276 \\
\hline & & Ages 31-40 & .02285 & .07497 & 1.000 & -.2451 & .2908 \\
\hline & & Ages 51-60 & .04970 & .05966 & .995 & -.1635 & .2629 \\
\hline & & Ages $61-70$ & -.09574 & .06567 & .907 & -.3304 & .1389 \\
\hline
\end{tabular}




\begin{tabular}{|c|c|c|c|c|c|c|c|}
\hline & & Ages 71-80 & .15582 & .15698 & .986 & -.4052 & .7168 \\
\hline & \multirow{5}{*}{ Ages 51-60 } & Ages 21-30 & -.03239 & .16915 & 1.000 & -.6369 & .5721 \\
\hline & & Ages $31-40$ & -.02685 & .07122 & 1.000 & -.2814 & .2277 \\
\hline & & Ages $41-50$ & -.04970 & .05966 & .995 & -.2629 & .1635 \\
\hline & & Ages $61-70$ & -.14544 & .06136 & .469 & -.3647 & .0738 \\
\hline & & Ages 71-80 & .10612 & .15522 & .998 & -.4486 & .6609 \\
\hline & \multirow{5}{*}{ Ages 61-70 } & Ages 21-30 & .11306 & .17136 & .999 & -.4994 & .7255 \\
\hline & & Ages 31-40 & .11859 & .07632 & .877 & -.1542 & .3914 \\
\hline & & Ages $41-50$ & .09574 & .06567 & .907 & -.1389 & .3304 \\
\hline & & Ages 51-60 & .14544 & .06136 & .469 & -.0738 & .3647 \\
\hline & & Ages 71-80 & .25156 & .15763 & .862 & -.3118 & .8149 \\
\hline & \multirow{5}{*}{ Ages 71-80 } & Ages 21-30 & -.13850 & .22292 & .999 & -.9352 & .6582 \\
\hline & & Ages 31-40 & -.13297 & .16173 & .995 & -.7109 & .4450 \\
\hline & & Ages $41-50$ & -.15582 & .15698 & .986 & -.7168 & .4052 \\
\hline & & Ages 51-60 & -.10612 & .15522 & .998 & -.6609 & .4486 \\
\hline & & Ages 61-70 & -.25156 & .15763 & .862 & -.8149 & .3118 \\
\hline \multirow{9}{*}{ Cabin Sales } & \multirow{5}{*}{ Ages 21-30 } & Ages 31-40 & -.35707 & .34681 & .983 & -1.5965 & .8824 \\
\hline & & Ages 41-50 & -.24666 & .33762 & .997 & -1.4533 & .9599 \\
\hline & & Ages 51-60 & -.17452 & .33444 & 1.000 & -1.3697 & 1.0207 \\
\hline & & Ages $61-70$ & -.30097 & .33881 & .992 & -1.5118 & .9099 \\
\hline & & Ages 71-80 & .03491 & .44075 & 1.000 & -1.5403 & 1.6101 \\
\hline & \multirow{4}{*}{ Ages 31-40 } & Ages 21-30 & .35707 & .34681 & .983 & -.8824 & 1.5965 \\
\hline & & Ages $41-50$ & .11041 & .14949 & .997 & -.4238 & .6447 \\
\hline & & Ages 51-60 & .18255 & .14215 & .948 & -.3255 & .6906 \\
\hline & & Ages $61-70$ & .05610 & .15215 & 1.000 & -.4877 & .5999 \\
\hline
\end{tabular}




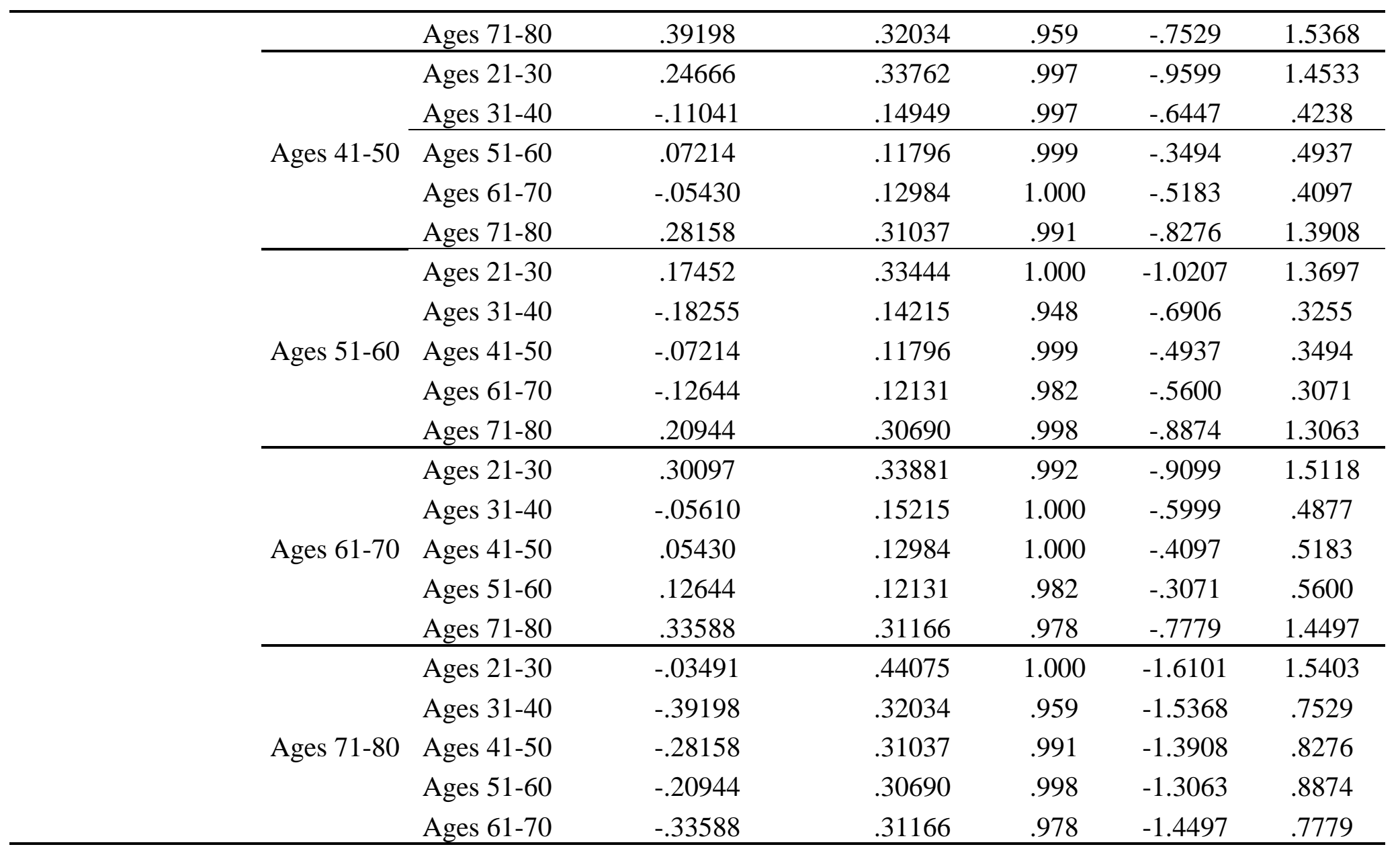


Table 4 provides the ANOVA information for the variable gender as it relates to each of the study variables (engagement, total cabin sales, and knowledge attainment). The reported $F$ ratio is 15.082 , having a probability of $p<.001$ for engagement. The reported $F$ ratio is 10.501 , having a probability of .001 for knowledge attainment. The reported $F$ ratio is 5.327, having a probability of .022 for total cabin sales. The ANOVA for gender and engagement $\left(p<.001, \eta^{2}=.05\right)$, showed significant results. The ANOVA result for gender and knowledge attainment $\left(p=.001, \eta^{2}=.03\right)$ and gender and total cabin sales $\left(p=.02 . \eta^{2}=.02\right)$, also showed statistically significant results. Post hoc analysis were not completed because there were only two groups. However, examination of the means of each variable showed that the female group means for engagement, knowledge attainment and cabin sales were greater than male group means in these segments (see Table 5).

Table 4

One-Way ANOVA Results - Gender

\begin{tabular}{llrrrrrr}
\hline & & $\begin{array}{c}\text { Sum of } \\
\text { Squares }\end{array}$ & $d f$ & $\begin{array}{c}\text { Mean } \\
\text { Square }\end{array}$ & $F$ & Sig. & $\eta^{2}$ \\
& Between Groups & 3.060 & 1 & 3.060 & 15.082 & $<.001$ & .05 \\
Engagement & Within Groups & 62.088 & 306 & .203 & & & \\
& Total & 65.148 & 307 & & & & \\
Knowledge & Between Groups & 1.386 & 1 & 1.386 & 10.501 & .001 & .03 \\
Attainment & Within Groups & 40.510 & 307 & .132 & & & \\
& Total & 41.896 & 308 & & & & \\
& Between Groups & 2.861 & 1 & 2.861 & 5.327 & .022 & .02 \\
Cabin Sales & Within Groups & 164.369 & 306 & .537 & & & \\
& Total & 167.230 & 307 & & & & \\
\hline
\end{tabular}


Table 5

Descriptive Statistics - Gender

\begin{tabular}{|c|c|c|c|c|c|c|c|c|c|}
\hline & & \multirow[t]{2}{*}{$N$} & \multirow[t]{2}{*}{ Mean } & \multirow[t]{2}{*}{ Std. Deviation } & \multirow[t]{2}{*}{ Std. Error } & \multicolumn{2}{|c|}{ 95\% CI for Mean } & \multirow[t]{2}{*}{ Minimum } & \multirow[t]{2}{*}{ Maximum } \\
\hline & & & & & & Lower Bound & Upper Bound & & \\
\hline \multirow{3}{*}{ Engagement } & Female & 272 & 3.9146 & .44768 & .02714 & 3.8611 & 3.9680 & 1.69 & 4.86 \\
\hline & Male & 36 & 3.6043 & .47131 & .07855 & 3.4449 & 3.7638 & 2.21 & 4.65 \\
\hline & Total & 308 & 3.8783 & .46066 & .02625 & 3.8267 & 3.9300 & 1.69 & 4.86 \\
\hline \multirow{3}{*}{$\begin{array}{l}\text { Knowledge } \\
\text { Attainment }\end{array}$} & Female & 273 & 4.1244 & .37167 & .02249 & 4.0801 & 4.1687 & 3.54 & 4.88 \\
\hline & Male & 36 & 3.9157 & .28962 & .04827 & 3.8177 & 4.0137 & 3.53 & 4.50 \\
\hline & Total & 309 & 4.1001 & .36882 & .02098 & 4.0588 & 4.1414 & 3.53 & 4.88 \\
\hline \multirow{3}{*}{ Cabin Sales } & Female & 272 & 2.0057 & .71156 & .04314 & 1.9207 & 2.0906 & .00 & 3.43 \\
\hline & Male & 36 & 1.7057 & .88082 & .14680 & 1.4076 & 2.0037 & .00 & 3.42 \\
\hline & Total & 308 & 1.9706 & .73805 & .04205 & 1.8879 & 2.0534 & .00 & 3.43 \\
\hline
\end{tabular}


Table 6 provides the ANOVA information for region as it relates to each of the study variables (engagement, total cabin sales, and knowledge attainment). The reported $F$ ratio is .359, having a probability of .838 for engagement. The reported $F$ ratio is 2.353, having a probability of .054 for total cabin sales. The reported $F$ ratio is .203 , having a probability of .936 for knowledge attainment. The ANOVA results for region and engagement $\left(p=.838, \eta^{2}=.01\right)$, region and knowledge attainment $\left(p=.936, \eta^{2}=.00\right)$ and region and total cabin sales $\left(p=.054, \eta^{2}=.03\right)$, showed non-significant results (See Table 6). Table 7 presents the descriptive results related to the group means of the region variable.

Table 6

One-Way ANOVA Results - Region

\begin{tabular}{llrrrrrr}
\hline & & \multicolumn{1}{c}{$\begin{array}{c}\text { Sum of } \\
\text { Squares }\end{array}$} & $d f$ & $\begin{array}{c}\text { Mean } \\
\text { Square }\end{array}$ & $F$ & Sig. & $\eta^{2}$ \\
\hline \multirow{3}{*}{ Engagement } & Between Groups & .307 & 4 & .077 & .359 & .838 & .01 \\
& Within Groups & 64.841 & 303 & .214 & & & \\
& Total & 65.148 & 307 & & & & \\
\hline \multirow{2}{*}{ Knowledge } & Between Groups & .112 & 4 & .028 & .203 & .936 & .00 \\
Attainment & Within Groups & 41.784 & 304 & .137 & & & \\
& Total & 41.896 & 308 & & & & \\
\hline \multirow{5}{*}{ Cabin Sales } & Between Groups & 5.038 & 4 & 1.260 & 2.353 & .054 & .03 \\
& Within Groups & 162.192 & 303 & .535 & & & \\
& Total & 167.230 & 307 & & & & \\
\hline
\end{tabular}


Table 7

Descriptive Statistics for One-Way ANOVA - Region

\begin{tabular}{|c|c|c|c|c|c|c|c|}
\hline \multirow{2}{*}{\multicolumn{2}{|c|}{ Dependent Variable (I) Region }} & \multirow[t]{2}{*}{ (J) Region } & \multirow[t]{2}{*}{ Mean Difference (I-J) } & \multirow[t]{2}{*}{ Std. Error } & \multirow[t]{2}{*}{ Sig. } & \multicolumn{2}{|c|}{ 95\% Confidence Interval } \\
\hline & & & & & & Lower Bound & Upper Bound \\
\hline \multirow{19}{*}{ Engagement } & \multirow{4}{*}{ Northeast } & Midwest & -.11712 & .10697 & .878 & -.4487 & .2144 \\
\hline & & South & -.07866 & .08927 & .941 & -.3553 & .1980 \\
\hline & & West & -.08143 & .11394 & .972 & -.4346 & .2717 \\
\hline & & Canada & -.03588 & .11756 & .999 & -.4002 & .3285 \\
\hline & \multirow{4}{*}{ Midwest } & Northeast & .11712 & .10697 & .878 & -.2144 & .4487 \\
\hline & & South & .03846 & .07770 & .993 & -.2024 & .2793 \\
\hline & & West & .03569 & .10512 & .998 & -.2901 & .3615 \\
\hline & & Canada & .08124 & .10904 & .968 & -.2567 & .4192 \\
\hline & \multirow{4}{*}{ South } & Northeast & .07866 & .08927 & .941 & -.1980 & .3553 \\
\hline & & Midwest & -.03846 & .07770 & .993 & -.2793 & .2024 \\
\hline & & West & -.00277 & .08704 & 1.000 & -.2725 & .2670 \\
\hline & & Canada & .04278 & .09173 & .994 & -.2415 & .3271 \\
\hline & \multirow{4}{*}{ West } & Northeast & .08143 & .11394 & .972 & -.2717 & .4346 \\
\hline & & Midwest & -.03569 & .10512 & .998 & -.3615 & .2901 \\
\hline & & South & .00277 & .08704 & 1.000 & -.2670 & .2725 \\
\hline & & Canada & .04555 & .11588 & .997 & -.3136 & .4047 \\
\hline & \multirow{3}{*}{ Canada } & Northeast & .03588 & .11756 & .999 & -.3285 & .4002 \\
\hline & & Midwest & -.08124 & 10904 & .968 & -.4192 & .2567 \\
\hline & & South & -.04278 & .09173 & .994 & -.3271 & .2415 \\
\hline
\end{tabular}




\begin{tabular}{|c|c|c|c|c|c|c|c|}
\hline & & West & -.04555 & .11588 & .997 & -.4047 & .3136 \\
\hline \multirow{20}{*}{$\begin{array}{l}\text { Knowledge } \\
\text { Attainment }\end{array}$} & \multirow{4}{*}{ Northeast } & Midwest & -.02883 & .08573 & .998 & -.2945 & .2369 \\
\hline & & South & .02582 & .07151 & .998 & -.1958 & .2474 \\
\hline & & West & .01087 & .09131 & 1.000 & -.2721 & .2939 \\
\hline & & Canada & .01004 & .09422 & 1.000 & -.2820 & .3020 \\
\hline & \multirow{4}{*}{ Midwest } & Northeast & .02883 & .08573 & .998 & -.2369 & .2945 \\
\hline & & South & .05464 & .06223 & .942 & -.1382 & .2475 \\
\hline & & West & .03970 & .08424 & .994 & -.2214 & .3008 \\
\hline & & Canada & .03887 & .08738 & .995 & -.2320 & .3097 \\
\hline & \multirow{4}{*}{ South } & Northeast & -.02582 & .07151 & .998 & -.2474 & .1958 \\
\hline & & Midwest & -.05464 & .06223 & .942 & -.2475 & .1382 \\
\hline & & West & -.01495 & .06972 & 1.000 & -.2310 & .2011 \\
\hline & & Canada & -.01577 & .07348 & 1.000 & -.2435 & .2120 \\
\hline & \multirow{4}{*}{ West } & Northeast & -.01087 & .09131 & 1.000 & -.2939 & .2721 \\
\hline & & Midwest & -.03970 & .08424 & .994 & -.3008 & .2214 \\
\hline & & South & .01495 & .06972 & 1.000 & -.2011 & .2310 \\
\hline & & Canada & -.00082 & .09287 & 1.000 & -.2886 & .2870 \\
\hline & \multirow{4}{*}{ Canada } & Northeast & -.01004 & .09422 & 1.000 & -.3020 & .2820 \\
\hline & & Midwest & -.03887 & .08738 & .995 & -.3097 & .2320 \\
\hline & & South & .01577 & .07348 & 1.000 & -.2120 & .2435 \\
\hline & & West & .00082 & .09287 & 1.000 & -.2870 & .2886 \\
\hline \multirow{4}{*}{ Cabin Sales } & \multirow{4}{*}{ Northeast } & Midwest & -.04600 & .16918 & .999 & -.5703 & .4784 \\
\hline & & South & -.27605 & .14118 & .432 & -.7136 & .1615 \\
\hline & & West & -.40293 & .18020 & .290 & -.9614 & .1556 \\
\hline & & Canada & -.35382 & .18593 & .461 & -.9301 & .2224 \\
\hline
\end{tabular}




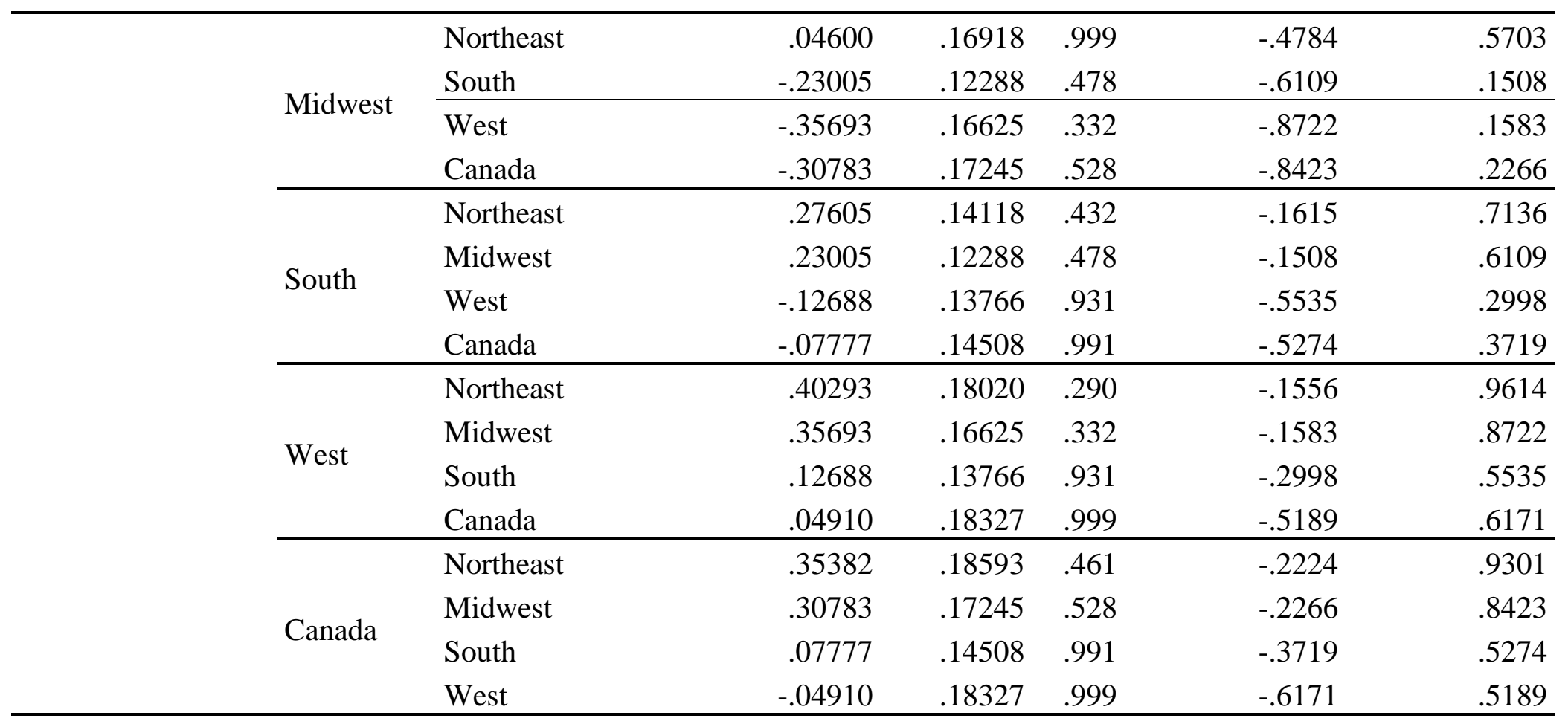


Table 8 presents the descriptive results related to the group means of the country variable. Table 9 provides the ANOVA information for country as it relates to each of the study variables (engagement, total cabin sales, and knowledge attainment). The reported $F$ ratio is .175 , having a probability of .676 for engagement. The reported $F$ ratio is .891 , having a probability of .346 for total cabin sales. The reported $F$ ratio is .061 , having a probability of .805 for knowledge attainment. The ANOVA results for country and engagement $\left(p=.676, \eta^{2}=.00\right)$, country and knowledge attainment $\left(p=.805, \eta^{2}=.00\right)$, and country and total cabin sales $\left(p=.346, \eta^{2}=.00\right)$, demonstrated non-significant results (see Table 9). No post hoc analyses were conducted, because none of the main effects were statistically significant.

Overall, the one-way ANOVA results investigating group mean differences by demographic variable suggested that were gender differences for engagement, knowledge attainment and total cabin sales, as well as a main effect for age (older workers had lower group means). Notwithstanding, as revealed by the $\eta^{2} s$, the effect sizes were all rather low, suggesting that although there were relatively small group mean differences in select cases, they were not theoretically relevant; still the researcher must remain mindful when interpreting the findings in light of these differences. 
Table 8

Descriptive Statistics for One-Way ANOVA - Country

\begin{tabular}{|c|c|c|c|c|c|c|c|c|c|}
\hline & & \multirow[t]{2}{*}{$N$} & \multirow[t]{2}{*}{ Mean } & \multirow[t]{2}{*}{ Std. Deviation } & \multirow[t]{2}{*}{ Std. Error } & \multicolumn{2}{|c|}{ 95\% Confidence Interval for Mean } & \multirow[t]{2}{*}{ Minimum } & \multirow[t]{2}{*}{ Maximum } \\
\hline & & & & & & Lower Bound & Upper Bound & & \\
\hline \multirow{3}{*}{ Engagement } & US & 279 & 3.8819 & .46267 & .02770 & 3.8273 & 3.9364 & 1.69 & 4.86 \\
\hline & CA & 29 & 3.8442 & .44728 & .08306 & 3.6740 & 4.0143 & 3.08 & 4.75 \\
\hline & Total & 308 & 3.8783 & .46066 & .02625 & 3.8267 & 3.9300 & 1.69 & 4.86 \\
\hline \multirow{3}{*}{$\begin{array}{l}\text { Knowledge } \\
\text { Attainment }\end{array}$} & US & 280 & 4.0984 & .36584 & .02186 & 4.0554 & 4.1415 & 3.54 & 4.88 \\
\hline & CA & 29 & 4.1163 & .40295 & .07483 & 3.9630 & 4.2695 & 3.53 & 4.88 \\
\hline & Total & 309 & 4.1001 & .36882 & .02098 & 4.0588 & 4.1414 & 3.53 & 4.88 \\
\hline \multirow{3}{*}{ Cabin Sales } & US & 279 & 1.9578 & .70293 & .04208 & 1.8750 & 2.0407 & .00 & 3.43 \\
\hline & CA & 29 & 2.0937 & 1.02437 & .19022 & 1.7041 & 2.4834 & .30 & 3.42 \\
\hline & Total & 308 & 1.9706 & .73805 & .04205 & 1.8879 & 2.0534 & .00 & 3.43 \\
\hline
\end{tabular}


Table 9

One-Way ANOVA Results - Country

\begin{tabular}{llrrrrrr}
\hline & & $\begin{array}{c}\text { Sum of } \\
\text { Squares }\end{array}$ & $d f$ & $\begin{array}{c}\text { Mean } \\
\text { Square }\end{array}$ & $F$ & Sig. & $\eta^{2}$ \\
\hline \multirow{3}{*}{ Engagement } & Between Groups & .037 & 1 & .037 & .175 & .676 & .00 \\
& Within Groups & 65.111 & 306 & .213 & & & \\
& Total & 65.148 & 307 & & & & \\
\hline \multirow{2}{*}{ Knowledge } & Between Groups & .008 & 1 & .008 & .061 & .805 & .00 \\
Attainment & Within Groups & 41.887 & 307 & .136 & & & \\
& Total & 41.896 & 308 & & & & \\
\hline \multirow{5}{*}{ Cabin Sales } & Between Groups & .485 & 1 & .485 & .891 & .346 & .00 \\
& Within Groups & 166.745 & 306 & .545 & & & \\
& Total & 167.230 & 307 & & & & \\
\hline
\end{tabular}

\section{Examination of Hypotheses}

The first hypothesized model examined the relationship between engagement (total number of minutes played in the game) and knowledge attainment (total number of fun points) of travel agents who play a serious game and was tested using linear regression analysis.

\section{Preliminary Correlational Analyses}

As shown below, a statistically significant relationship between engagement (total number of minutes playing the game) and knowledge attainment was found $(r=.57, p<$ .001). Further, there was a statistically significant relationship between engagement and total cruise sales (total cabins sold) $(r=.15, p<.01)$. The correlation between knowledge attainment (total fun points) and total cabin sales was also statistically significant $(r=$ $.17, p=.003)$, although it was not tested as a hypothesis in this research. What this finding may suggest is that there may be a modest link between engagement and total 
cruise sales that is mediated by knowledge attainment (see Table 10). The current study was not designed to evaluate whether knowledge attainment mediates the link between engagement and total cruise sales. However, this intriguing possibility points to the utility of future research that could investigate this potential mediation effect.

Table 10

Preliminary Correlational Analyses

\begin{tabular}{|c|c|c|c|c|}
\hline & & Engagement & Cabin Sales & $\begin{array}{l}\text { Knowledge } \\
\text { Attainment }\end{array}$ \\
\hline \multirow{3}{*}{ Engagement } & Pearson Correlation & 1 & .154 & $.568^{* *}$ \\
\hline & Sig. (1-tailed) & & .007 & $<.001$ \\
\hline & $N$ & 308 & 307 & 308 \\
\hline \multirow{3}{*}{ Cabin Sales } & Pearson Correlation & .154 & 1 & .17 \\
\hline & Sig. (1-tailed) & .007 & & .003 \\
\hline & $N$ & 307 & 308 & 308 \\
\hline \multirow{3}{*}{$\begin{array}{l}\text { Knowledge } \\
\text { Attainment }\end{array}$} & Pearson Correlation & $.568^{* *}$ & .17 & 1 \\
\hline & Sig. (1-tailed) & $<.001$ & .003 & \\
\hline & $N$ & 308 & 308 & 309 \\
\hline
\end{tabular}

\section{Linear Regression Analyses for $\mathbf{H}_{01}$}

Linear regression analyses were performed to test $\mathrm{H}_{01}$ that stated there is no relationship between travel agent engagement playing the Adventures Game and 
knowledge attainment. The sampling distribution for this test statistic is the $t$ distribution with $n-2$ degrees of freedom. For this hypothesis, there are $n-2=308-2=306$ degrees. The critical value for $\alpha=.05$ is $t_{c v}= \pm 1.96$. If the calculated value for the test statistic exceeds the critical value, the null hypothesis would be rejected.

Because the observed value of the test statistic $(t=14.454)$ exceeded the critical value $\left(t_{c v}= \pm 1.96\right)$, the null hypothesis $\mathrm{H}_{0}: \beta=0$ was rejected. The probability that we would observe a regression coefficient of .510 by merely chance if the null hypothesis is true was less than .001 because the significance was $<.001$.

The $R^{2}$ value is .406. This means that the variables of engagement and knowledge attainment share $40.6 \%$ of their variance in common. The adjusted $R^{2}$ which accounts for overestimation was .404 . The extent to which $R^{2}$ is overestimated depends primarily on the ratio of the number of predictor variables to the size of the sample. The ratio was 1:306, making the slippage between the reported $R^{2}(.406)$ and the adjusted $R^{2}(.404)$ very small, which is ideal (Tabachnick \& Fidell, 1996; see Tables 11-13).

The regression source identifies variation shared between the predictor (engagement) and the dependent variable (knowledge attainment - total fun points). The $F$-test is used to examine whether the amount of variance explained in the dependent variable is likely due to chance. Our reported $F$ value is 208.834 with a significance level of $<.001$. The amount of variance explained in knowledge attainment - total fun points using engagement as a predictor variable is statistically significant.

The unstandardized regression coefficient for the predictor variable, engagement, is .510. A positive coefficient indicates a positive relationship with the dependent variable. The $t$-test is used as a test of the regression coefficient $(\beta)$. Under a null hypothesis, the 
value of the regression coefficient is assumed to be zero. The $t$-test is performed to determine whether the obtained coefficient differs from zero. With a reported $t$-value of 14.451 and a significance level of $.000(p<.001)$, we can safely conclude that our regression coefficient does differ from zero. Therefore, the contribution of engagement to knowledge attainment - fun points is statistically significant. This result agrees with that of the overall $F$-test reported earlier. Both the $t$-test and the overall $F$ address the question of whether engagement can be used to predict knowledge attainment - total fun points. In this case, squaring the result from the $t$-test here will result in the $F$ ratio reported earlier. That is: $(14.451)^{2}=208.834$.

Table 13 summarizes the information pertaining to the regression coefficients and this information is important because the statistics can be used to make predictions about the dependent variable. All the unstandardized coefficients are positive, indicating that these predictors are positively related to the dependent variable, knowledge.

The statistic reported for collinearity is Variance Inflation Factor (VIF; see Table 13). This statistic is equal to 1 divided by the tolerance. Therefore, if the tolerance is 1 , the VIF would also be a 1. A lower tolerance is known to show an overlap amongst the predictors, which would yield a higher VIF. In the same light, as the VIF statistic increases, the greater an overlap will exist amongst the predictors. In addition, the variability of regression coefficients $(B)$ becomes inflated when the VIF is high. The reported VIF value for the predictor is 1 , which does not lead to any concerns. In plain language, because the tolerance statistic is greater than one and the VIF is less than 10 , there is no evidence of multicollinearity (Tabachnick \& Fidell, 1996). The first alternative hypothesis was thus supported. 
Table 11

Linear Regression Model Summary Statistics for $H_{01}$

\begin{tabular}{cccccccccc}
\hline Model & $R$ & $\begin{array}{c}R \\
\text { Square }\end{array}$ & $\begin{array}{l}\text { Adjusted } \\
\end{array}$ & & SEE Square & & \multicolumn{5}{c}{ Change Statistics } \\
\cline { 5 - 10 } & & & & $\begin{array}{c}R \text { Square } \\
\text { Change }\end{array}$ & $\begin{array}{c}F \\
\text { Change }\end{array}$ & $d f 1$ & $d f 2$ & $\begin{array}{c}\text { Sig. } F \\
\text { Change }\end{array}$ \\
& & & & & & & & & \\
\hline 1 & .637 & .406 & .404 & .28463 & .406 & 208.834 & 1 & 306 & $<.001$ \\
\hline
\end{tabular}

a. Predictor: (Constant), Engagement

b. Dependent Variable: Knowledge Attainment

Table 12

ANOVA Statistics for $\mathrm{H}_{01}$

\begin{tabular}{rlrrrrr}
\hline Model & & Sum of Squares & $d f$ & Mean Square & $F$ & Sig. \\
\hline & Regression & 16.918 & 1 & 16.918 & 208.834 & $<.001^{\mathrm{b}}$ \\
1 & Residual & 24.790 & 306 & .081 & & \\
& Total & 41.708 & 307 & & & \\
\hline
\end{tabular}

a. Dependent Variable: Knowledge Attainment

b. Predictor: (Constant), Engagement

The constant is known as the expected mean value of $\mathrm{Y}$ when $\mathrm{X}=0$ (Shannon \& Davenport, 2001). However, the purpose of the regression model is to understand the relationship between the predictor and the response. Therefore, the constant typically has no meaning when it comes to evaluating the regression model (Tabachnick \& Fidell, 1996). 
Table 13

Linear Regression Coefficient Statistics for $\mathrm{H}_{01}$

\begin{tabular}{|c|c|c|c|c|c|c|c|}
\hline \multirow[t]{2}{*}{ Model } & \multicolumn{2}{|c|}{$\begin{array}{l}\text { Unstandardized } \\
\text { Coefficients }\end{array}$} & \multirow{2}{*}{$\begin{array}{c}\text { Standardized } \\
\text { Coefficients }\end{array}$} & \multirow[t]{2}{*}{$t$} & \multirow[t]{2}{*}{ Sig. } & \multicolumn{2}{|c|}{$\begin{array}{c}\text { Collinearity } \\
\text { Statistics }\end{array}$} \\
\hline & $B$ & $\begin{array}{l}\text { Std. } \\
\text { Error }\end{array}$ & & & & Tolerance & VIF \\
\hline (Constant) & 2.125 & .138 & & 15.431 & $<.001$ & & \\
\hline Engagement & .510 & .035 & .637 & 14.451 & $<.001$ & 1.000 & 1.000 \\
\hline
\end{tabular}

a. Dependent Variable: Knowledge Attainment

\section{Linear Regression Analyses for $\mathbf{H}_{02}$}

Linear regression analyses were performed to test $\mathrm{H}_{02}$ that stated there is no relationship between travel agent engagement playing the Adventures Game and total cabin sales. The sampling distribution for this test statistic is the $t$ distribution with $n-2$ degrees of freedom. For this hypothesis, there are $n-2=308-2=306$ degrees. The critical value for $\alpha=.05$ are $t_{c v}= \pm 1.96$. If the calculated value for the test statistic exceeds the critical value, the null hypothesis would be rejected.

Because the observed value of the test statistic $(t=2.725)$ exceeded the critical value $\left(t_{c v}= \pm 1.96\right)$, the null hypothesis $\mathrm{H}_{0}: \beta=0$ was rejected. The probability that we would observe a regression coefficient of .247 by merely chance if the null hypothesis is true was less than .01, because the significance presented in Table 14 was .007 .

The $R^{2}$ value is .024 . This means that the variables of engagement and cabin sales share $2.4 \%$ of their variance in common. The adjusted $R^{2}$ which accounts for overestimation was .021. The extent to which $R^{2}$ is overestimated depends primarily on the ratio of the number of predictor variables to the size of the sample. The ratio was 
1:308, making the slippage between the reported $R^{2}(.024)$ and the adjusted $R^{2}(.021)$ very small, which is ideal (Tabachnick \& Fidell, 1996; see Tables 14-16).

The regression source identifies variation shared between the predictor (engagement) and the dependent variable (total cabin sales). The F-test is used to examine whether the amount of variance explained in the dependent variable is likely due to chance. Our reported $F$ value is 7.428 with a significance level of .007 . The amount of variance explained in total cabin sales using engagement as a predictor variable is statistically significant.

The unstandardized regression coefficient for our predictor variable, engagement, is .247. A positive coefficient indicates a positive relationship with the dependent variable. The $t$-test is used as a test of the regression coefficient $(\beta)$. Under a null hypothesis, the value of the regression coefficient is assumed to be zero. The $t$-test is performed to determine whether the obtained coefficient differs from zero. With a reported $t$ value of 2.725 and a significance level of .007 $(p<.001)$, we can safely conclude that our regression coefficient does differ from zero. Therefore, the contribution of engagement to total cabin sales is statistically significant. This result agrees with that of the overall Ftest reported earlier. Both the $t$-test and the overall $F$ address the question of whether engagement can be used to predict total cabin sales. In this case, squaring the result from the $t$-test here will result in the $F$ ratio reported earlier. That is: $(2.725)^{2}=7.428$.

Table 16 summarizes the information pertaining to the regression coefficients and this information is important because the statistics can be used to make predictions about the dependent variable. All the unstandardized coefficients are positive, indicating that the predictor that is positively related to the dependent variable, Cabin Sales. 
The statistic reported for collinearity is Variance Inflation Factor (VIF; see Table 16). This statistic is equal to 1 divided by the tolerance. Therefore, if the tolerance is 1 , the VIF would also be a 1. A lower tolerance is known to show an overlap among the predictor would yield a higher VIF. In the same light, as the VIF statistic increases, the greater an overlap will exist amongst the predictor. In addition, the variability of regression coefficients $(B)$ becomes inflated when the VIF is high. The reported VIF value for the predictor is 1 , which does not lead to any concerns. As with the first hypothesis, in plain language, because the tolerance statistic is greater than one and the VIF is less than 10, there is no evidence of multicollinearity (Tabachnick \& Fidell, 1996). Therefore, the second alternative hypothesis was supported.

Table 14

Linear Regression Model Statistics for $\mathrm{H}_{02}$

\begin{tabular}{|c|c|c|c|c|c|c|c|c|c|}
\hline \multirow[t]{2}{*}{ Model } & \multirow[t]{2}{*}{$R$} & \multirow{2}{*}{$\begin{array}{c}R \\
\text { Square }\end{array}$} & \multirow{2}{*}{$\begin{array}{l}\text { Adjusted } \\
R \text { Square }\end{array}$} & \multirow[t]{2}{*}{ SEE } & \multicolumn{5}{|c|}{ Change Statistics } \\
\hline & & & & & $\begin{array}{c}R \text { Square } \\
\text { Change }\end{array}$ & $\begin{array}{c}F \\
\text { Change }\end{array}$ & $d f 1$ & $d f 2$ & $\begin{array}{c}\text { Sig. F } \\
\text { Change }\end{array}$ \\
\hline 1 & .154 & .024 & .021 & .73161 & .024 & 7.428 & 1 & 305 & .007 \\
\hline
\end{tabular}

a. Predictors: (Constant), Engagement 
Table 15

ANOVA Statistics for $\mathrm{H}_{02}$

\begin{tabular}{llrrrrr}
\hline Model & & Sum of Squares & $d f$ & Mean Square & $F$ & Sig. \\
\hline \multirow{3}{*}{1} & Regression & 3.976 & 1 & 3.976 & 7.428 & .007 \\
\cline { 2 - 7 } & Residual & 163.252 & 305 & .535 & & \\
\cline { 2 - 7 } & Total & 167.228 & 306 & & & \\
\hline
\end{tabular}

a. Dependent Variable: Cabin Sales

b. Predictors: (Constant), Engagement

Table 16

Linear Regression Coefficient Statistics for $\mathrm{H}_{02}$

\begin{tabular}{|c|c|c|c|c|c|c|c|c|}
\hline \multirow[t]{2}{*}{ Model } & & \multicolumn{2}{|c|}{$\begin{array}{l}\text { Unstandardized } \\
\text { Coefficients }\end{array}$} & \multirow{2}{*}{$\begin{array}{c}\begin{array}{c}\text { Standardized } \\
\text { Coefficients }\end{array} \\
\text { Beta }\end{array}$} & \multirow[t]{2}{*}{$t$} & \multirow[t]{2}{*}{ Sig. } & \multicolumn{2}{|c|}{$\begin{array}{l}\text { Collinearity } \\
\text { Statistics }\end{array}$} \\
\hline & & $B$ & $\begin{array}{l}\text { Std. } \\
\text { Error }\end{array}$ & & & & Tolerance & VIF \\
\hline \multirow{2}{*}{1} & (Constant) & 1.011 & .355 & & 2.849 & .005 & & \\
\hline & Engagement & .247 & .091 & .154 & 2.725 & .007 & 1.000 & 1.000 \\
\hline
\end{tabular}

a. Dependent Variable: Cabin Sales

\section{Summary}

Results of this study support the hypotheses proposed in this study. The variable knowledge attainment as measured by fun points was significantly associated with travel agent engagement measured as minutes played. The variable total cabin sales was significantly associated with travel agent engagement. Chapter 5 discusses the results and implications of these findings for research, theory, and practice. 


\section{CHAPTER V \\ DISCUSSION}

Chapter 5 provides a brief summary of the study, followed by a discussion of the results. Implications for theory, research, and practice are offered followed by limitations of the study.

\section{Summary of the Study}

The following study examined the relationships among engagement, knowledge attainment and total cruise sales. The study assessed travel agents' training outcomes of knowledge attainment and engagement. Research has consistently shown that games have been used for a long period of time for training purposes and can be used to build the connection between learning and work (Juul, 2005).

Games were initially used for entertainment purposes and evolved into being used in academia and other fields (Juul, 2005). Kapp (2012) defined a game as, "a system in which players engage in an abstract challenge, defined by rules, interactivity, and feedback, that results in quantifiable outcome often eliciting an emotional reaction" (p. 7). Games are based within a virtual space where the players' actions are linked to their scores (in this case fun points) and limited by the rules outlined in the game. Within serious games and in the Adventures game a player interacts with the game content and with other players through avatars (Kapp, 2012). Each game also includes an abstract reality that gives players an illusion that they are in a realistic situation. In the same light, games have goals and learning objectives to challenge players and motivate them as they play. Each game has rules that provide structure and feedback to maintain the players' engagement (Kapp, 2012). 
There was clear evidence in the literature that through the use of gaming elements and theories that games were effective in promoting engagement and learning in players (Liyakasa, 2012; Sridharan, Hrishikesh, \& Raj, n.d.). The reality was that games tapped into the best qualities of learners, motivating them and tapping into their inner competitive side when a challenge was presented (Sridharan et al., n.d.). Gaming encouraged the players to be enthusiastic about gaining new knowledge through their interactions elements in the virtual environment.

Engagement is when the motivation of learners is piqued when positive experiences grab and sustain players' cognitive and motor competencies (Chaiklin, 2003). Engaged learners demonstrated involvement in educational activities through their behavior, such as excitement and playing for hours. When given the opportunity, they initiated the desire to play, tried their best and focus on the game to learn new skills and master new knowledge. Engagement decreased when the game was too easy (Chaiklin, 2003).

The purpose of the study was to examine the relationship between engagement, knowledge attainment, and cabin sales of travel agents who play a serious game. The research study focused on the following two research questions:

Research Question One. Is there a relationship between engagement (total number of minutes playing the game) of travel agents who play the Adventures Game (a serious game designed with three levels that allows the travel agent to attain fun points) and their knowledge attainment (total number of fun points earned)? 
Null Hypothesis $\left(H_{01}\right)$ for Research Question One. There is no relationship between engagement (as measured by number of minutes playing the game) of travel agents playing the Adventures Game and knowledge attainment (as measured by the total number of fun points).

Alternative Hypothesis One $\left(H_{1}\right)$ for Research Question One. There is a positive relationship between engagement (as measured by number of minutes playing the game) of travel agents playing the Adventures Game and knowledge attainment (as measured by the total number of fun points).

Research Question Two. Is there a relationship between engagement and playing serious games on the agent's total cruise sales?

Null Hypothesis Two $\left(\mathrm{H}_{02}\right)$ for Research Question Two. There is no relationship between engagement (as measured by total number of minutes playing the game) of a travel agent who plays the serious game and their total cruise sales.

Alternative Hypothesis Two $\left(\mathrm{H}_{2}\right)$ for Research Question Two. There is a positive relationship between engagement (as measured by total number of minutes playing the game) of a travel agent who plays the serious game and their total cruise sales.

\section{Discussion of the Results}

Guided by current literature and theory, the following section provides a brief discussion of the results of each hypothesis tested. A combination of linear regression analyses and correlations was performed to investigate the relationships among the variables of interest. Results of this study show that there were statistically significant relationships between the variables that were examined in the study. This section begins by exploring $H_{1}$, followed by $H_{2}$. 


\section{Hypothesis 1}

$H_{1}$ was tested using linear regression analysis to assess if there was a relationship between engagement and knowledge attainment of travel agents while playing a serious game. Results indicated that the prediction of engagement to knowledge attainment measured by fun points was found to be statistically significant. Findings show support for $H_{1}$ and thus, the null hypothesis was rejected.

As evident in the results, there was a strong, statistically significant positive relationship between engagement and knowledge attainment. A majority of the research that supports these findings focus on gamification and engagement as it relates to corporate entities. There was limited research on this topic within the tourism industry.

Research has shown that corporate training has faced many challenges due to the ever changing nature of our workforce. Employees were no longer just engaging in traditional forms of training. They were shifting from the classroom environment of instructor-led training to eLearning and even mobile or game-based learning. Over the last few years, there has been a trend in individuals finding training boring or unexciting and wanting a more engaging training opportunity. Businesses and corporate entities have begun to adopt gamification in the workforce to increase engagement, especially with the millennial generation, and influence employee behaviors. For example, the company examined in this study adopted game-based learning to increase engagement of travel agents as they participated in their training opportunities. The serious game was designed with game mechanics such as attainable challenges, a passport book with stamps to reward agents as they play and a leader board for recognition. 
The Adventures game was designed with clearly defined learning objectives with associated learning outcomes to be achieved. The purpose of the game was to increase engagement of travel agents in the training programs offered by the cruise line. Research has demonstrated that serious games, supported by learning objectives and game mechanics, have the ability to engage and motivate individuals or employees. In addition, the introduction of gaming attributes such as a story line, challenges, rewards and/or leader boards may make the learning experience more powerful and further engages the learner. This was especially evident in the serious game designed for travel agent learning. Travel agents were provided the opportunity to select the level of difficulty they wished to play, providing a challenging environment. In addition, the questions they were required to answer throughout the game were displayed in varying challenging levels to further engage the learners and assess their knowledge about the topics at hand. Travel agents answered the questions throughout the game on various topics related to cruising. To complete the level and attain sufficient fun points, travel agents were required to answer the questions correctly and in a timely fashion. The higher the fun points values, the more stamps they received as recognition for achieving various thresholds in the game.

Moreover, the findings presented here were further supported by research conducted by Ducheneaut and Moore (2004) on social learning in MMOG games and activity theory. According to Ducheneaut and Moore (2004), gamers develop social skills through interactivity and with other players or objects within the game. The development of the team lead to advancement of their social skills from group organization to instrumental coordination. Instrumental coordination allows the players to 
be focused on achieving the same goals and objectives in the game. The same behavior was prevalent in the Adventures Game. In Level One, players developed a team by selecting a group of baseball cards, this team was then used to answer prevalent questions that would assist them in attaining points to be able to advance in the home run derby. In Level Two, the player used the virtual groups to answer questions concerning the booking process and gain fun points to advance and complete the level. In Level Three, the player used the individuals at each station to answer questions about the cruise experience onboard. Their social skills were enhanced throughout the game through their interactions with each of the game elements. The interactivity and development of social skills encouraged and enhanced the engagement of the player.

In the same light, activity theory further supports the idea behind engagement through social interaction. Farangal (2012) noted that games which contain challenge, fantasy, realistic representations of the real world increase engagement and social activity. In the Adventures game, players were presented realistic representations of the cruising industry. In Level One, players were presented with the skills to sell a cruise and were able to learn about cruise rookies (a key group of potential sales that include first time cruisers). In Level Two, players were presented with a travel agency that had multiple tables and many different groups arriving to purchase a cruise. Players were required to answer questions pertaining to booking and selling a cruise. In Level Three, players were presented with a virtual image of the ship and had to answer questions about the onboard experiences of cruisers by moving cruisers to various parts of the ship. This serious game provided learners the opportunity to develop their investigative skills and enhance their life skills through play, for example, practicing selling a cruise and 
answering questions of potential clients in their travel agency. While being engaged in the game, the players also enhanced their knowledge by answering questions throughout each of the levels in the game.

Games contain traits such as clear goals, rules of engagement, and a feedback system to motivate gamers. Games provided the opportunity for engagement and involvement by the player. The serious game investigated as part of this research provided opportunities for engagement and social interaction amongst players. The players learned how to be fully engaged in the booking process and gained experience as a guest as they navigated the opportunities available onboard the ship. The players also gained knowledge of the booking process, an understanding of the clientele wishes and desires, as well as gained insight into the potential guest experience while onboard the ship. In turn, the players were engaged and also attained knowledge through playing the serious game.

In addition, Sitzmann (2011) also provided additional support for the results exhibited by $\mathrm{H}_{1}$ as it relates to the positive relationship between engagement and knowledge attainment from playing a serious game. Sitzmann (2011) indicated in his research that individuals who participated in game-based learning exhibited a 20\% higher confidence level than those who did not. These same individuals were able to master the skills on the job at a greater level than their counterparts. The individuals were able to master the skills from what they learned by playing the game and were able to exhibit the skills on the job. Sitzmann (2011) showed that game-based training can lead to skill mastery and knowledge attainment. 
By showing that a strong, positive relationship exists between learner (i.e., travel agent) engagement and knowledge attainment while playing a serious game, the results support the bulk of the prior research that engagement and knowledge attainment are linked positively. Further research can be completed to gain insight into the motivators and elements of engagement that are predictive of knowledge attainment while playing a serious game.

\section{Hypothesis 2}

The second hypothesis stated there was a significant relationship between travel agents' engagement playing the Adventures Game and the travel agents' total cabin sales. The findings show support for $H_{2}$ and thus, the null hypothesis was rejected.

A positive, statistically significant relationship between engagement (total number of minutes playing the game) and total cabin sales was found $(r=.154, p=.007)$. Travel agents played a range of 161 minutes to 80,000 minutes and sold a range of 1 to 2,600 cruise cabins. Though there is limited research on the relationship between engagement and total cabin sales, some connections can be made based upon current research on engagement.

Gaming has been shown to boost engagement in learners and impact production such as sales. Serious games have been shown to elicit and engage learners to motivate them towards a specific behavior or action. For example, Marriott has a hotel game that focuses on increasing brand awareness and as an educational tool to provide a behindthe-scenes look at what it takes to run a hotel (Lauby, 2016). The game simulates a hotel environment by having the player begin the game by managing a virtual hotel restaurant kitchen. The player performs each management skill, purchasing equipment and 
ingredients using a set budget, hiring and training employees, and serving guests in the restaurant. Each player attains points based upon the satisfaction of customers and profit achieved. The game provides a fun and engaging environment that fulfills the purpose of giving individuals a full picture of hotel operations (Lauby, 2016).

The same can be said of the Adventures game that was examined in this research. Travel agents need to be successful in their role of selling cruises, understand their customers, the policies and procedures of selling a cruise, and the cruise experience, to recommend the product that best fits the customer's needs. The Adventures game attempts to fulfill this role through the three levels of play. Players are engaged at the onset of playing through the selection of team baseball cards to navigate level one, the movement of individuals to answer booking-related questions in level two, or the movement of an individual to different parts of the ship to learn about the ship features.

Each level engages the player, while encouraging knowledge and skill attainment in a fun and interactive manner. Players may not realize they are learning, because they are fully engaged and immersed in the gaming environment. The knowledge attained through playing is associated with their ability to make a sale. In addition, the players' motivation dictates and provides direction to what they do to learn. Nowadays, with the presence of the digital generation, which is a large segment of our workforce, learners are not as motivated by the traditional forms of teaching. The digital generation tends to lose focus quickly, disengage rapidly and feel the need for instant gratification that is not available in traditional forms of teaching. On the other hand, they seem to be more engaged when game-based learning is incorporated into the learning environment. 
In addition, the presence of the attributes that impact flow as detailed by Csikszentmihalyi (1990) and the impact on motivation as outlined by Malone (1980). For example, Csikszentmihalyi (1990) states that feedback and challenge are important to elicit flow and provide a fun and engaging learning environment. In the Adventures game, players are provided in-game feedback such as scores and a passport with stamps that detail their successes throughout the game. In addition, the players are able to monitor their progress by looking at the meter bar located at the top of the screen in each level. Lastly, they are able to compare their successes with other travel agents by seeing where they rank on the leader board in relation to their peers. In the same light, the game offers levels of challenge providing an equilibrium between their level of skill and the level of challenge presented with. To keep the player engaged and motivated, the game needs to contain the right amount of challenge. If the game is too easy, the learner will lose focus and disengage. In the same light, if the game is too difficult the learners will get frustrated and will often times quit before successfully completing the game because they feel they are unable to be successful. This theory posits that ultimately, keeping the learner engaged and motivated will lead to success.

A key component to designing a serious game was providing game elements that increased the motivation of the learner (Malone, 1980). Malone (1980) emphasized the importance of incorporating game elements, such as reward structures and learning objectives and goals to elicit motivation. The first element that was included in the game was clear goals and learning objectives. Learning objectives gave the player direction in how to successfully complete the game and providing meaning to the player. The players need to feel that the outcome they are seeking is meaningful to them to maintain their 
motivation. In turn, the motivation of the learners directly impacts the engagement of the player and their desire to reach success. In the process (and sometimes without consciously realizing it), they learn how to operate within the game environment; actively think, experiment and learn how to safely accomplish their work; and practice their "lessons learned" to develop consistent and productive thought processes.

The serious game empowers the player with the tools to identify and target specific customers. In addition, the player learns the policy and procedures relating to booking cruises. For example, the player will learn about the amount for cruise deposits, final payment amounts and dates, rate codes and restrictions, the age guest must be to cruise in the Caribbean or Europe. These are just a few examples of questions that the player is asked through level two. Each of these are very important as they can make or break a sale. The travel agent must be knowledgeable about all of the policies and procedures, as well as terms and conditions for a rate code, to ensure the sale is successful and ultimately the individual sails on the cruise. Lastly, the player is able to learn about the last component of cruise sales, the cruising experience.

A common objective in cruising is ensuring that the customer is paired with the correct cruise line and the right product. When a customer is placed with the wrong cruise line and product, there is a great chance of failure and dissatisfaction. Knowing your customers and their respective needs is very important to making and retaining a sale. Travel agents are presented with the opportunity to sell many types of cruises ranging from Caribbean to Alaska and even Europe. Selecting the best option for your customer will be based upon knowing their needs, wants and desires and pairing it with the right product. Level 3 of the game allows the player to gain insight into the cruising 
experience on board each of the 24 cruise ships. The player learns about the various features onboard and in port at the various locations. The complete package presented in the game provides the player the skill set and knowledge to make a cruise sale.

As presented in the findings, there was a modest positive relationship between travel engagement and cruise sales. Additional analyses were completed and showed a relationship between knowledge attainment and total cabin sales; although this was not tested as a hypothesis in this research. What this finding may suggest is that there could be a modest link between engagement and total cabin sales that is mediated by knowledge attainment.

The mediation effect can be evaluated by evaluating the flow of the game and its role in encouraging engagement. It might also be beneficial for researchers to evaluate other components that might predict engagement that were not addressed in this study. For example, examining the motivation of the learner and the role it has had on increasing engagement, increasing knowledge attainment and ultimately the role it has on cruise sales.

Motivation can also be examined by delving into the three components' identified in Malone's (1980) theory of intrinsically motivated instruction, known as: challenge, fantasy and curiosity. Challenge can be evaluated through the goals and objectives identified in the game and conducting an outcome evaluation. Fantasy was described as a location that, "evokes mental images of things not present to the senses or within the actual experience of the person involved" (Knapp, 2012, p. 55). Furthermore, games that incorporated fantasies create more interesting and engaging environments for learning. Players tended to gravitate towards games which incorporate emotional impactful 
fantasies. This can be evaluated through interviewing the individuals in the game and gaining an understanding of influence it has on learning environment.

Another component that can be evaluated by the researcher is curiosity. To increase the curiosity of learners, the learners need to feel that they can be successful (Reio et al., 2006). In addition, the availability of intermittent feedback and hiding items throughout the game piques the curiosity of the player. In the design phase of a game, the structure of the game is considered to ensure various components and variables appear slowly and intermittently to encourage the player to think intuitively and engage their curiosity. When the structure and flow of the game is not considered, the learner becomes disengaged and the purpose of the game becomes ineffective for the player (Knapp, 2012). The researcher in the future can use the theory surrounding curiosity to gain further insight into the components that impact engagement and its overall impact on knowledge attainment and cabin sales.

The Adventures game contained components such as challenge, fantasy, learning objectives, and feedback that are potential predictors for travel agents' engagement. However, there is potential to delve further into the linkages that might exist between knowledge attainment and engagement and total cabin sales. It would be beneficial to determine the optimal level of balance between these variables to be able to predict cruise sales.

\section{Implications for Theory, Research, and Practice}

There was evidence that engagement provides a link to knowledge attainment when playing a serious game in the corporate or training world. Over the years, game- 
based training has been embraced by businesses and training professionals. The following sections examine implications of this study to game-based learning theory, research and practice.

\section{Implications for Theory}

The findings emphasized the ability of engagement and knowledge attainment in predicting travel agents' success in selling cruises. Prior to this study, there was limited or no research on the relationship between engagement, knowledge attainment and cruise sales. The findings presented in this study support current research on motivation, flow and play.

The findings presented here support the current research on motivation. Malone (1981) in his theory of intrinsic motivation noted that games are considered rewarding when a combination of the following attributes (fantasy, challenge, and curiosity) is incorporated into the game-based learning. Fantasy relates to manner in which the individual can see himself/herself through the images presented in the game in real life. Challenge relates to the level of difficulty and level of drive presented in the game to engage the learner. Curiosity is the desire of the player to continue playing the game to determine what occurs if they complete a particular action.

Each of these attributes is present in the Adventures game. Travel agents are able to visualize and fantasize the process for booking guest and the cruise experience onboard one of the fun ships. The player is transformed into an avatar that represents them virtually throughout the game. The spaces, whether the cruise ship in level three or the travel agency office in level two, provide a visual representation of the real-life environment. 
In addition, in each level the player is able to select the level of difficultly they wish to play. As they progress further into the game the level of difficulty increases and other levels of difficulty are made available for selection. Not only are the level of difficulty presented but the game questions displayed in each level are changed frequently to keep the learner engaged and "on their toe" in terms of learning the material.

Lastly, curiosity is incorporated into the game through the presence of multiple interactive actions. For example, the player in the game is able to select a baseball card which then randomly provides them a team and requires the player to answer questions about that team. In level two, the player selects various individuals to move to a desk to speak to the travel agent. Each individual is different and has varying questions or needs when booking a cruise. The player is required to answer the questions relating to that individual or set of individuals. Finally, in level three the player selects an avatar of an individual or group cruising and moves them to a location on the ship. Upon moving the avatar they are required to answer questions about the cruise experience. Each of these activities maintain the learners' curiosity level and keeps them engaged. In conclusion, the Adventures game supports the theory presented from Malone (1981) by demonstrating that attending to the attributes necessary to make an effective serious game for learning purposes.

The findings presented here also provide theoretical support for flow presented by Csikszentmihalyi (1990) and play as presented by Huizinga (1949). Csikszentmihalyi (1990) described flow as the direction and pattern of activity that are transmitted over time. In addition, flow is the balance between anxiety and boredom when the right level 
of challenge and skill are present in the game. The concept of flow involves the idea of play. Huizinga (1949) stated that play was considered as an optional activity that was completed outside of the ordinary life in an imaginary space. He noted that play was a crucial component to gaming. Serious games that integrated each of these components (play, goals, flow, feedback, etc.) elicit a comprehensive and engaging learning environment. The findings presented in the study focused primarily on engagement and knowledge attainment. However, there is thought that play and flow are key attributes to impact knowledge attainment and engagement of a learner. A player is engaged in a game when the optimal level of flow is present. This incorporates the level of challenge, feedback presented, and learning objectives identified within the game. In addition, a learner is engaged when they are enjoying and having fun doing the task at hand. A game that is playful provides a simulated environment that is conducive to long-term engagement.

Therefore, the theories presented by Csikszentmihalyi (1990) and Huizinga (1949) demonstrate the ability of a game to empower the learner to be engaged and use the skills attained to be successful at selling cruises. These are empowered thru the knowledge and skills attainment by playing in a fun environment and having optimal flow. The Adventures game empowers the player with the tools to identify and target specific customers. In addition, the player learns the policy and procedures relating to booking cruises. For example, the player will learn about the amount for cruise deposits, final payment amounts and dates, rate codes and restrictions, and the age guests must be to cruise in the Caribbean or Europe. These are just a few examples of questions that the player is asked through level two. Each of these are very important as they can make or 
break a sale. The travel agent must be knowledgeable about all of the policies and procedures, as well as terms and conditions for a rate code, to ensure the sale is successful and ultimately the individual sales on the cruise. Lastly, the player is able to learn about the last component of cruise sales, the cruising experience.

The findings also provide theoretical support for activity theory as presented by Kaptelinin et al. (1995). In activity theory, players consciously think about how to perform a task and the skills needed to be successful. The activity consisted of two types, internal and external. Internal activities focused on the mental processes used to complete the activity. External activities focused on activities that indicated an interaction with the environment or game space. Activity theory stated that internal and external activities were understood by evaluating their impact based upon each other. Internalization was the translation of external activities into internal activities. Internalization dealt with practicing a skill without performing the task on a real object, such as using a simulation to learn how to care for a patient.

These activity-theory attributes can be seen in the Adventures game. Players are placed in a virtual environment where they use their internal processes to interact with the virtual cruise environment. In each level, the player is required to process the actions needed to be completed and then in turn complete the skill or attain the knowledge necessary to successfully respond to the questions. The integration of the serious game into a LMS further enhances the activity experience. The player is able to, when stuck on a particular topic or do not understand a particular task, use the materials in the LMS to 
guide their path. The following study did not evaluate the impact of the trainings and materials on the LMS on increasing engagement or its role in activity, but is a potential area to look into for future research.

Even though the findings support the theories undergirding this study, it is important that further research be conducted to delve into possible additional attributes of engagement that might be associated with knowledge attainment. With the growing interest in game-based training and using various modalities to train individuals and the demographic changes of the cruising industry, it is essential to adapt training to meet the needs of learners and provide different modalities for learning. Game-based training in this field has the potential to make a large impact on learning and performance, if designed appropriately and with the right intentions.

\section{Implications for Practice}

The results of this research suggest a number of implications for serious game developers, game researchers, and industry practitioners. First, it is clear that engagement is one of the core benefits of a serious game. Learning outcomes were tied to engagement, indicating that the design of a serious game is not only contingent upon appropriate instructional design, but also tied to providing a fun and engaging learning environment. In other words, engagement of the learner is an attribute that should be addressed during the design phase of developing a serious game. This conclusion is in line with existing theoretical discussion of serious games, including the benefits of motivation and play (Rozendaal et al., 2010), maximizing engagement through striking balance between players' interest and challenge (Hoffman \& Nadelson, 2010) and the intrinsic and extrinsic motivation of learners while playing the game (Malone, 1981). 
Second, game-based training promotes learning. When a player progresses through a game there should be learning. For example, when the player is actively engaged with a game, their mind is focused on understanding the system they are working with and the experience of playing. When a company harnesses the full potential of a well-design game the end result is a workforce of highly motivated learners who avidly engage with and apply the knowledge attained. On the contrary, when the training administered is boring or unstimulating, the player is not being engaged and motivated. In other words, the player is not really learning meaningfully. Learning is a function of the player attaining skill and engaging their thought processes to be able to respond to a variety of scenarios under pressure. Learning is not simply memorizing the material and regurgitating the material back (Reio et al., 2006). Therefore, it is not having more time to learn in the classroom; instead, it is finding effective and interactive experiences that can motivate and actively engage the player throughout the learning process and thereby sustaining this behavior.

This is where game-based learning such as the Adventures Game plays a role. An effective game-based learning environment will give the player clear goals, a selection of activities, and experiences that influence their behaviors along the way. The gaming environment gives them the ability to take risk and experiment through the learning process while actively learning how to perform the task properly. The learner maintains high engagement while practicing theses skills and transfers the skills from a virtual environment to real-life experiences. This conclusion is in line with existing theoretical discussion of the effectiveness of game-based learning in virtual environments, the development of leadership skills through online games (Reeves, 
Malone, \& O'Driscoll, 2006), the development of high level and complex skills in gamebased training (Squire, 2005) and application of skills acquired in a simulated environment to the workplace as exhibited by Cold Stone Creamery's serious game (Jana, 2006).

In short, the use of game-based training has the potential to provide a major impact on the cruising and travel industry. Travel professionals are able to acquire new skills sets in a simulated environment and then apply them to their real-life experience. This has the potential to have a larger impact on their cruise sales if more cruise companies adapt this training approach.

\section{Implications for Research}

This study was a starting point for further research into the use of game-based training for training travel agents on selling cruises. The travel agent community is a unique segment of adult learners as they tend to be middle-aged and female. The study's findings showed there was a positive relationship between engagement and knowledge attainment with this specific sample. Further research into the variables studied here with various demographic makeups (e.g., more proportional representation by gender, age and ethnicity) could extend further what we know about the degree to which engagement and knowledge attainment are linked.

Research has shown that a skillfully designed serious game can enhance skill development and provide a fun environment that stimulates learning. There are important components necessary in a game to enhance learning, visualization, experimentation, and creativity of play (Betz, 1995). The first component visualization is essential to enhancing diversity and developing problem solving skills for learners (Hooper \& Rieber, 
1995). The second component experimentation encourages the player to react quickly and explore the environment visible on the screen. Lastly, the incorporation of play provides a fun environment that influences the players' ability to formulate ideas and compete with other users in the game (Leutner, 1993). Serious games have enhanced skill development of everyday needs, such as developing confidence, encouraging risk taking, and improved communication skills of the player. Though this study focused on engagement, the association of play with knowledge attainment is important to evaluate further as there is a potential link. This presents itself as a potential area for future research.

The researcher noticed while conducting the study that there was a larger number travel agents who were removed from the analysis due to having no fun points or playing the game for less than a minute. The researcher believes these travel agents launched the serious game to inquire about the game and then decided to close the game due to lack of interest or lack of desire to play at that time. This is a potential area for future research to determine why these travel agents chose to not play the serious game.

In addition, it would be beneficial to understand what was associated with the travel agents being engaged. Did they find the training to be challenging? Curiosityinducing? Was there an optimal level of flow? Did feedback matter? Future research could be designed to test these notions more fully. An experimental study, for example, could introduce an intervention designed to measure these variables pre- and post-test to begin to establish claims about causality. A phenomenological study could be used to follow-up this study to investigate how and why the experience of engagement was associated with greater knowledge attainment. What mattered most could be teased out 
through semi-structured interviews and think-aloud protocols that delve into the extrinsic and intrinsic motivation of players as they navigate the game. Lastly, it would be beneficial to further examine the weak, but positive link between engagement and total cabin sales. It may be that it is insufficient to rely too heavily on a games-based approach to foster learning and its application; using the games-based approach to augment overall training efforts in combination with a number of tried-and-true approaches (e.g., retreats; direct instruction) might be the best approach to promote optimal learning and performance in the form of cruise sales.

Another potential area for further research is to compare the generational differences that might exist when the game-based training is applied. In this study, there was a large range of ages amongst travel agents (30-80 years old). This lead to the researcher wondering if there might be generational differences in the use of a gamebased training model to apply knowledge attained. In addition, future research can also examine gender differences in the application of game-based training. In this instance, the demographics of players was mostly women, which is consistent with the demographics of travel agents. However, it would be beneficial to see if there are gender differences as it relates to knowledge attainment and the engagement of the learner.

\section{Limitations of the Study}

As is the case for all research, the present study has limitations. This study was designed to examine travel agents' engagement related to playing the Adventures game and its association with knowledge attainment and cabin sales. One of the limitations of this study was that the data collected was restricted to game participation data that was collected by a single large cruise line, rather than a random sample of cruise lines or 
cruise line agents. The study also had a relatively low participation rate, although consistent with prior research conducted in large workplaces; therefore, the results should not be generalized without much caution beyond this study. Another possible limitation has to do with the nonexperimental, correlational research design in that causality between the variables cannot be implied from such data. As mentioned in the section above, an experimental study might be designed to test for causal linkages between the variables.

Another limitation of the study is the technology used to house the serious game. The game was designed using a SCORM package that is integrated into the Learning Management System. Based upon the way the game was designed, the system is unable to record the number of complete and incomplete instances of play. In addition, it is unable to record instances where inactivity occurred or the number of instances where the game timed out due to inactivity. Therefore, this might cause a potential impact on the data received as it relates to duration of time played.

\section{Conclusions}

In summary, the following study focused on evaluating the relationship between engagement and knowledge attainment, as well as between engagement and cruise sales. The research findings demonstrated a link between each of these variables. The study showed that for a travel agent to be successful selling cruises, they need to acquire the knowledge, and be actively engaged. It is evident that learning is a process that occurs at each learner's pace. When the learning environment incorporates actions to engage and motivate the learner, the player is able to be successful in applying the knowledge attained. In addition, these findings open the door to further research to explore the 
potential mediation effect of engagement with knowledge attainment and cruise sales. In conclusion, these findings are the initial correlational stepping stones to gaining a full understanding of the role of game-based learning in the tourism industry. 


\section{REFERENCES}

Aarseth, E. (2001, February). Computer game studies, year one. The International Journal of Computer Game Research, 1. Retrieved from http://www.gamestudies.org/0101/editorial.html.

Aarseth, E. (2004). Genre trouble: Narrativism and the art of simulation. In N.WardripFruin \& P. Harrington (Eds.), First person: New media as story, performance, and game (pp. 45 - 47). Cambridge, MA: MIT Press.

Alberts, A., Gartska, J., \& Stein, F. (1999). Network centric warfare: Developing and leveraging information superiority (pp. 5-6). Washington, DC: C4ISR Cooperative Research Program, Department of Defense.

Banet, B. (1979). Computers and early learning: A new direction for High/Scope Foundation. Calculators/Computers, 3, 17.

Berlyne, D. E. (1949). Interest as a psychological concept. British Journal of Psychology, 39, 184-185.

Berlyne, D. E. (1950). Novelty and curiosity as determinants of exploratory behavior. British Journal of Psychology, 41, 50-68.

Berlyne, D. E. (1954). A theory of human curiosity. British Journal of Psychology, 45, 180-191.

Berlyne, D. E. (1960). Conflict, arousal, and curiosity. New York, NY: McGraw-Hill.

Berlyne, D. E. (1966, July). Curiosity and exploration. Science, 153, 25-33.

Betz, J. A. (1995). Computer games: Increase learning in an interactive multidisciplinary environment. Journal of Educational Technology Systems, 24, 195-205.

Bonk, C. J. \& Dennen, V. P. (2005). Massive multiplayer online gaming: a research framework for military training and education. Washington, D.C.: Advanced Distributed Learning Initiative, Office of the Under Secretary of Defense (Personnel \& Readiness). Retrieved from https://search.wikileaks.org/gifiles/attach/9/9907_Massive\%20Multiplayer\%20Ga mes\%20for\%20military\%20training.pdf

Boyle, E. A., Connolly, T. M., \& Hainey, T. (2011). The role of psychology in understanding the impact of computer games. Entertainment Computing, 2, 69 74. 
Cameron, B. \& Dwyer, F. (2005). The effect of online gaming, cognition and feedback type in facilitating delayed achievement of different learning objectives. Journal of Interactive Learning Research, 16, 243-258.

Campbell, D.T. and Stanley, J. (1963). Experimental and quasi-experimental designs for research. Boston, MA: Houghton Mifflin.

Chaiklin, S. (2003). The zone of proximal development in Vygotsky's analysis of learning and instruction. Retrieved from http://www.cles.mlc.edu.tw/ cerntcu/099curriculum/Edu_Psy/Chaiklin_2003.pdf

Cordova, D. I. (1993). The effects of personalization and choice on students' intrinsic motivation and learning. Ph.D. dissertation, Stanford University.

Csikszentmihalyi, M. (1975). Beyond boredom and anxiety. San Francisco, CA: JosseyBass.

Csikszentmihalyi, M. (1979). Intrinsic rewards and emergent motivation. In M. R. Lepper \& D. Greene (Eds.), The hidden costs of reward. Morristown, N.J.: Lawrence Erlbaum Associates.

Csikszentmihalyi, M. (1988). The flow experience And its significance for human psychology. In M. Csikszentmihalyi \& I. S. Csikszentmihalyi (Eds.), Optimal experience: Psychological studies of flow in consciousness (pp. 15-35). Cambridge, United Kingdom: Cambridge University Press.

Csikszentmihalyi, M. (1990). Flow: The psychology of optimal experience. New York, NY: Harper \& Row.

Csikszentmihalyi, M. (1993). The evolving self: A psychology for the third millennium. New York, NY: Harper Collins.

de Freitas, S. (2006). Learning in immersive worlds: A review of game-based learning. Prepared for the JISC e-learning programme. Retrieved from https://core.ac.uk/download/files/169/30618159.pdf

Deater-Deckard, K., Chang, M., \& Evans, M. E. (2013). Engagement states and learning from educational games. In F. C. Blumberg \& S. M. Fisch (Eds.), Digital games: A context for cognitive development. New Directions for Child and Adolescent Development, 139, 21-30.

Denis, G., \& Jouvelot, P. (2005, June). Motivation-driven educational game design: Applying best practices to music education. Paper presented at the 2005 ACM SIGCHI International Conference on Advances in Computer Entertainment Technology, Valencia, Spain. 
Dessouky, M. M., Verma, S., Bailey, D. E., \& Rickel, J. (2001). A methodology for developing a web-based factory simulator for manufacturing education. IIE Transactions, 33, 167-180.

Deterding, S., Dixon, D., Khaled, R. \& Nacke, L. (2011). From Game Design Elements to Gamefulness: Defining "Gamification" in MindTrek '11, Tampere, Finland.

Dorling, A., \& McCaffery, F. (2012). The gamification of SPICE. In Software process improvement and capability determination (pp. 295-301). Berlin: Springer.

Douglas, Y. \& Hargadon, A. (2000). The pleasure principle: Immersion, engagement, flow. Hyperterxt 2000. Retrieved from ftp://ftp.cse.buffalo.edu/users/azhang/disc/disc01/cd1/out/papers/hypertext/p153douglas.pdf

Ducheneaut, N. \& Moore, R. J. (2004). The social side of gaming: A study of interaction patterns in a massively multiplayer online game. $C S C W^{\prime} 04$. Retrieved from http://pdf.textfil.es/academics/cscw2004-swg.pdf

Entertainment Software Association (2012). 2012 Annual Report. Retrieved from http://www.theesa.com/wpcontent/uploads/2014/10/ESA_2012_Annual_Report.pdf

Entertainment Software Association (2014). 2014 Annual Report. Retrieved from http://www.theesa.com/wp-content/uploads/2015/03/ESA-2014-AnnualReport.pdf

Ericsson, K. A., Krampe, R. T., and Tesch-Romer, C. (1993). The role of deliberate practice in the acquisition of expert performance. Psychological Review, 100(3), 363-406. Retrieved from https:/graphics8.nytimes.com/images/blogs/freakonomics/pdf/DeliberatePractice \%28PsychologicalReview\%29.pdf

Eskelinen, M. (2001, July). The gaming situation. Game Studies, 1. Retrieved from: http://www.gamestudies.org/0101/eskelinen/

Eskelinen, M. (2004). Toward computer game studies. In N. Wardrip-Fruin \& P. Harrington (Eds.), First person: New media as story, performance, and game (pp. 36-49). Cambridge, MA: MIT Press.

Facer, K., Joiner, R., Stanton, D., Reid, J., Hull, R., \& Kirk, D. (2004). Savannah: Mobile gaming and learning? Journal of Computer Assisted Learning, 20, 399-409. 
Farangal, S. (2012). Reality is broken to be rebuilt: how a game's mindset can show science educators new ways of contribution to science and world? Cultural Studies of Science Education, 7, 1037-1044

Federation of American Scientists. (2006). Summit on Educational Games. Retrieved from: http://fas.org/programs/ltp/policy_and_publications/summit/.

Forster, W. (2005). The encyclopedia of game machines - consoles, handheld \& home computers 1972-2005. Hagen Schmid, Berlin: Magdalena Gniatczynska.

Garris, R., Ahlers, R., \& Driskell, J. E. (2002). Games, motivation, and learning: a research and practice model. Simulation \& Gaming, 33, 441-467.

Gay, L. R. \& Airasian, P. (2000). Educational research: Competencies for analysis and application (6 ${ }^{\text {th }}$ Edition). Upper Saddle River, New Jersey: Merrill Publishing Company.

Gee, J. P. (2003). What video games have to teach us about learning and literacy. New York, NY: Palgrave Macmillan.

GoCCL (2013). History of the cruise line. Retrieved June 3, 2013, from https://www.goccl.com.

Gredler, M. E. (1996). Educational games and simulations: A technology in search of a (research) paradigm. In D. H. Jonassen (Ed.), Handbook of research for educational communications and technology (pp. 521-540). New York: Simon \& Schuster Macmillan.

Halttunen, K., \& Sormunen, E. (2000). Learning information retrieval through an educational game. Is gaming sufficient for learning? Education for Information, 18, 289.

Harmon, A. (2003, April 3). More than just a game, but how close to reality? As a war tests its value, video training draws praise and concern in the military. The New York Times. Retrieved from http://query.nytimes.com/gst/fullpage.html?res=9B0CE3D81F39F930A35757C0 A9659C8B63

Harris, R. (1990). Language, Saussure and Wittgenstein: How to play games with words. London, England: Psychology Press.

Herz, J., \& Macedonia, M. (2002) Computer games and the military: Two views. Defence Horizons, Vol. 11. Washington, DC: Centre for Technology and National Security Policy, National Defense University. 
Hinkle, D. E., Wiersma, W, \& Jurs, S. G. (2003). Applied statistics for the behavioral sciences ( $5^{\text {th }}$ Edition). Boston, MA: Houghton Mifflin Company.

Hoffman, B., \& Nadelson, L. (2010). Motivational engagement and video gaming: A mixed methods study. Educational Technology Research and Development, 58, 245-270.

Hooper, S., \& Rieber, L. P. (1995). Teaching with technology. In A. C. Ornstein (Ed.), Teaching: Theory into practice. Needham Heights, MA: Allyn and Bacon.

Huizinga, J. (1949). Homo ludens: A study of the play element in culture. London, Boston: Routledge Kegan Paul.

Jana R. (2006, March 27). On-the-job video gaming. Business Week, 3977, 43.

Ju, E., \& Wagner, C. (1997). Personal computer adventure games: Their structure, principles, and applicability for training. The DATA BASE for Advances in Information Systems, 28, 78-92.

Juul, J. (2001, July). Games telling stories? A brief note on games and narratives. Game Studies, 1. Retrieved from http://www.gamestudies.org/0101/juul-gts/

Juul, J. (2005). Half-real: Video games between real rules and fictional worlds, Cambridge, MA: The MIT Press.

Jonassen, D. H. (1988). Instructional designs for microcomputer courseware. Hillsdale, NJ: Lawrence Erlbaum.

Kaptelinin, V., Kuutti, K., and Bannon, L. (1995). Activity theory: Basic concepts and applications. In Blumenthal et al. (Eds.) Human-computer interaction. Volume 1015 of the series Lecture Notes in Computer Science. Springer. 189-201.

Keller, J. M. (1979). Motivation and instructional design: A theoretical perspective. Journal of Instructional Development, 2, 26-34.

Kiili, K. (2005a). Digital game-based learning: Towards an experiential gaming model. Internet and Higher Education, 8, 13-24.

Kiili, K. (2005b). Content creation challenges and flow experience in educational games: The IT-Emperor case. Internet \& Higher Education, 8, 183-198.

Kiili, K. (2007). Foundation for problem-based gaming. British Journal of Educational Technology, 38, 394-404. 
Kirriemuir, J (2002). A survey of the use of computer And video games in classrooms. Internal report for Becta (British Educational Communications and Technology Agency). www.becta.org.uk

Klawe, M. M. (1994). The educational potential of electronic games and the E-GEMS project. In T. Ottman, \& I. Tomek (Eds.), Proceedings of ED-MEDIA 94: World Conference on Educational Multimedia and Hypermedia (pp. 25-30). Charlottesville, VA: AACE.

Knapp, K. M. (2012). The gamification of learning and instruction: Game-based methods and strategies for training and education. San Francisco, CA: Pfeiffer.

Knight, W. (2003). Million-user online game previewed. New.scientist.com. Retrieved from: http://www.newscientist.com

Kohl, J. (2013). Applying Gamification to Software Testing. Retrieved from: http://www.kohl.ca/2013/APPLYING-GAMIFICATION-IN-SOFTWARETESTING/.

Kolbert, E. (2001, May 28). Pimps and dragons. The New Yorker.

Koster, R. (2005). A theory of fun for game design. Scottsdale, AZ: Paraglyph Press.

Kuzma, T.W. \& Bohnenblust, S.E. (2001). Basic statistics for the health sciences, 4th edition. Mountain View, CA: Mayfield Publishing Company.

Lane, J.L., Slavin, S., \& Ziv, A. (2001). Simulation in medical education: A Review. Simulation \& Gaming, 32, 297.

Lauby, S. (2016). Using games can help drive employee engagement. Retrieved from https://www.americanexpress.com/us/small-business/openforum/articles/usinggames-can-help-drive-employee-engagement/

Lepper, M. R. \& Cordova, D. I. (1992). A desire to be taught: Instructional consequences of intrinsic motivation. Motivation and Emotion, 16, 187-208.

Lesgold, A. M. (1982). Computer games for the teaching of reading. Behavior Research Methods, 14, 224-226.

Leutner, D. (1993). Guided discovery learning with computer-based simulation games: effects of adaptive and non-adaptive instructional support, Learning and Instruction, 3, 113-32. 
Magnussen, R. \& Misfeldt, M. (2004). Player transformation of educational multiplayer games. In paper presented at the other players conference, Denmark. Copenhagen.

Malone, T. W. (1980). What makes things fun to learn? A study of intrinsically motivating computer games. Ph.D. dissertation, Stanford University.

Malone, T. (1981). Toward a theory of intrinsically motivating instruction. Cognitive Science, 4, 333-369.

Malone, T. \& Lepper, M. (1987). Making learning fun: A taxonomy of intrinsic motivations of learning. In R. E. Snow\& M. J. Farr (Eds.), Aptitude, learning, and instruction: Vol. 3. Conative and affective process analyses (pp. 223-253). Hillsdale, NJ: Lawrence Erlbaum.

Marinho, N. (2012, June 23). Corporations look to serious games for organizational development. Retrieved from http://e27.co/corporations-look-to-serious-gamesfor-organisational-learning-and-development/.

McFarlane, A., Sparrowhawk, A. \& Heald, Y. (2002). Report on the educational use of games. Department for Education and Skills. Retrieved from http://nexus.hsbremerhaven.de/Library.nsf/bf25ab0f47ba5dd785256499006b15a4/be501a19594 142bac125736e00588a6d/\$FILE/Games_in_Educa_teem_gamesined_full.pdf

McGonigal, J. (2011). Reality Is broken: Why games make us better and how they can change the world. New York, New York: Penguin Press.

McLuhan, M. (1994). Understanding media: The extensions of man. Cambridge, MA: MIT Press.

Michael, D. \& Chen, S. (2006) Serious games: Games that educate, train, and inform. Boston, MA: Thomson Course Technology.

Millians, D. (1999). Thirty years and more of simulations and games. Simulation \& Gaming. 30, 352-355.

Mitchell, A., \& Savill-Smith, C. (2004). The use of computer and video games for learning: A review of the literature. London, UK: Learning and Skills Development Agency (LSDA), Ultralab, m-learning project. Retrieved from http://www.itari.in/categories/futuretrendsineducation/ComputerGamesinLearning .pdf.

Mumtaz, S. (2001). Children's enjoyment and perception of computer use in the home and the school. Computers \& Education, 36, 347-362. 
Murray, J. H. (1997). Hamlet On the holodeck: The future of narrative in cyberspace. New York: Free Press.

Murray, J. H. (2006). Take from toward a cultural theory of gaming: Digital games and the co-evolution of media, mind, and culture. Popular Communication, 4, 185-202.

Myers, D. (1990). Computer games genres. Play \& Culture, 3, 286-301.

Oblinger, D. (2004). The next generation of educational engagement. Journal of interactive media in education, 2004(1). Retrieved from http://jime.ubiquitypress.com/articles/10.5334/2004-8-oblinger/

Oliver, M. \& Pelletier, C. (2004) Activity theory and learning from digital games: implications for game design. Paper presented at Digital Generations: Children, young people and new media. London.

Oracle (2012). Using social gaming to drive engagement: Insights and best practices for brand managers. Retrieved from http://www.oracle.com/us/products/socialgaming-for-engagement-1841595.pdf

Papastergiou, M. (2009). Digital game-based learning in high school computer science education: Impact on educational effectiveness and student motivation.

Computers \& Education. 52, 1-12.

Papastergiou, M., \& Solomonidou, C. (2005). Gender issues in Internet access and favourite Internet activities among Greek high school pupils inside and outside school. Computers \& Education, 44, 377-393.

Paraskeva, F., Mysirlaki, S., and Papagianni, A. (2010). Multiplayer online games as educational tools: Facing new challenges in learning. Computers \& Education, 54, 498-505.

Passport (2013). In Taleo learn. Retrieved May 28, 2013, from http://carnival.learn.com.

Perla, P. (1990). The art of wargaming. Annapolis, Maryland: Naval Institute Press.

Posner, M. I. (1978). Chronometric explorations of mind. Englewood Heights, NJ: Erlbaum.

Posner, M. I. \& Rothbart, M. K. (2007). Research on attention networks as a model for the integration of psychological science. Annual Review of Psychology, 58. 123. 
Prensky (2001). Digital game-based learning.The Digital game-based learning revolution. New York: McGraw-Hill.

Prensky, M. (2006). In presentation at the 2006 Educause Learning Initiative (eli) annual meeting, January 30, 2006. San Diego, California.

Quinn, C. N. (1994). Designing educational computer games. In K. Beattle, C. McNaught, S. Wills (Eds). Interactive multimedia in university education: Designing for change in teaching and learning (pp. 45-57). Elsevier Science BV, Amsterdam.

Randel, J. M., Morris, B. A., Douglas Wetzel, C., \& Whitehill, B.V. (1992). The effectiveness of games for educational purposes: A review of the research. Simulation and Gaming, 25, 261-276.

Reeves, B., Malone, T. \& O'Driscoll, T. (2006). Leadership’s online labs. Retrieved from https://hbr.org/2008/05/leaderships-online-labs/ar/1

Reio, T. G., Jr., \& Crim., S. J. (2013). Social presence and student satisfaction as predictors of online enrollment intent. The American Journal of Distance Education, 27, 122-133.

Reio, Jr., T. G., Petrosko, J. M., Wiswell, A. K., and Thongsukmag, J. (2006). The measurement and conceptualization of curiosity. The Journal of Genetic Psychology, 167, 117-135.

Reio, Jr., T. G., \& Wiswell, A. (2000). Field investigation of the relationship among adult curiosity, workplace learning, and job performance. Human Resource Development Quarterly, 11, 5-30.

Ricci, K. E., Salas, E., \& Cannon-Bowers, J. A. (2002). Do computer-based games facilitate knowledge acquisition and retention? Military Psychology, 8, 295307.

Rice, K. (2013). Aging travel agent workforce threatens industry, Travel Weekly. Retrieved from: http://www.travelweekly.com/Travel-News/Travel-AgentIssues/Aging-travel-agent-workforce-threatens-the-industry/

Rickard, W., \& Oblinger, D. (2004). Higher education leaders symposium: Unlocking the potential of gaming technology. Redmond, WA: Microsoft Corporation. Retrieved from http://net.educause.edu/ir/library/pdf/NLI0417.pdf.

Rollings, A., \& Adams, E. (2003). On game design. Indianapolis, IN: New Riders. 
Rozendaal, M. C., Braat, B. A., \& Wensveen, S. A. (2010). Exploring sociality and engagement in play through game-control distribution. Ai \& Society, 25, 193201.

Salen, K., \& Zimmerman, E. (2003). Rules Of play: Game design fundamentals. Cambridge, MA: MIT Press.

Sawyer, B. (2002). Serious games: Improving policy through game-based learning and simulation. Foresight and governance project. Washington, DC.: Woodrow Wilson International Center for Scholars, Publication 2002-1. Retrieved from https://www.wilsoncenter.org/publication/executive-summary-seriousgames-improving-public-policy-through-game-based-learning-and

Scalese, R. J., Obeso, V. T., \& Issenberg, S. B. (2007). Simulation technology for skills training and competency assessment in medical education. Journal of General Internal Medicine, 23(Suppl I), 46-49.

Sealund, B. (2012). AGREEMENT SA689-1111. Sealund Innovative Training Solutions.

Sellers, J. (2001). Arcade fever: The fan's guide to the golden age of video games. Philadelphia, PA: Running Press.

Shannon (1975). Proceedings of the 1998 Winter Simulation Conference. D. J. Medeiros, E. F. Watson, J. S. Carson, \&M. S. Manivannan, eds. Introduction to the art and science of simulation.

Shute, V.J., Ventura, M. Bauer, M. \& Zapata-Rivera, D. (2009). Chapter 18: Melding the power of serious games and embedded assessment games and embedded assessment to monitor and foster learning. Retrieved from http://myweb.fsu.edu/vshute/pdf/shute\%202009_c.pdf.

Sitzmann, T. (2011). A meta-analytic examination of the instructional effectiveness of computer-based simulation games. Personnel Psychology, 64, 489-528.

Siwek, S. E. (2014). Video games in the 21st Century: The 2014 report. Retrieved from http://www.theesa.com/wpcontent/uploads/2014/11/VideoGames21stCentury_2014.pdf

Skinner, E. A., \& Belmont, M. J. (1993). Motivation in the classroom: Reciprocal effects of teacher behavior and student engagement across the school year. Journal of Educational Psychology, 85, 571-581.

Slagle, M. (2006). Poll: 4 in 10 Americans play video games [Electronic Version]. Washington Post. 
Snider, M. (2003). Wired to another world. Macleans. Toronto. 116 (9), 23-25.

Springer, K. (2010). Educational research: A contextual approach. John Wiley and Sons, Inc.

Squire, K. (2005). Changing the game: What happens when video games enter the classroom?. Innovate, 1(6). Retrieved from http://nsuworks.nova.edu/cgi/viewcontent.cgi?article=1168\&context=innovate

Sridharan, M., Hrishikesh, A., \& Raj, L. S. (n.d.). An academic analysis of gamification. Retrieved from http://www.scribd.com/doc/144954754/AnAcademic-Analysis-of-Gamification.

Steinkuehler, C. A. (2004). Learning in massively multiplayer online games. Proceedings of the 6th International Conference on Learning Sciences, 521 - 528.

Subrahmanyam, K. \& Greenfield, P. M. (1994). Effects of video game practice on spatial skills in girls and boys. Journal of Applied Developmental Psychology, 15, 13-32.

Sweetser, P., \& Wyeth, P. (2005). GameFlow: A model for evaluating player enjoyment in games. Computers in Entertainment (CIE), 3, 3-33.

Swan, C. (2012, May-June). Gamification: A new way to shape behavior. Communication World.

Tabachnick, B. G., \& Fidell, L. S. (1996). Using multivariate statistics. New York, NY: HarperCollins College Publishers.

Tomasello, M. (2000). The cultural origins of human cognition. Cambridge, MA: Harvard University Press.

Trochim, W. M. K. (2005). Research methods: The concise knowledge base. Cincinnati, OH: Atomic Dog Publishing. Retrieved from http://www.socialresearchmethods.net/kb/

Trybus, J. (2014). Game-based learning: What it is, why it works, and where it's going. New Media Institute. Retrieved from http://www.newmedia.org/game-based-learning-what-it-is-why-it-works-and-where-its-going.html.

Turkle, S. (1995). Life on the screen: Identity in the age of the Internet. New York, New York: Touchstone.

U.S. Department of Labor (2014). Bureau of Labor Statistics: Occupation Outlook Handbook. Retrieved from http://www.bls.gov/ooh/sales/travel-agents.htm. 
VanSickle, R. (1978). Designing simulation games to teach decision-making skills. Simulation \& Games, 9(4). 413-428.

Vockell, E. (2004). Educational psychology: A practical approach. Purdue University Calumet, on-line book.

Vogel, J. J., Vogel, D. S., Cannon-Bowers, J., Bowers, C. A., Muse, K., \& Wright, M. (2006). Computer gaming and interactive simulations for learning: A metaanalysis. Journal of Educational Computing Research, 34, 229-243.

Waal, B. D. (1995). Motivations for video game play: A study of social, cultural and physiological factors. Master's thesis, School of Communication, Simon Fraser University.

Wardrip-Fruin, N., \& Harrigan, P. (Eds.). (2004). First person: New media as story, performance, and game. Cambridge, MA: MIT Press.

Winchester, J.M. (2013). Case study: Serious games - battling the villians of fun. Elearning! Magazine. October/November 2013. 39-40.

Wittgenstein, L. (1958). Philosophical investigations (3rd ed.). (G. E. M. Anscombe, Trans.). New York: MacMillan. (Original work published 1953)

Zyda, M. (2005). From visual simulation to virtual reality to games. IEEE Computer Society. 


\section{APPENDIX}

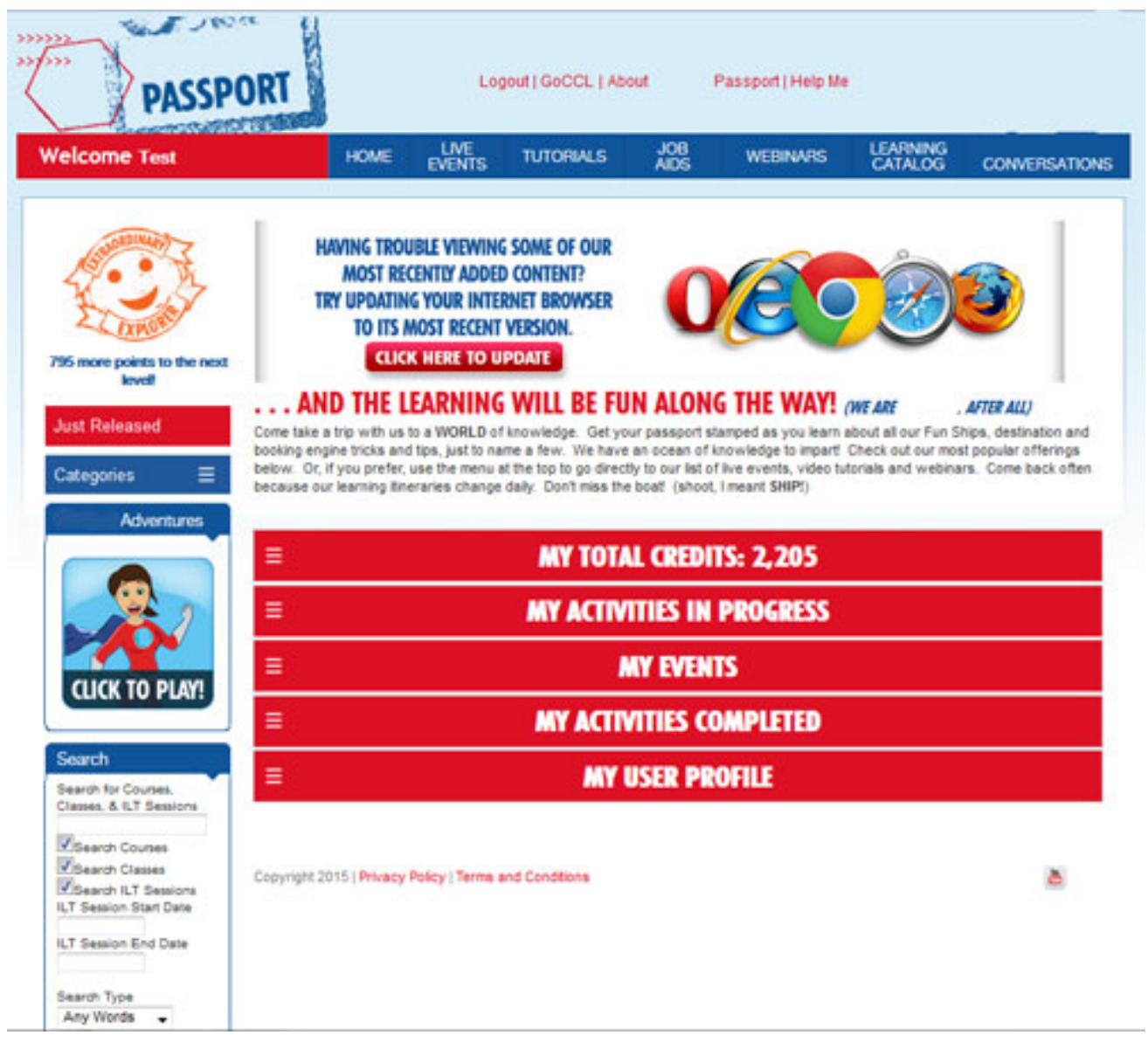

Figure 1: Home Page of the Passport. This figure demonstrates the location of where the serious game is launched. Adapted from Passport, In Taleo Learn, 2013, Retrieved May 28, 2013, from http://carnival.learn.com. Copyright 2013 by Taleo Learn. Reprinted with permission. 

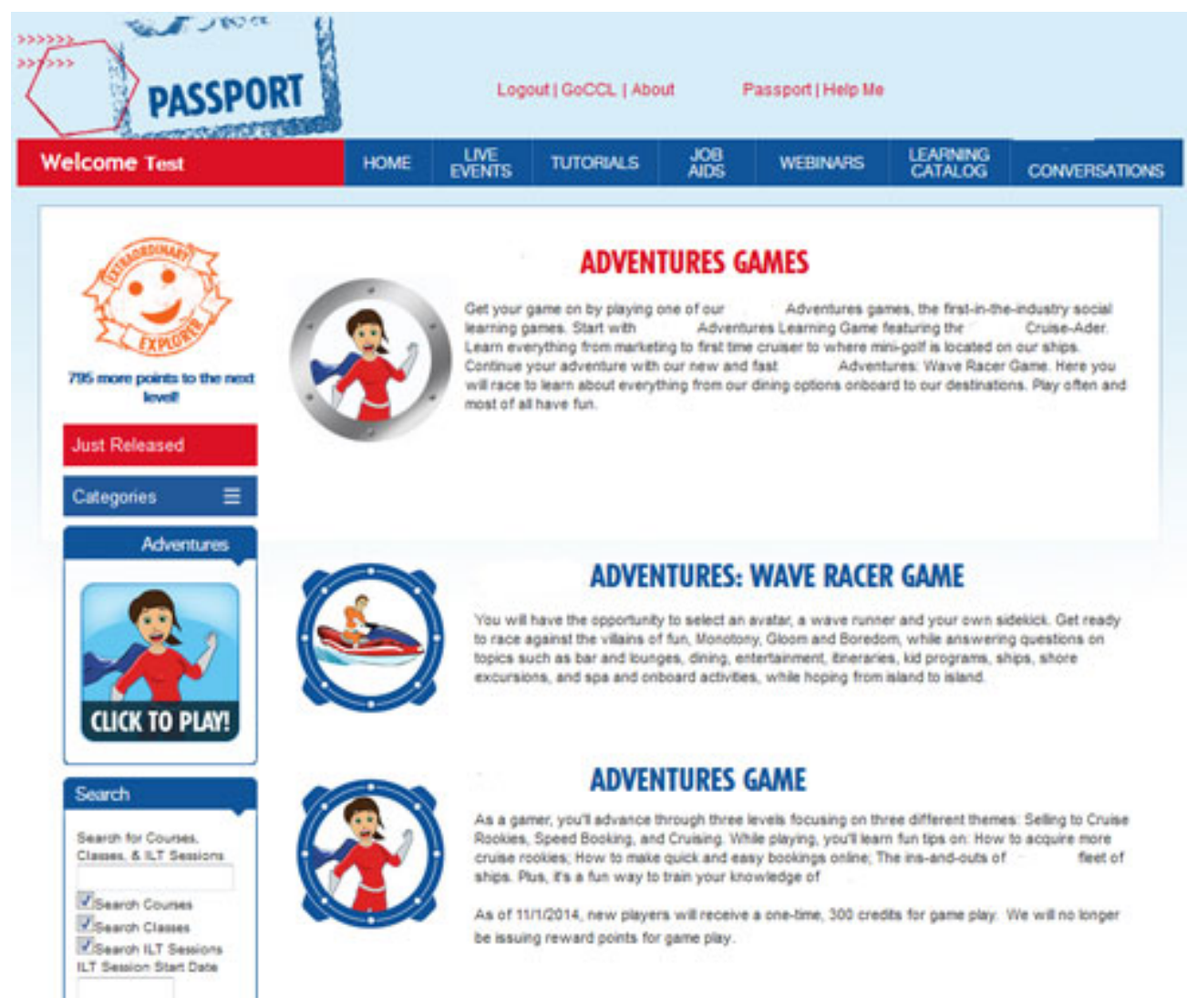

Figure 2: Adventures Games Page. This figure demonstrates the location of where the serious game is launched. Adapted from Passport, In Taleo Learn, 2013, Retrieved May 28, 2013, from http://carnival.learn.com. Copyright 2013 by Taleo Learn. Reprinted with permission. 


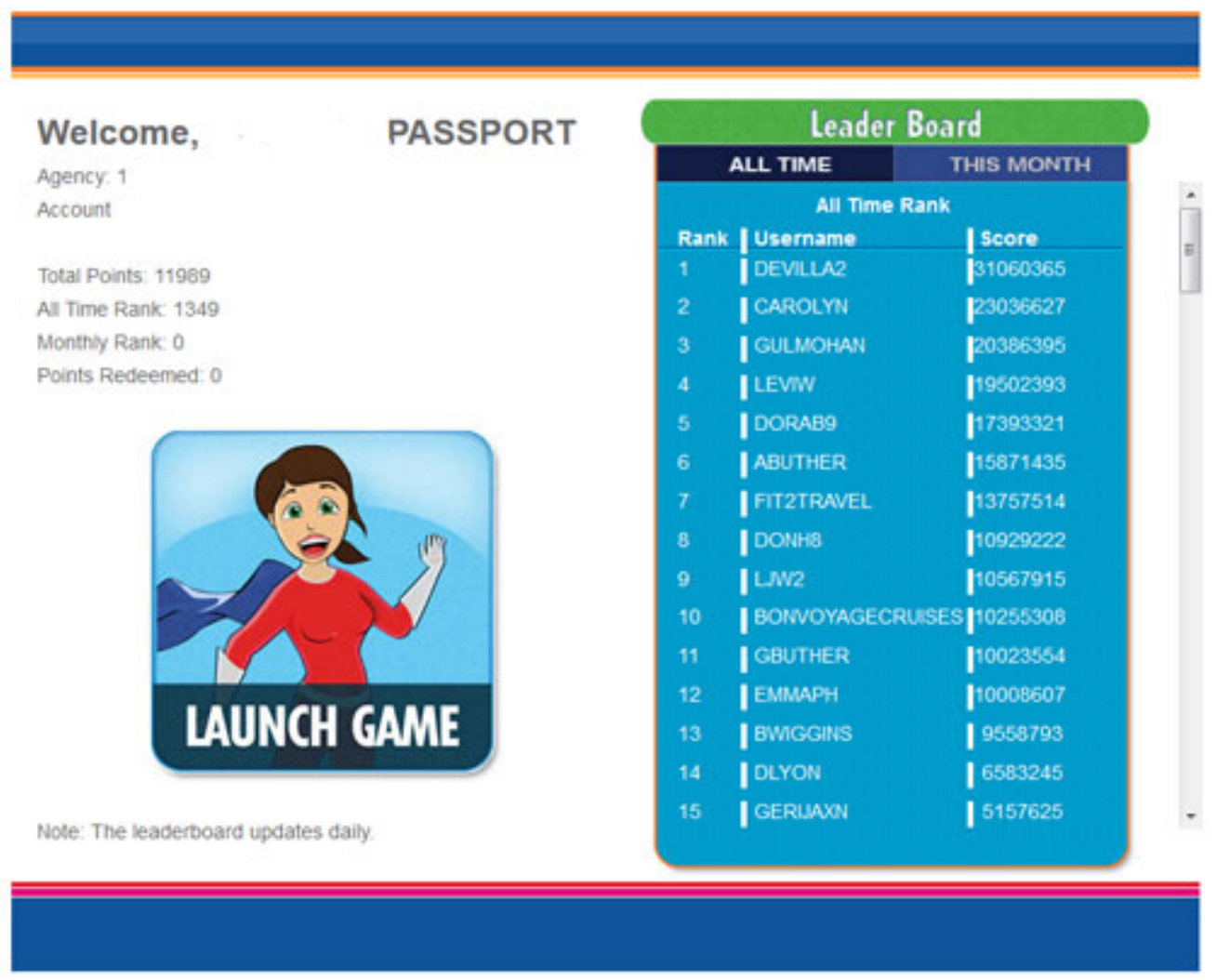

Figure 3: Ranking Page. This figure demonstrates the page where agents are able to view their monthly and all-time ranking in the Adventures Game. Adapted from Passport, In Taleo Learn, 2013, Retrieved May 28, 2013, from http://carnival.learn.com. Copyright 2013 by Taleo Learn. Reprinted with permission. 
Adventures Learning Game will always appear in your My Learning Profile.

The Adventures Learning Game is always available for you to play, so will never display as completed.

Come back often to play as the questions in the game will be updated periodically.

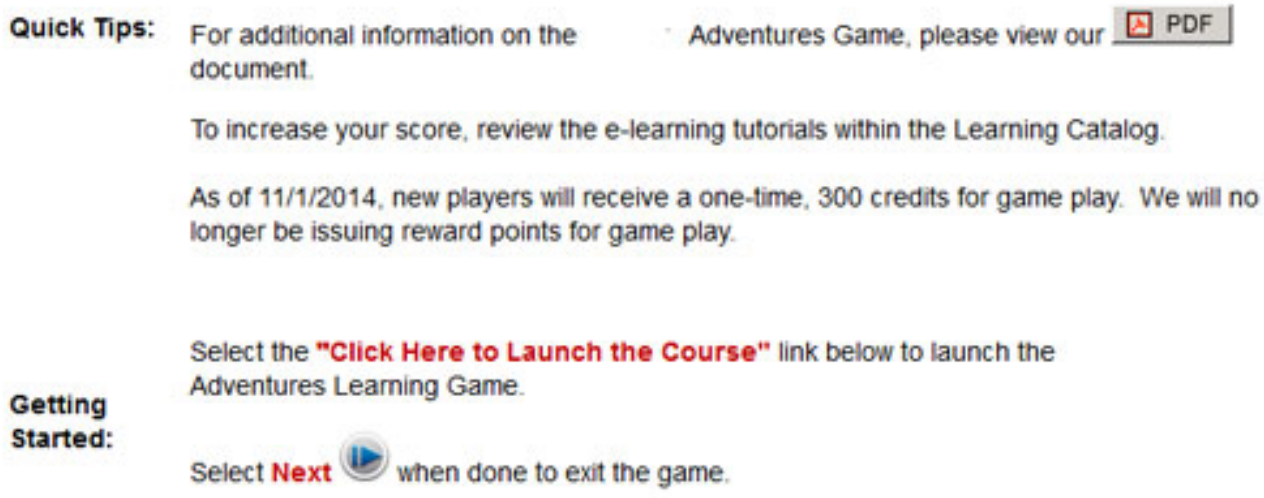

Click here to launch the course...

Figure 4: Adventures Game Launch Page. This figure demonstrates the page where agents are able to click here to launch the Adventures Game. Adapted from Passport, In Taleo Learn, 2013, Retrieved May 28, 2013, from http://carnival.learn.com. Copyright 2013 by Taleo Learn. Reprinted with permission.

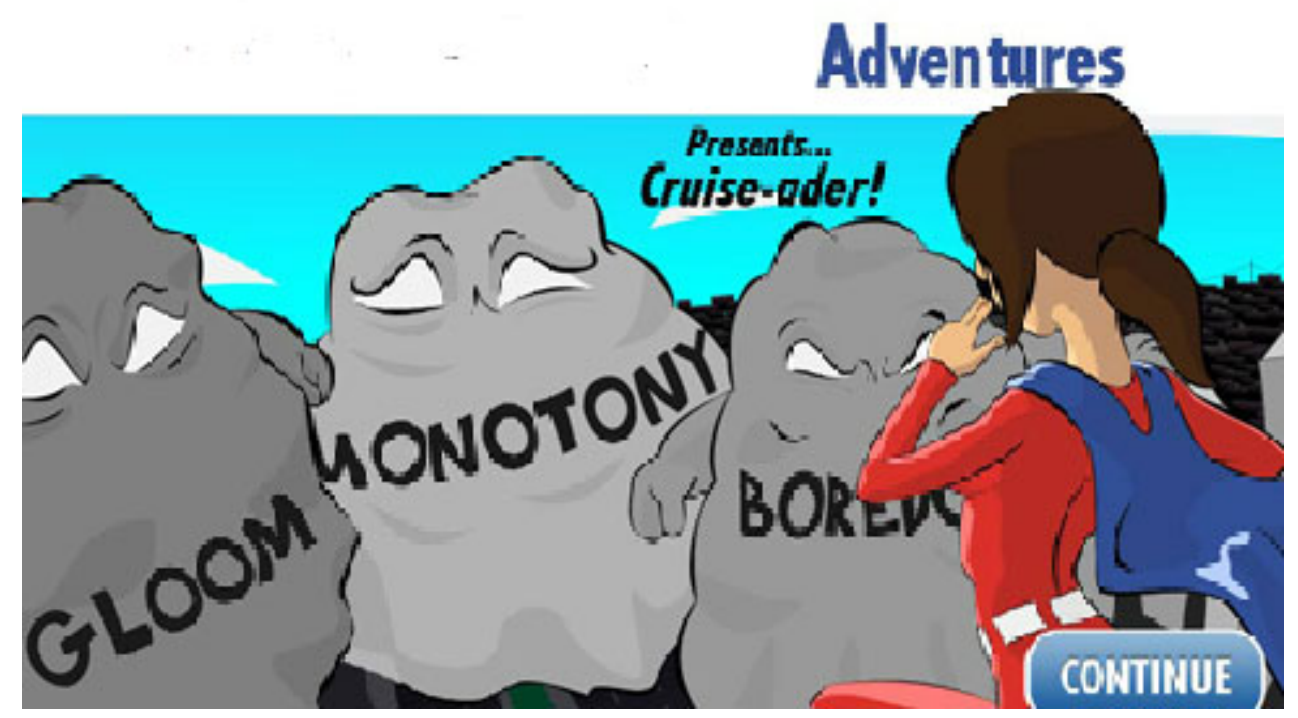

Figure 5: Adventures Launch Screen. This figure demonstrates the page where agents start the Adventures Game. Adapted from Passport, In Taleo Learn, 2013, Retrieved May 28, 2013, from http://carnival.learn.com. Copyright 2013 by Taleo Learn. Reprinted with permission. 


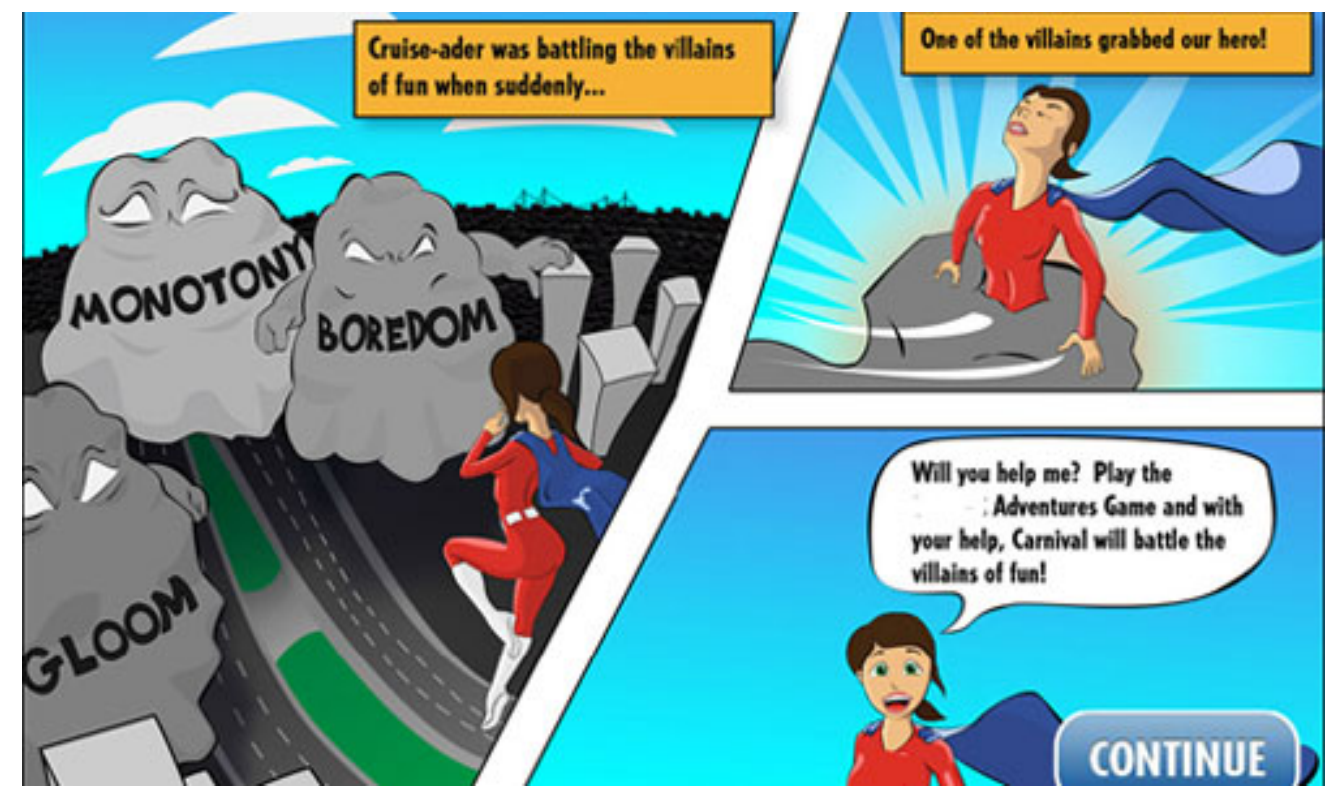

Figure 6: Adventures Avatar Screen. This figure demonstrates the page where agents are presented with the Cruisader Avatar and comic. Adapted from Passport, In Taleo Learn, 2013, Retrieved May 28, 2013, from http://carnival.learn.com. Copyright 2013 by Taleo Learn. Reprinted with permission.

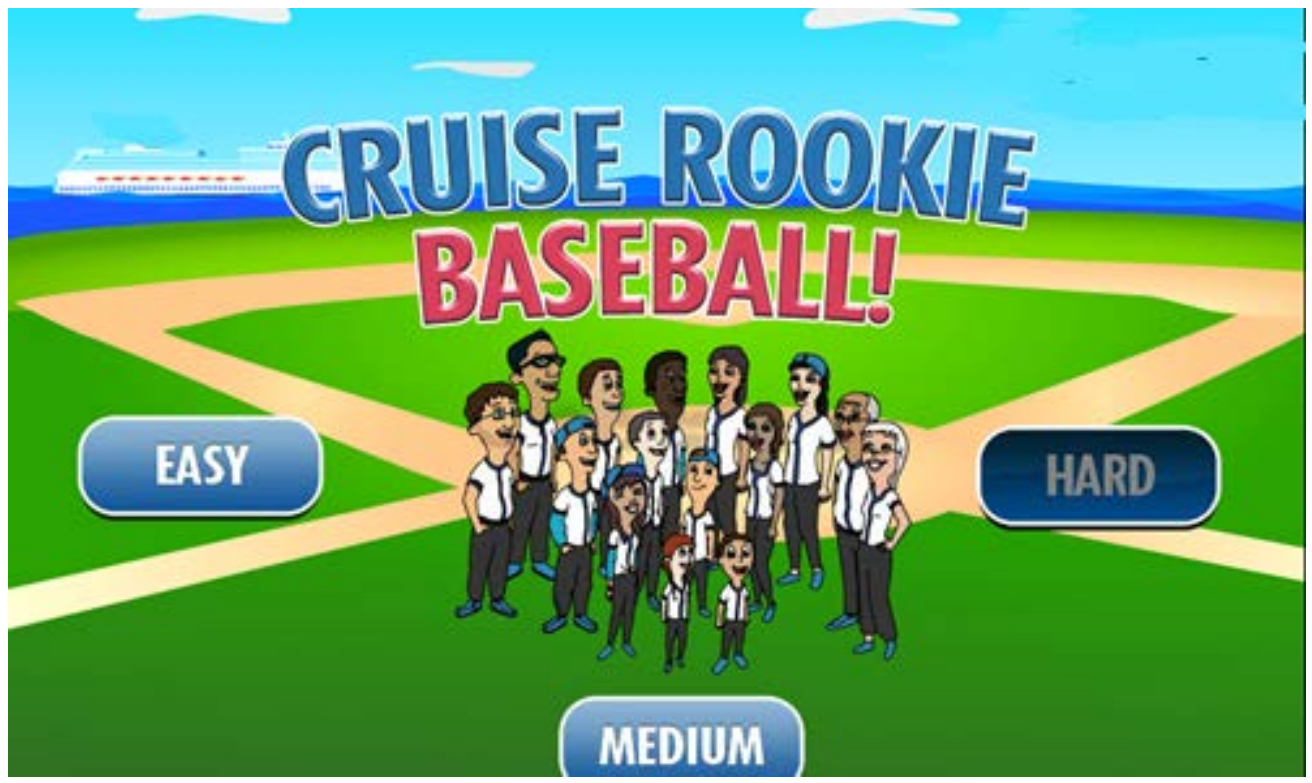

Figure 7: Level One - Cruise Rookie Baseball! launch screen. This figure demonstrates the page where agents begin the Cruise Rookie Baseball level and select their level of difficulty. Adapted from Passport, In Taleo Learn, 2013, Retrieved May 28, 2013, from http://carnival.learn.com. Copyright 2013 by Taleo Learn. Reprinted with permission. 


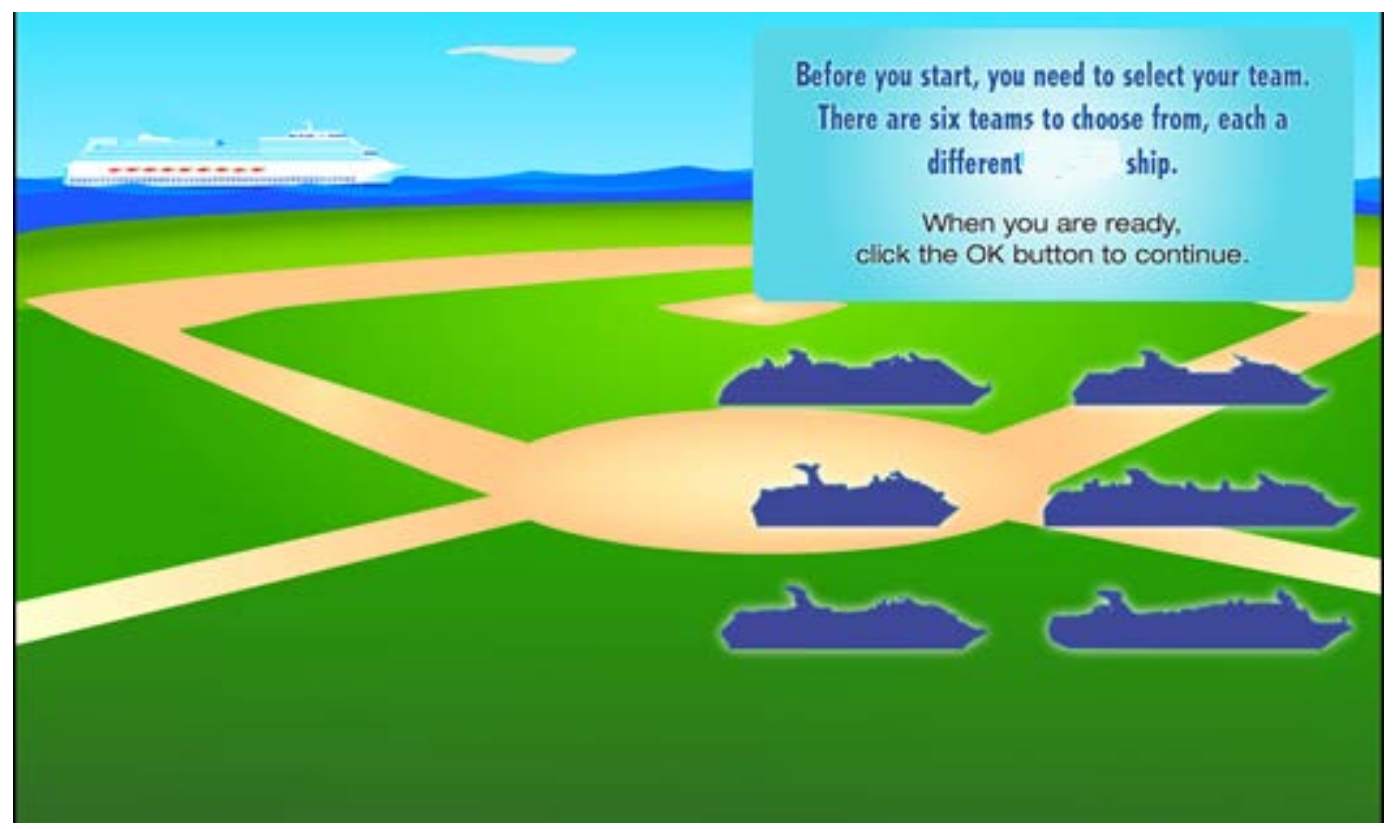

Figure 8: Level One - Select Your Team Screen. This figure demonstrates the page where agents are able to select their team. Adapted from Passport, In Taleo Learn, 2013, Retrieved May 28, 2013, from http://carnival.learn.com. Copyright 2013 by Taleo Learn. Reprinted with permission.

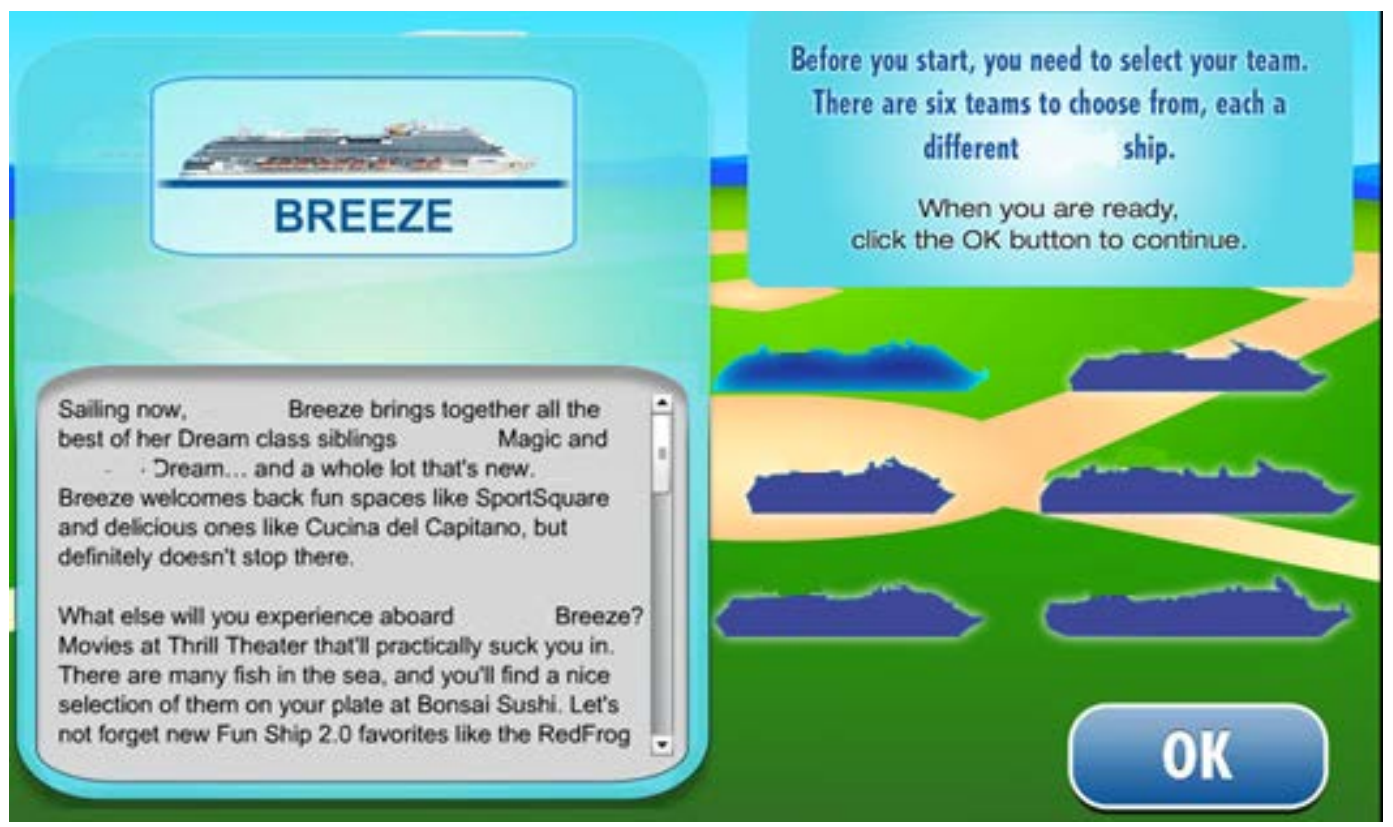

Figure 9: Level One - Selection of the Team and Description. This figure demonstrates the page where agents are able to view the description of their team. Adapted from Passport, In Taleo Learn, 2013, Retrieved May 28, 2013, from http://carnival.learn.com. Copyright 2013 by Taleo Learn. Reprinted with permission. 


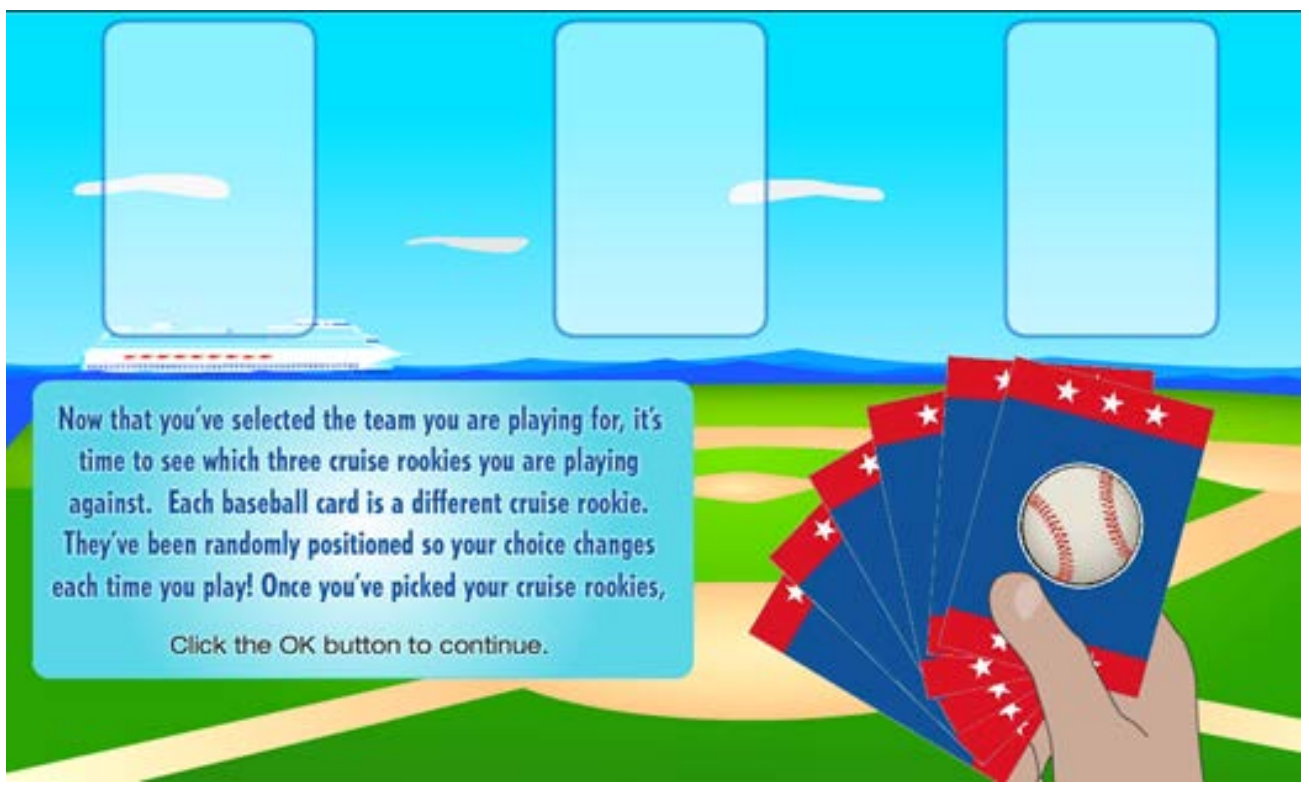

Figure 10: Level One - Cruise Rookie Selection. This figure is the page where agents are able to select the three cruise rookies they are playing against. Adapted from Passport, In Taleo Learn, 2013, Retrieved May 28, 2013, from http://carnival.learn.com. Copyright 2013 by Taleo Learn. Reprinted with permission.

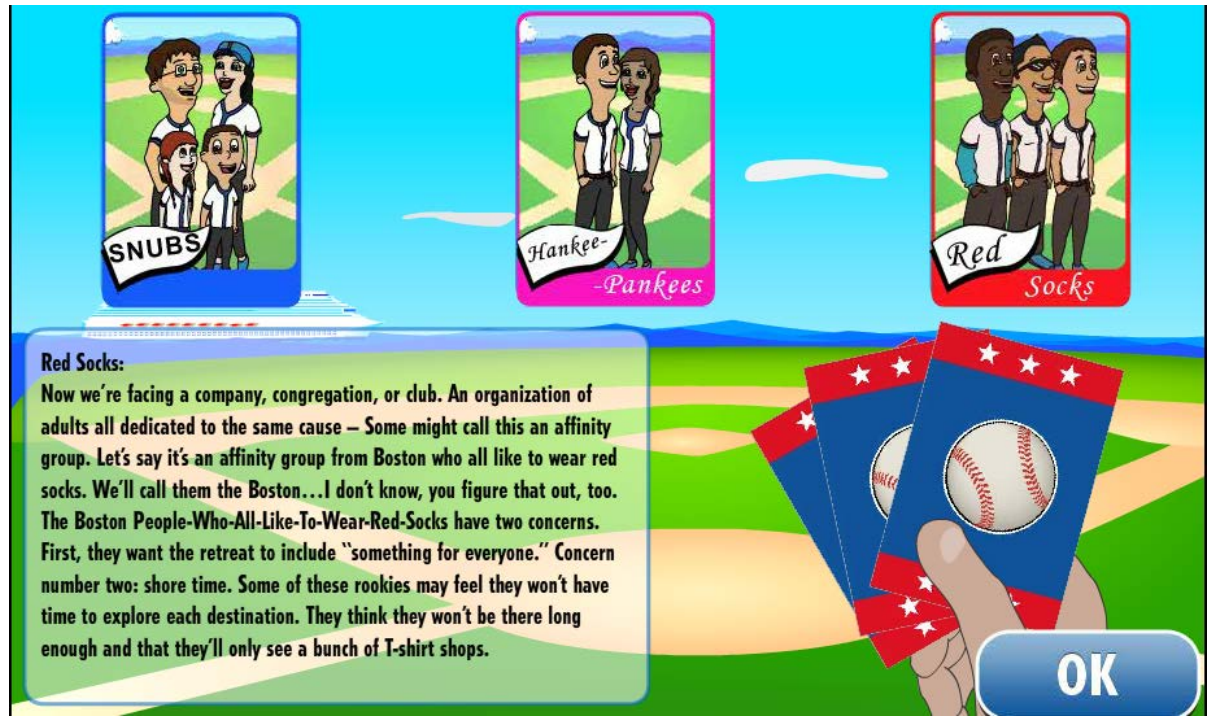

Figure 11: Selection of your Opponents. This figure demonstrates the process for selecting cruise rookies and the description of each group. Adapted from Passport, In Taleo Learn, 2013, Retrieved May 28, 2013, from http://carnival.learn.com. Copyright 2013 by Taleo Learn. Reprinted with permission. 


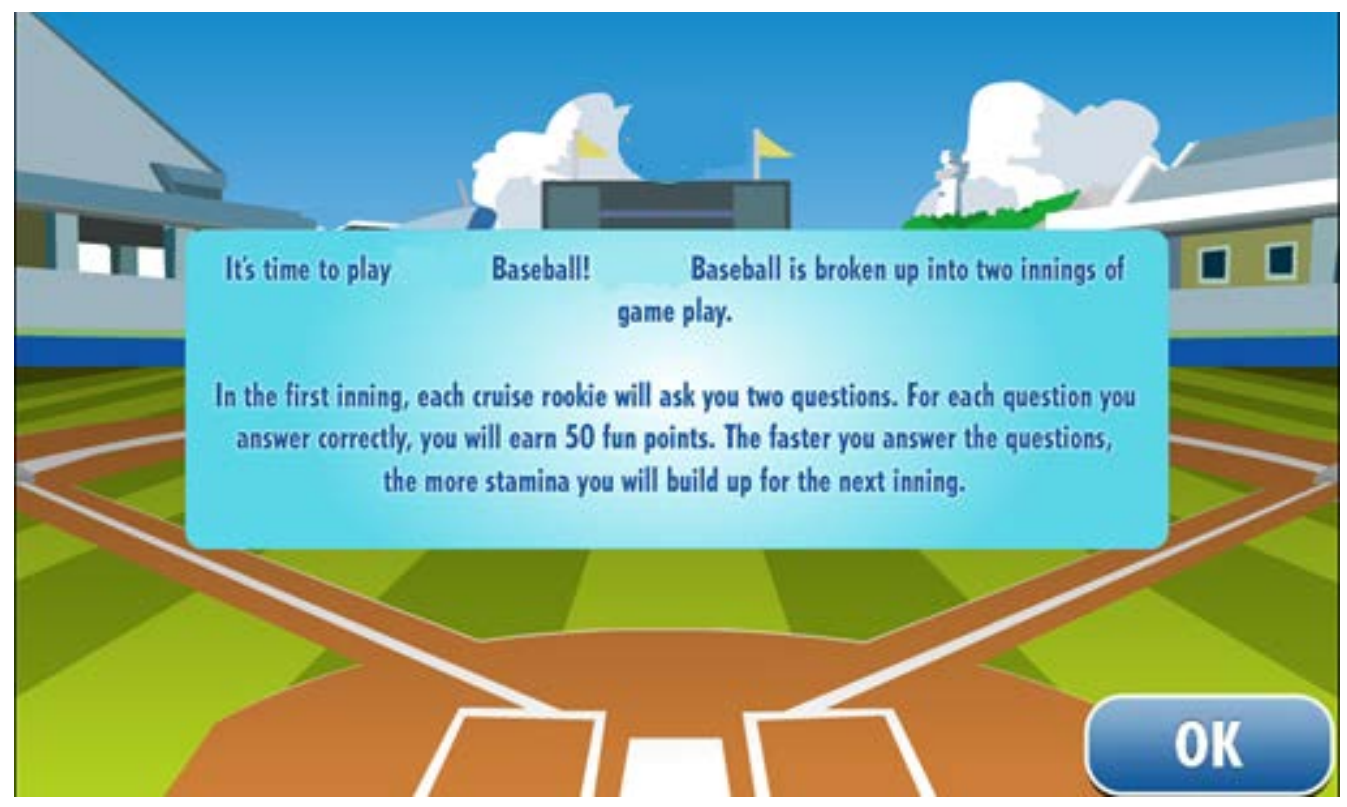

Figure 12: Inning One - Cruise Rookie Baseball. This figure is where agents learn how to play Cruise Rookie baseball. Adapted from Passport, In Taleo Learn, 2013, Retrieved May 28, 2013, from http://carnival.learn.com. Copyright 2013 by Taleo Learn. Reprinted with permission.

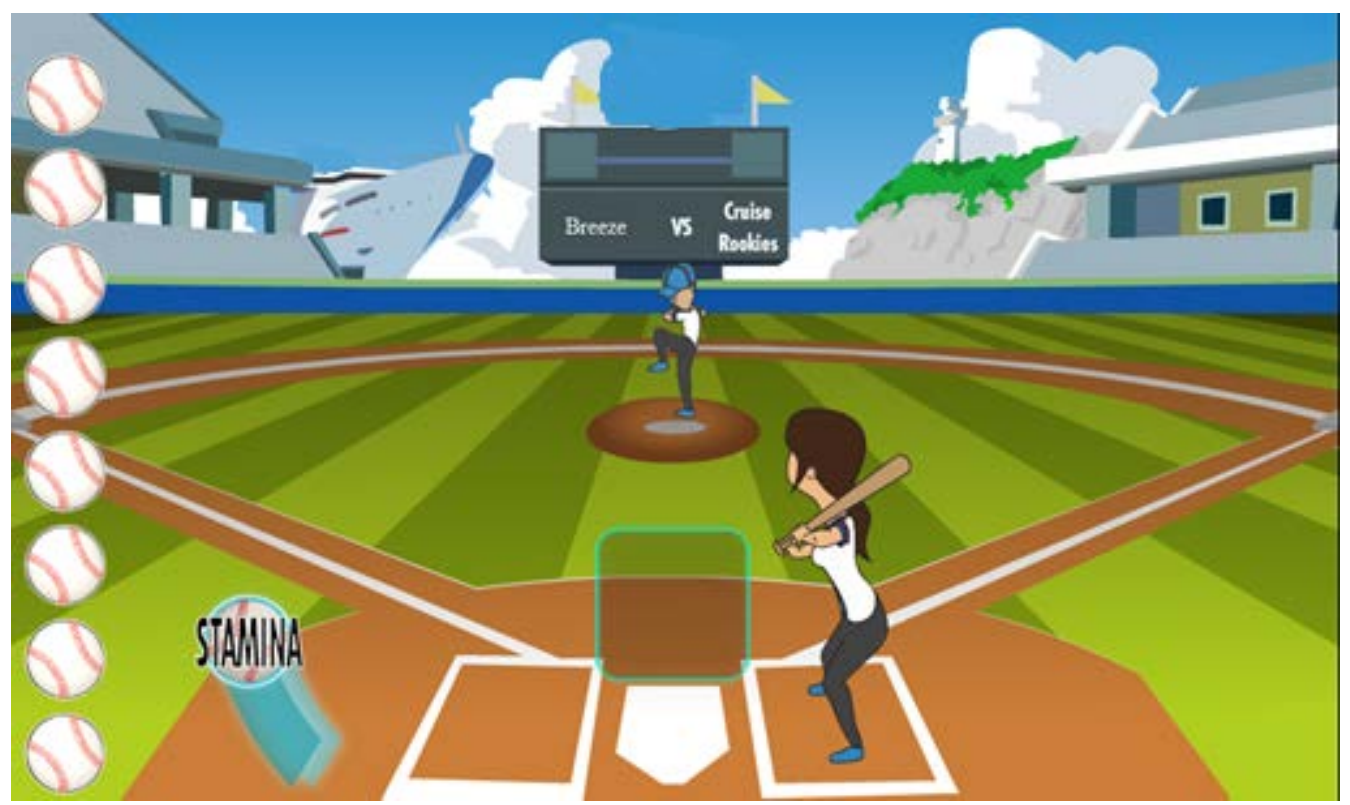

Figure 13: Inning Two - Home Run Derby. This figure is the page where agents learn how to participate in the home run derby. Adapted from Passport, In Taleo Learn, 2013, Retrieved May 28, 2013, from http://carnival.learn.com. Copyright 2013 by Taleo Learn. Reprinted with permission. 


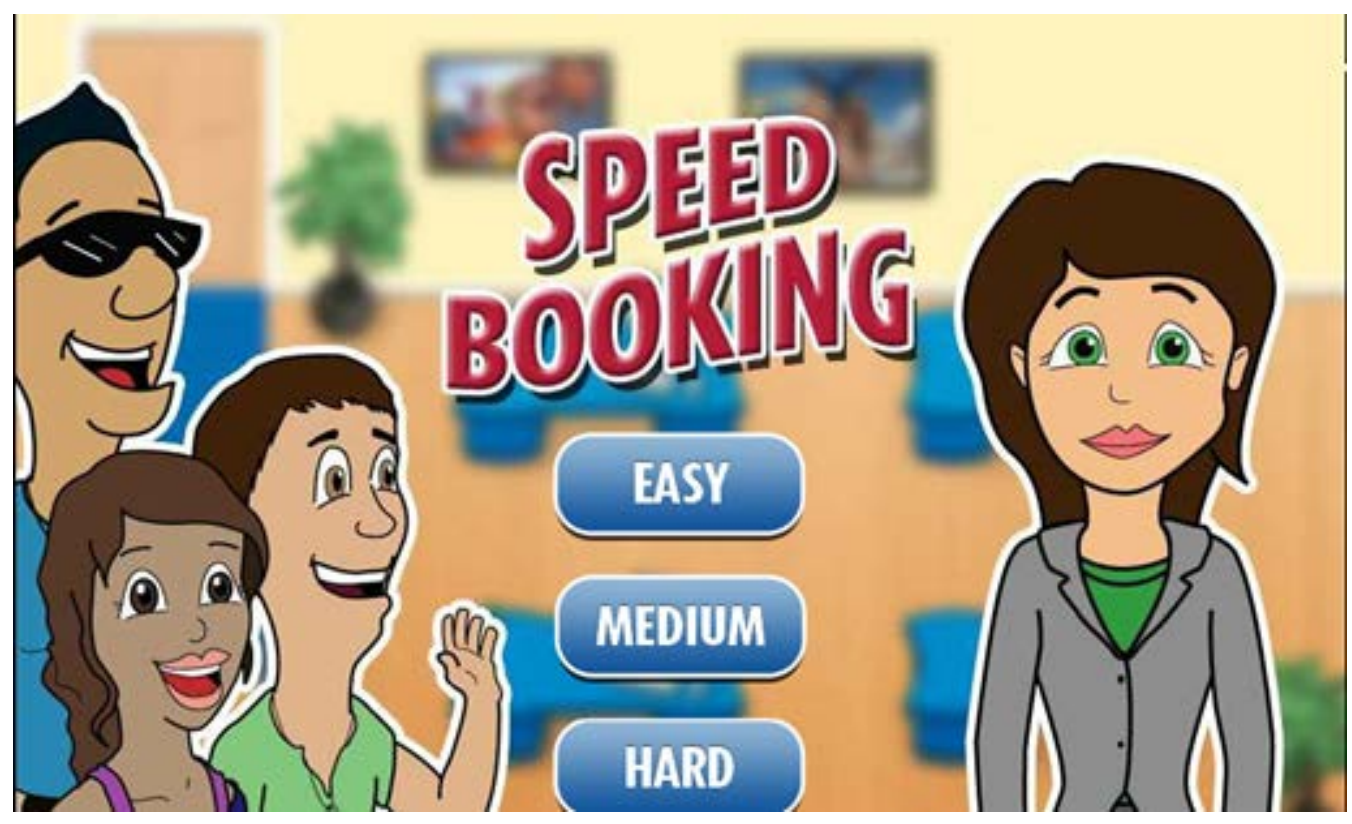

Figure 14: Level Two - Launch Page. This figure is the page where agents launch level two and select their level of difficulty. Adapted from Passport, In Taleo Learn, 2013, Retrieved May 28, 2013, from http://carnival.learn.com. Copyright 2013 by Taleo Learn. Reprinted with permission.

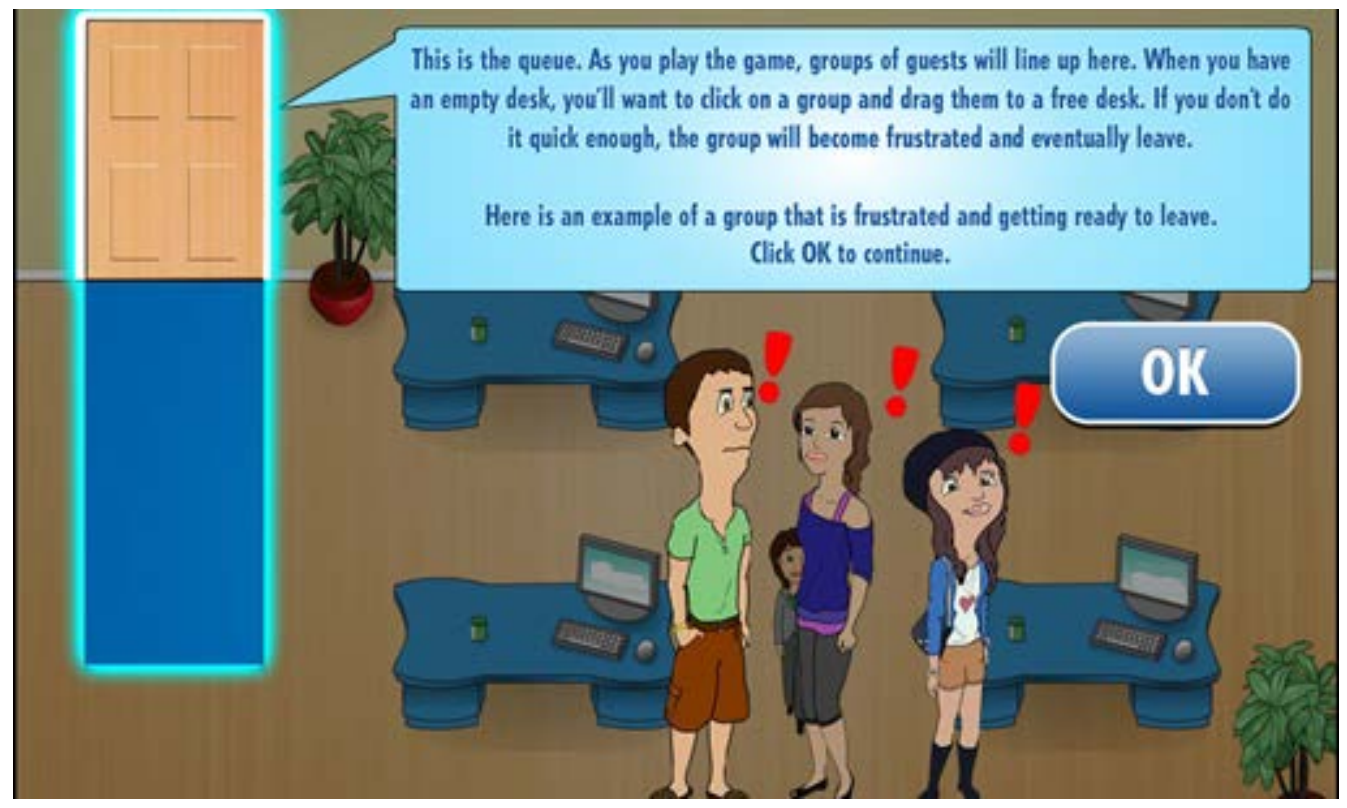

Figure 15: Level Two - Queue for Cruisers. This figure provides an overview of navigating the queue in level two. Adapted from Passport, In Taleo Learn, 2013, Retrieved May 28, 2013, from http://carnival.learn.com. Copyright 2013 by Taleo Learn. Reprinted with permission. 


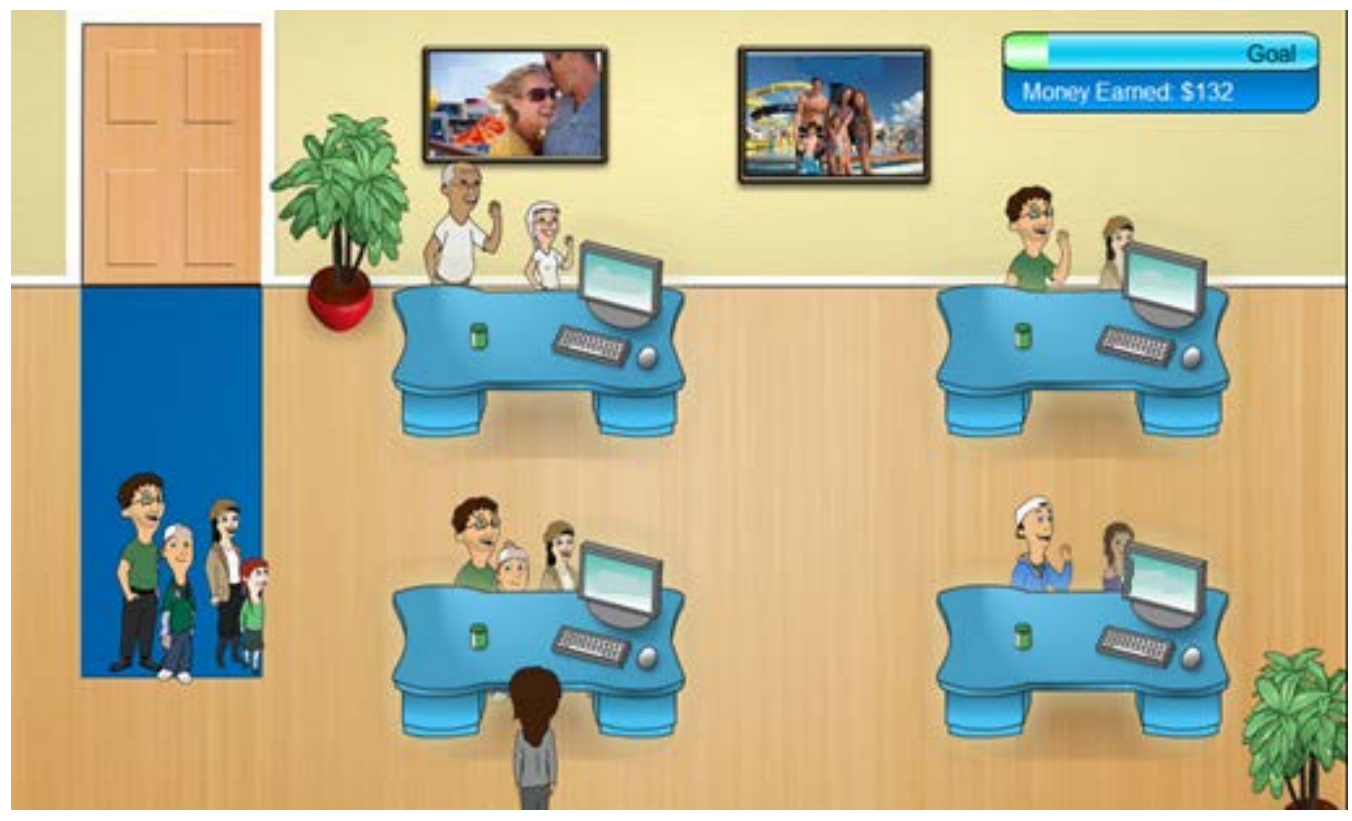

Figure 16: Level Two - Sample Game in Progress. This figure represents a sample game in progress within level two. Adapted from Passport, In Taleo Learn, 2013, Retrieved May 28, 2013, from http://carnival.learn.com. Copyright 2013 by Taleo Learn. Reprinted with permission.

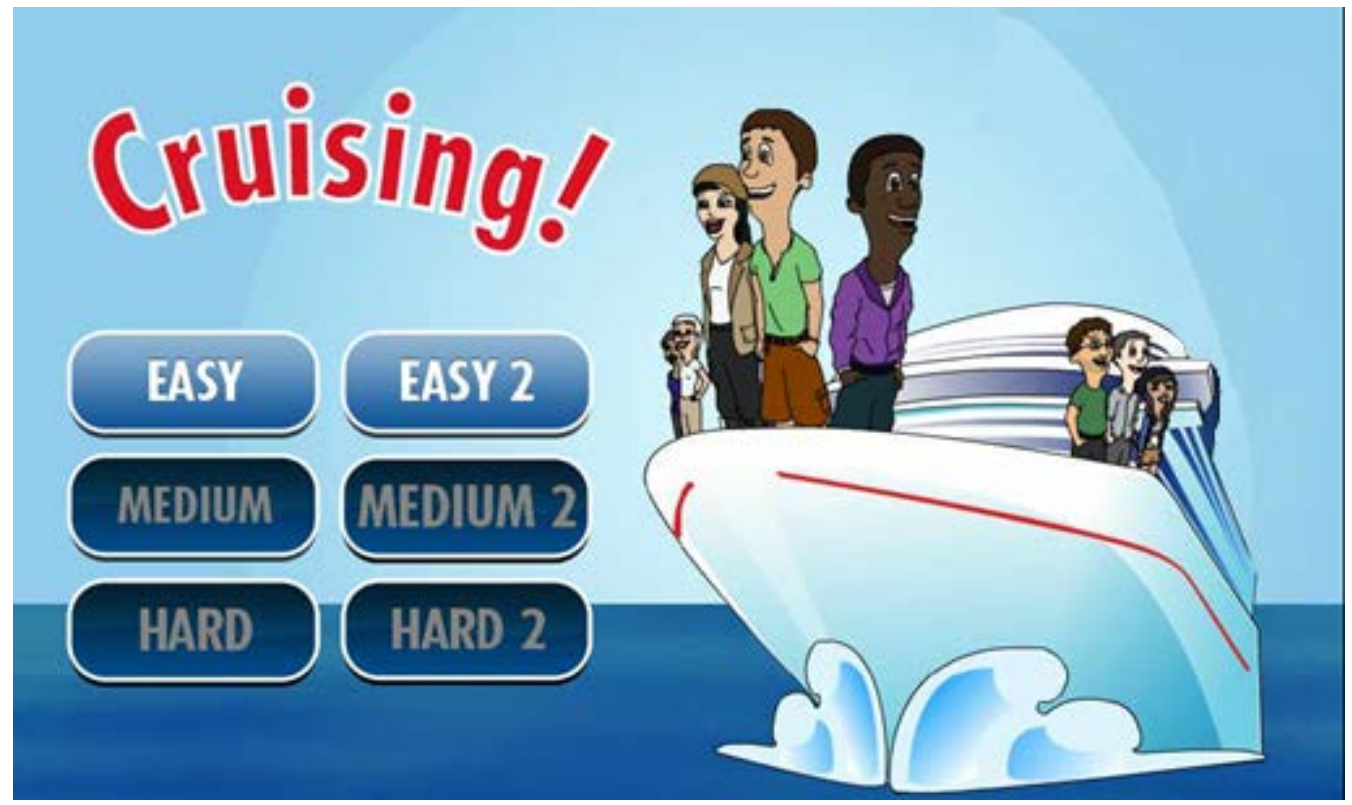

Figure 17: Level Three - Launch Page. This figure is the page where the agent launches level three and selects their level of difficulty. Adapted from Passport, In Taleo Learn, 2013, Retrieved May 28, 2013, from http://carnival.learn.com. Copyright 2013 by Taleo Learn. Reprinted with permission. 


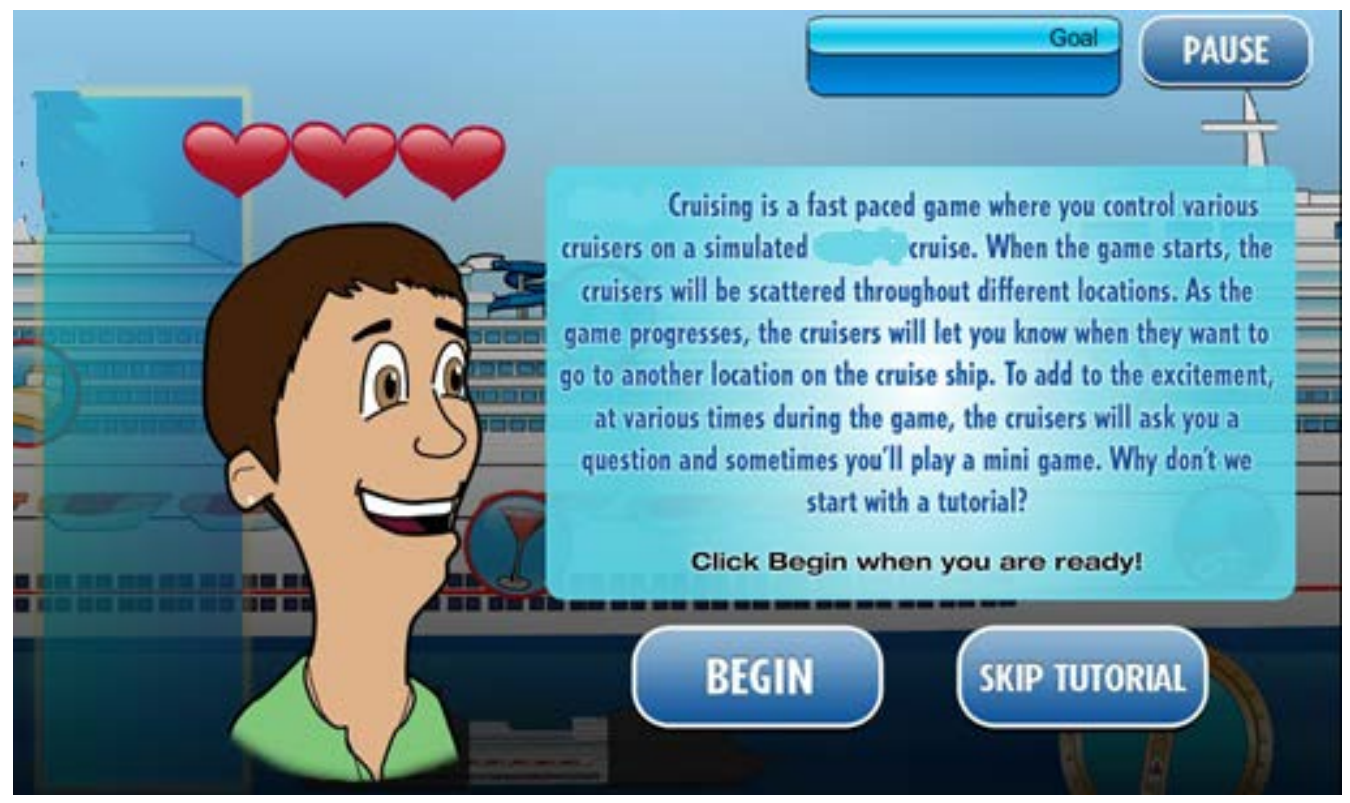

Figure 18: Level Three - Begin Page and Tutorial Launch. This figure is the page where agents are able to view a tutorial concerning level three or begin the level. Adapted from Passport, In Taleo Learn, 2013, Retrieved May 28, 2013, from http://carnival.learn.com. Copyright 2013 by Taleo Learn. Reprinted with permission.

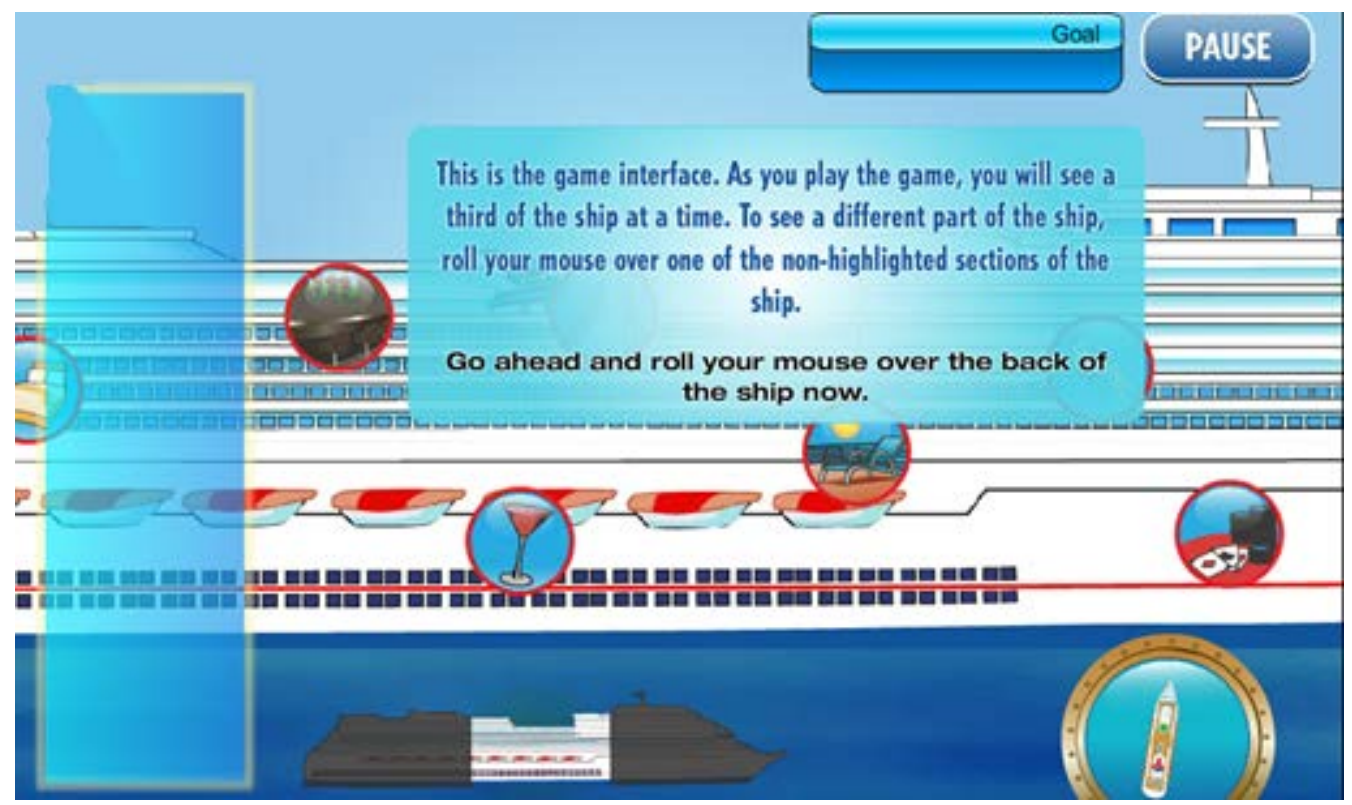

Figure 19: Level Three - Navigating the Ship. This figure is the page where agents are able to learn about the level three interface. Adapted from Passport, In Taleo Learn, 2013, Retrieved May 28, 2013, from http://carnival.learn.com. Copyright 2013 by Taleo Learn. Reprinted with permission. 


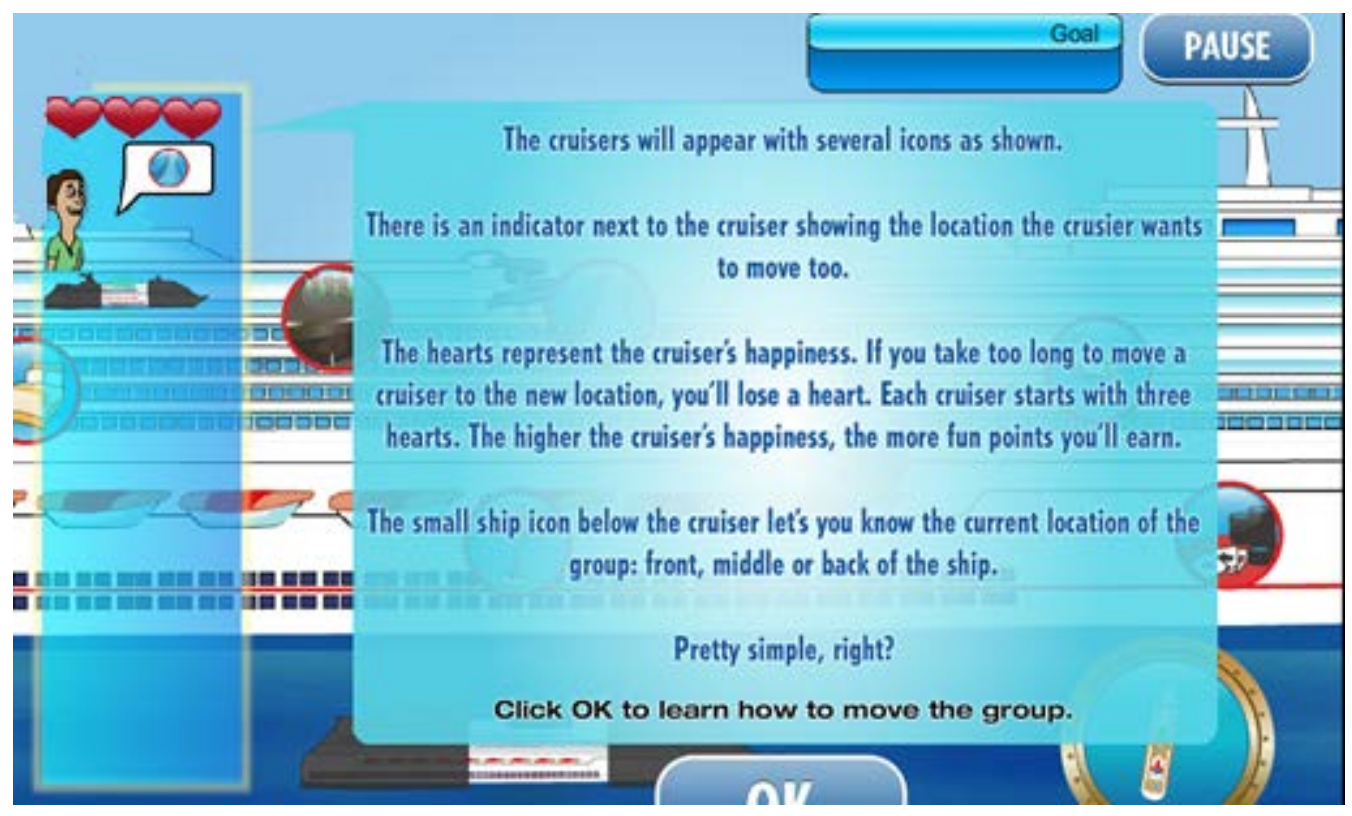

Figure 20: Level Three - Cruiser Icons. This figure describes the role of the cruiser and their icons during level three. Adapted from Passport, In Taleo Learn, 2013, Retrieved May 28, 2013, from http://carnival.learn.com. Copyright 2013 by Taleo Learn. Reprinted with permission.

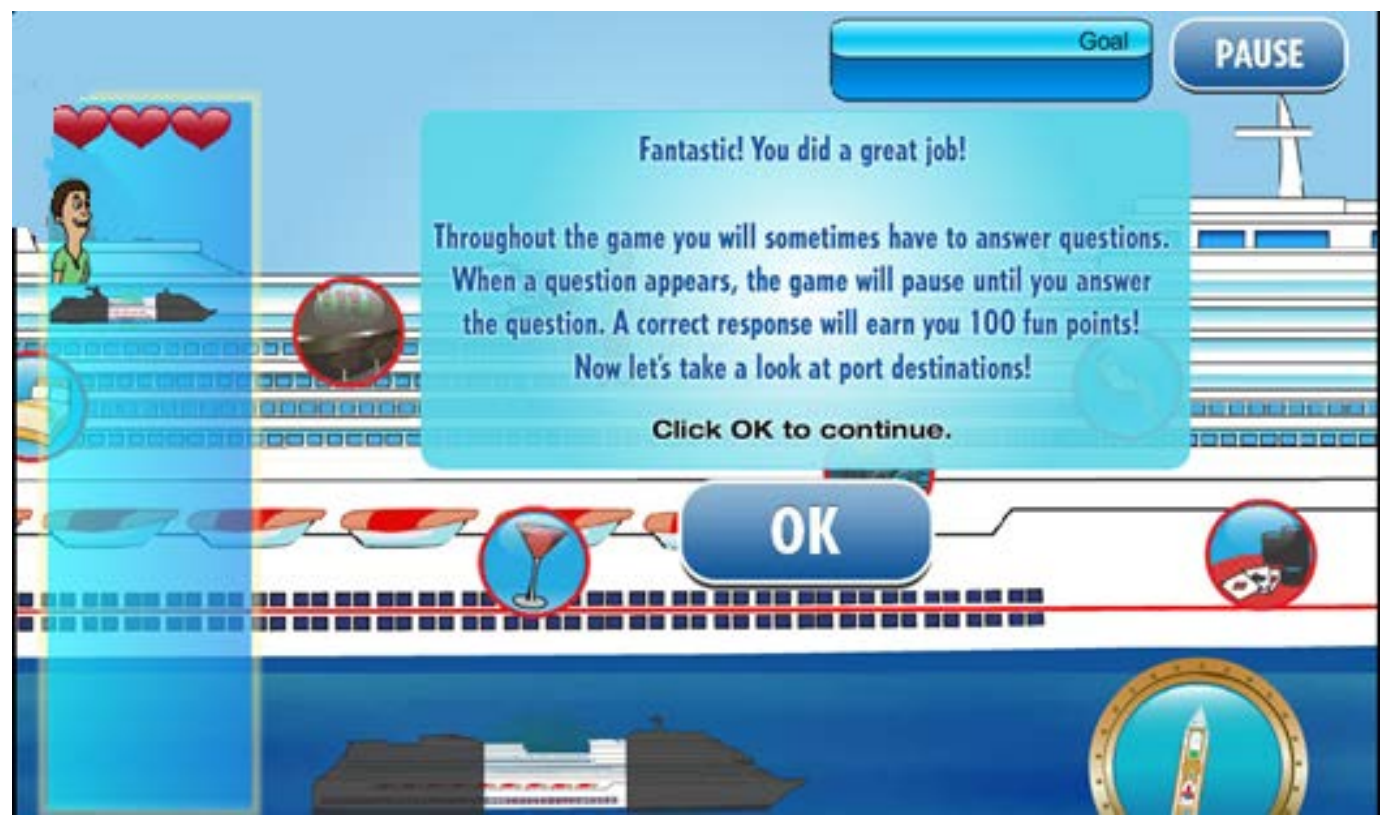

Figure 21: Level Three - Navigating Game Questions. This figure is the page where agents are able to select the three cruise rookies they are playing against. Adapted from Passport, In Taleo Learn, 2013, Retrieved May 28, 2013, from http://carnival.learn.com. Copyright 2013 by Taleo Learn. Reprinted with permission. 


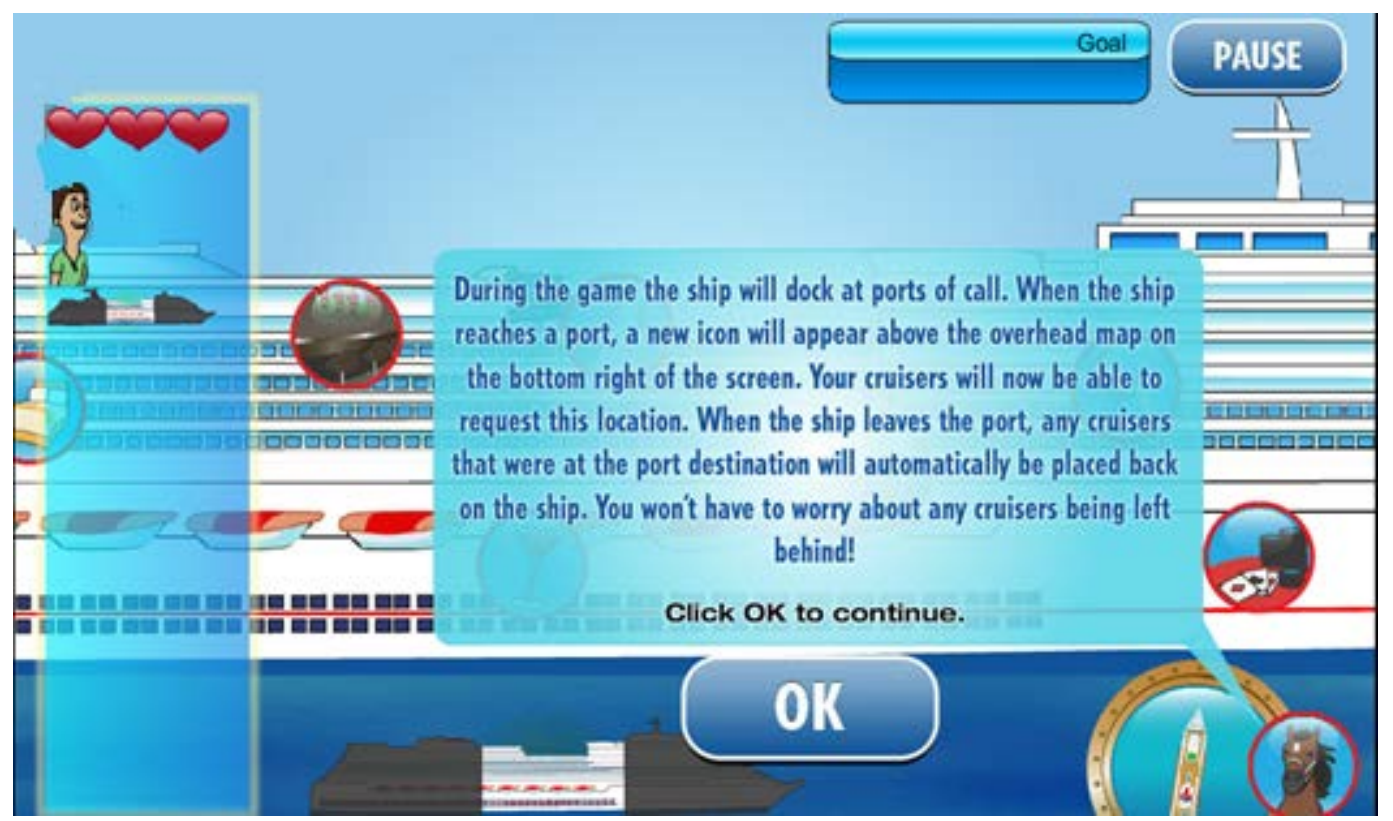

Figure 22: Level Three - Ports of Call and Overhead Map. This figure describes the features such as the ports of call and overhead map that appear in level three. Adapted from Passport, In Taleo Learn, 2013, Retrieved May 28, 2013, from http://carnival.learn.com. Copyright 2013 by Taleo Learn. Reprinted with permission.

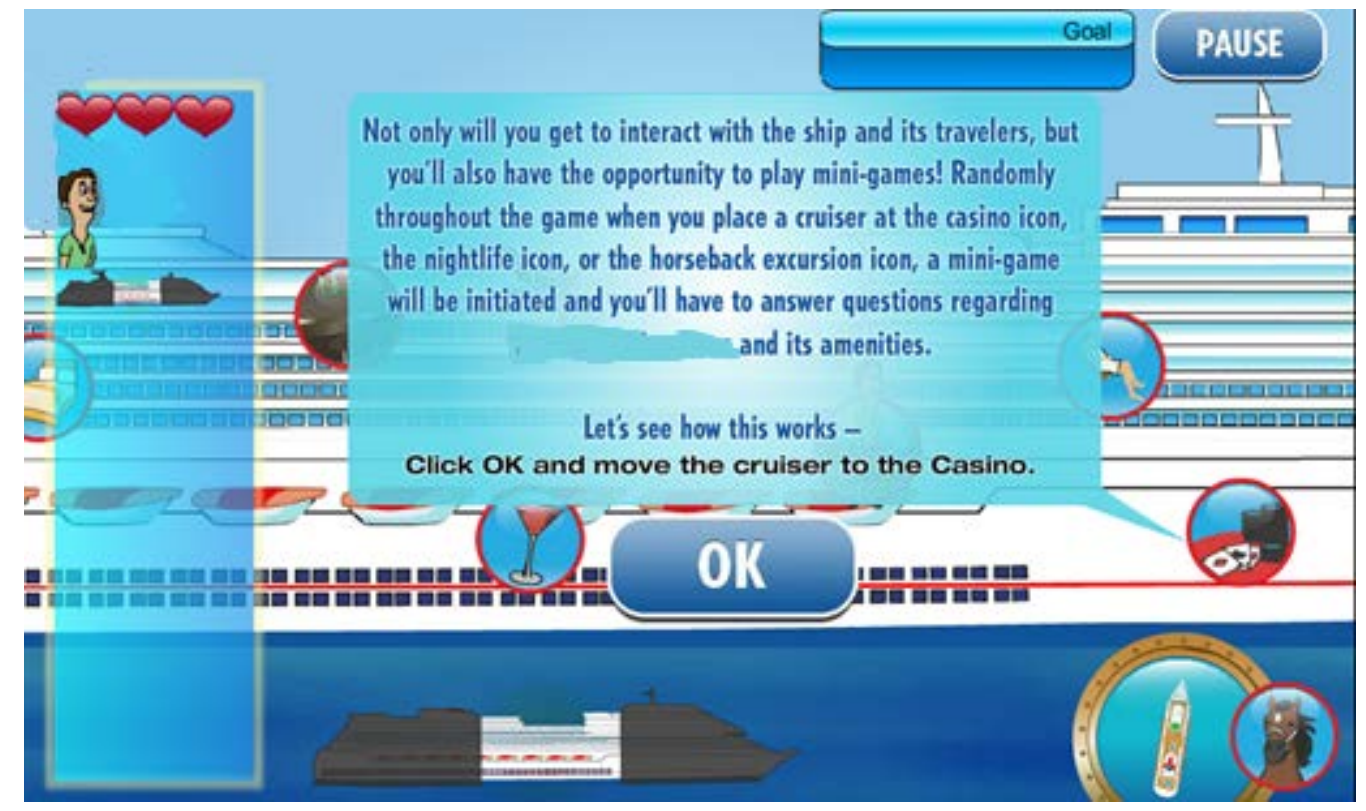

Figure 23: Level Three - Description and Overview of Mini-games. This figure is the page where agents are able to select the three cruise rookies they are playing against. Adapted from Passport, In Taleo Learn, 2013, Retrieved May 28, 2013, from http://carnival.learn.com. Copyright 2013 by Taleo Learn. Reprinted with permission. 


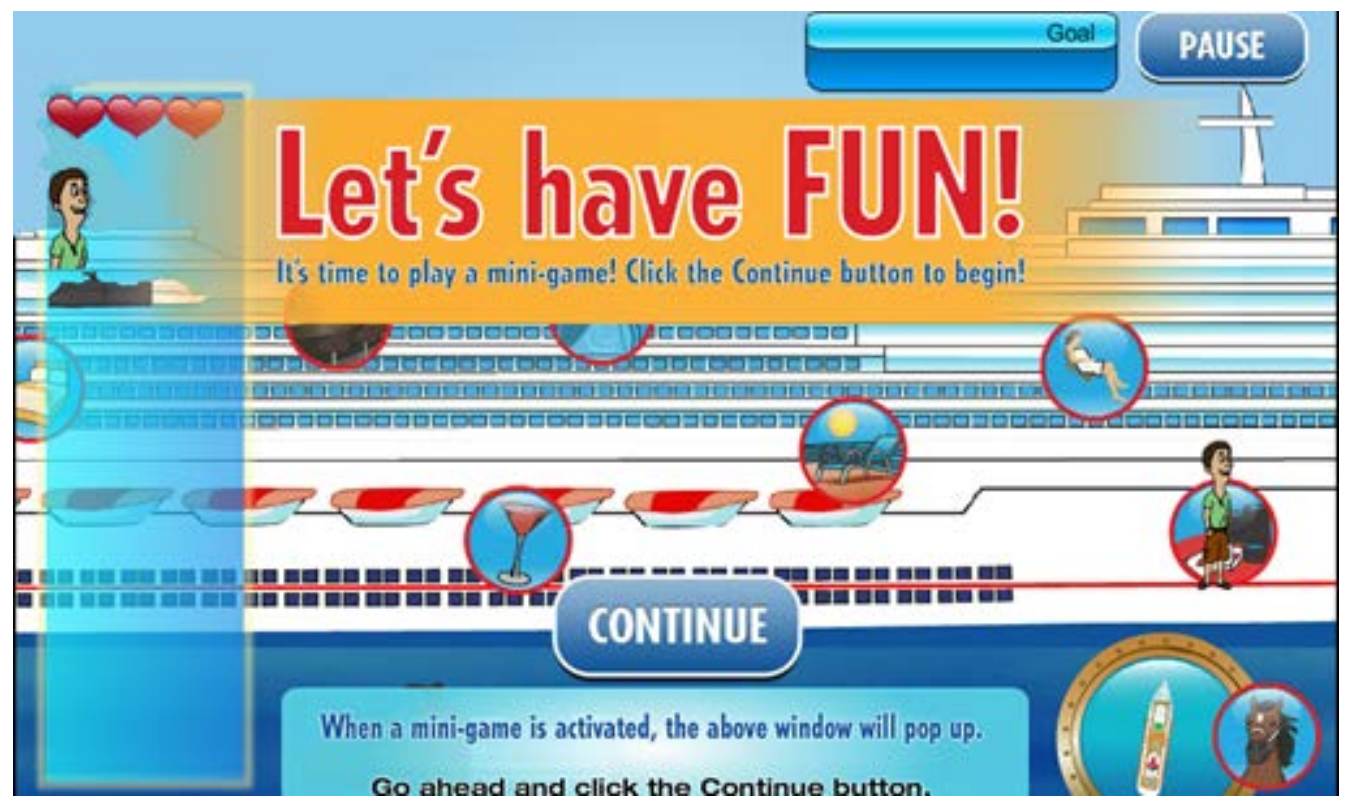

Figure 24: Level Three - Launch Page for a Mini-game. This figure is the page where agents are able to select launch a mini-game in level three. Adapted from Passport, In Taleo Learn, 2013, Retrieved May 28, 2013, from http://carnival.learn.com. Copyright 2013 by Taleo Learn. Reprinted with permission.

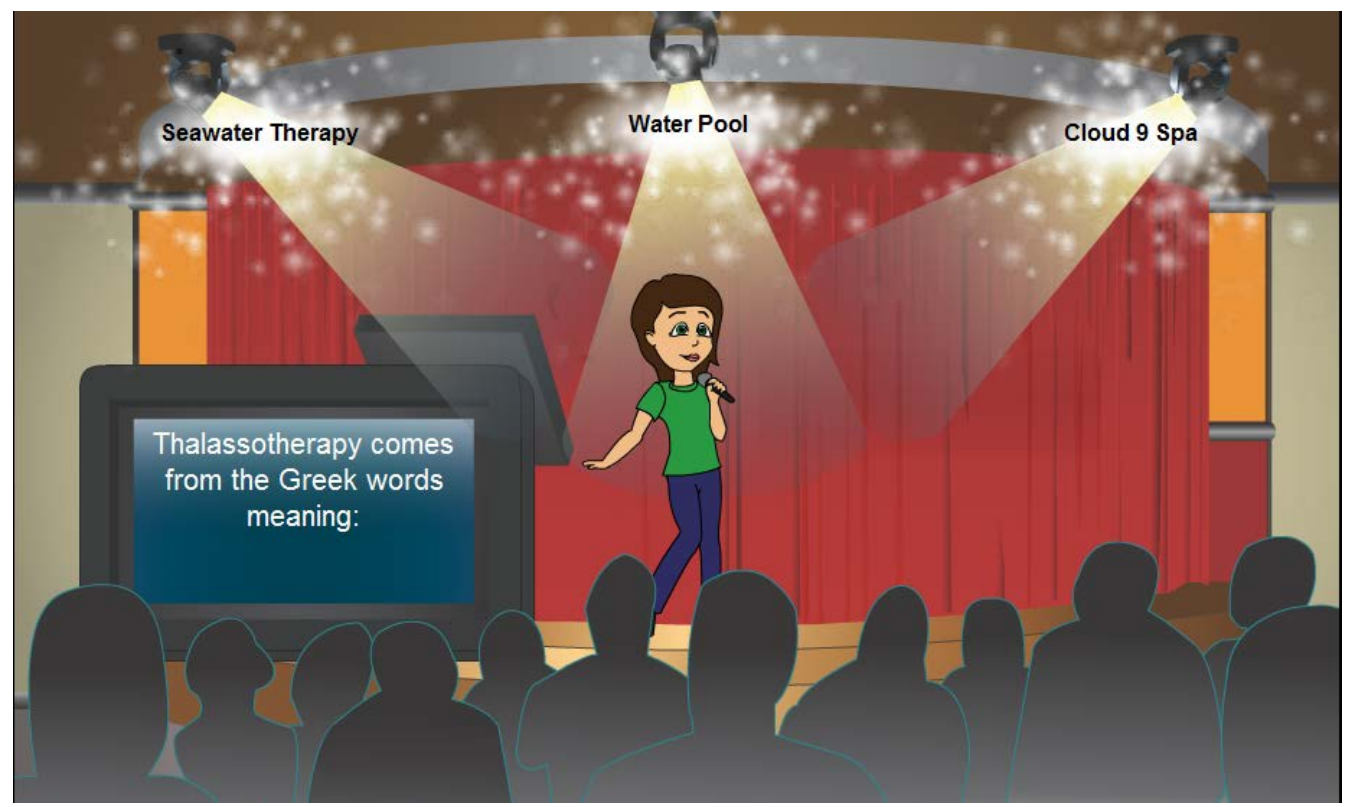

Figure 25: Level Three - Karaoke Mini-game. This figure represents the karaoke minigame. Adapted from Passport, In Taleo Learn, 2013, Retrieved May 28, 2013, from http://carnival.learn.com. Copyright 2013 by Taleo Learn. Reprinted with permission. 


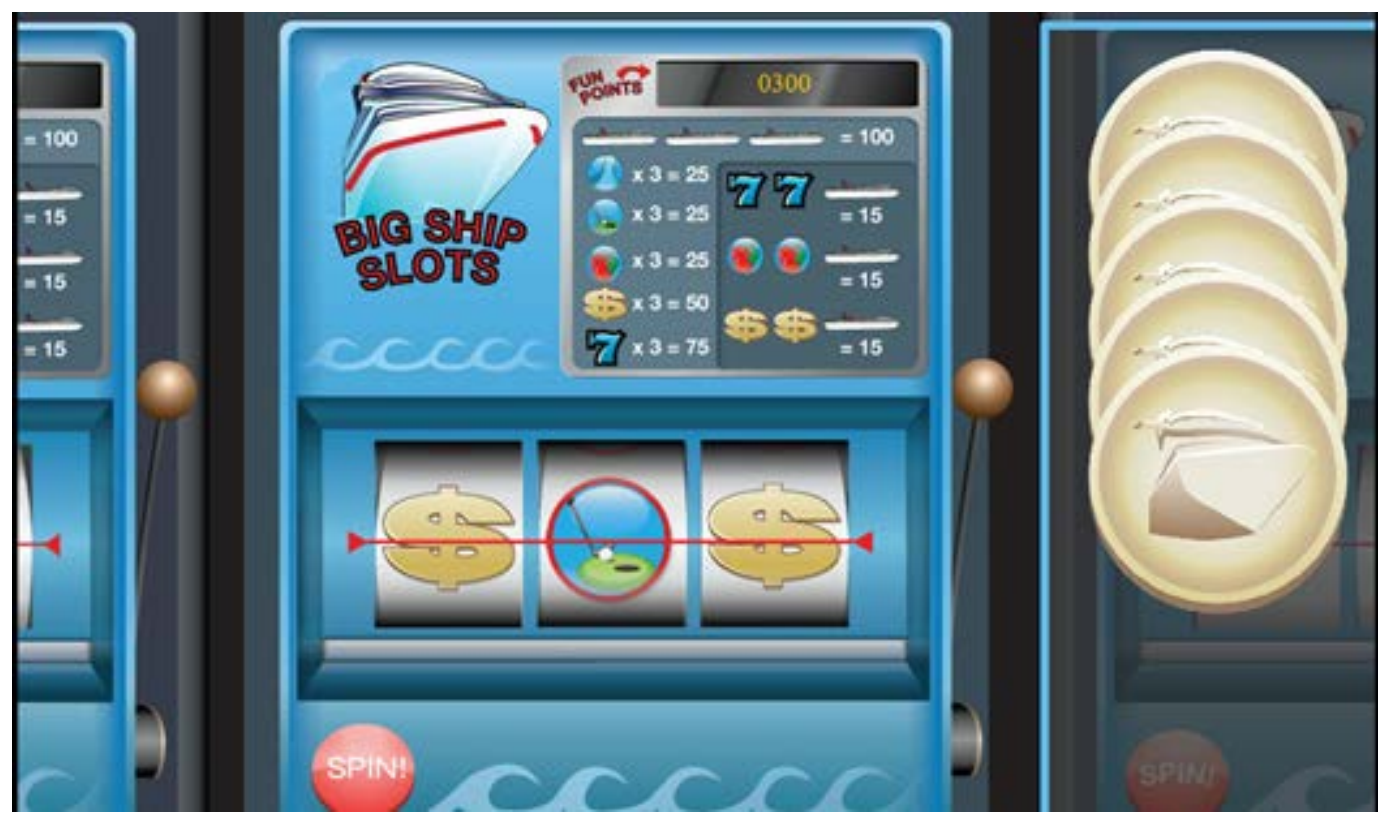

Figure 26: Level Three - Casino Mini-game. This figure represents the casino minigame. Adapted from Passport, In Taleo Learn, 2013, Retrieved May 28, 2013, from http://carnival.learn.com. Copyright 2013 by Taleo Learn. Reprinted with permission.

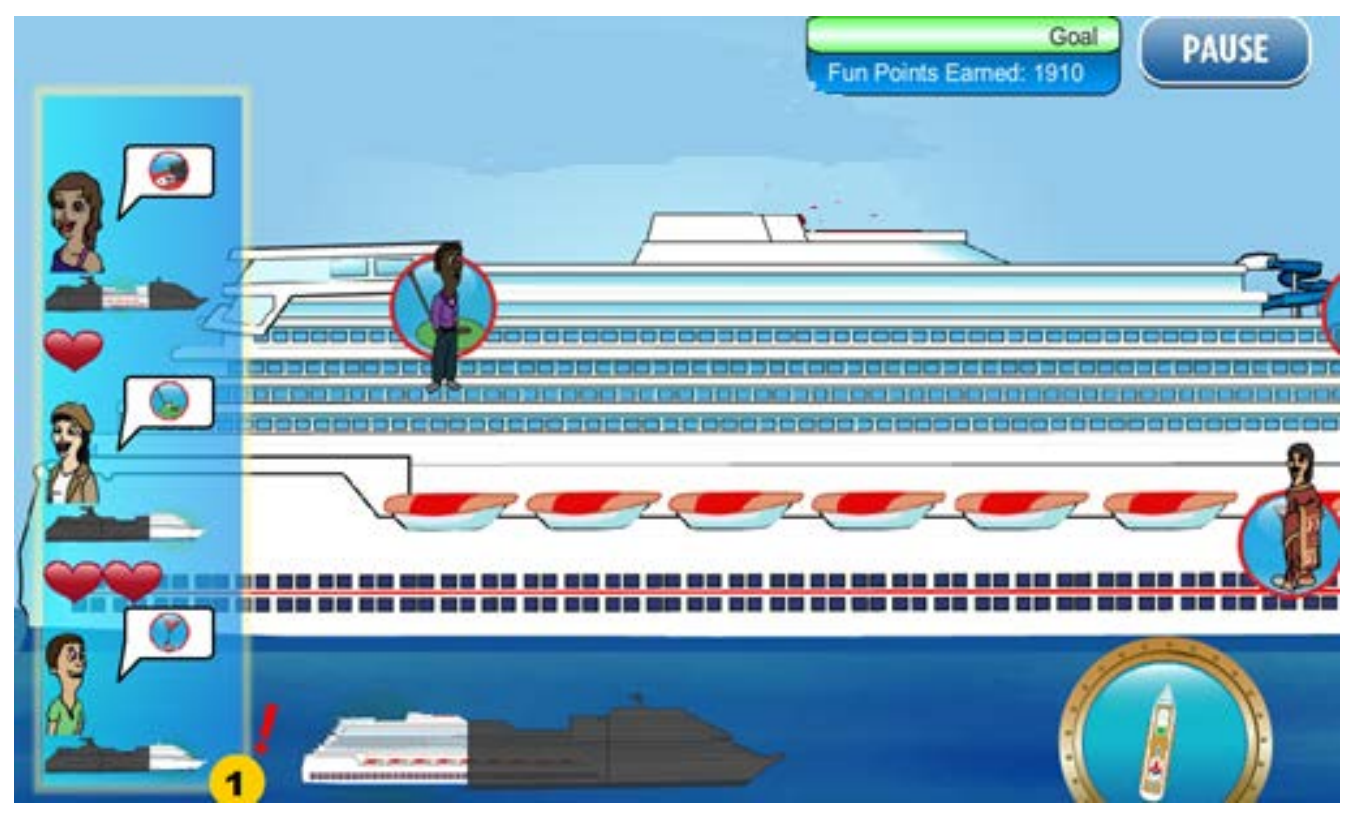

Figure 27: Level Three - Sample Game In Progress. This figure represents a sample level three game in progress. Adapted from Passport, In Taleo Learn, 2013, Retrieved May 28, 2013, from http://carnival.learn.com. Copyright 2013 by Taleo Learn. Reprinted with permission. 


\section{Congratulations!}

\section{You've completed every level of the game!}

Your score has been submitted to the leader board and you can now new your passport to see the total amount of achievements you've earned!

To view your achievements click the Passport icon below. To start this game again, click the Play Again button.

If you are ready to leave the game, click the Close burton to clost the game and return to the learning management system.

\section{PASSPORT PLAY AGAIN}

\section{CLOSE}

Figure 28: Game Completion Screen. This figure represents the completion page that each agent receives once they complete all three levels. Adapted from Passport, In Taleo Learn, 2013, Retrieved May 28, 2013, from http://carnival.learn.com. Copyright 2013 by Taleo Learn. Reprinted with permission.

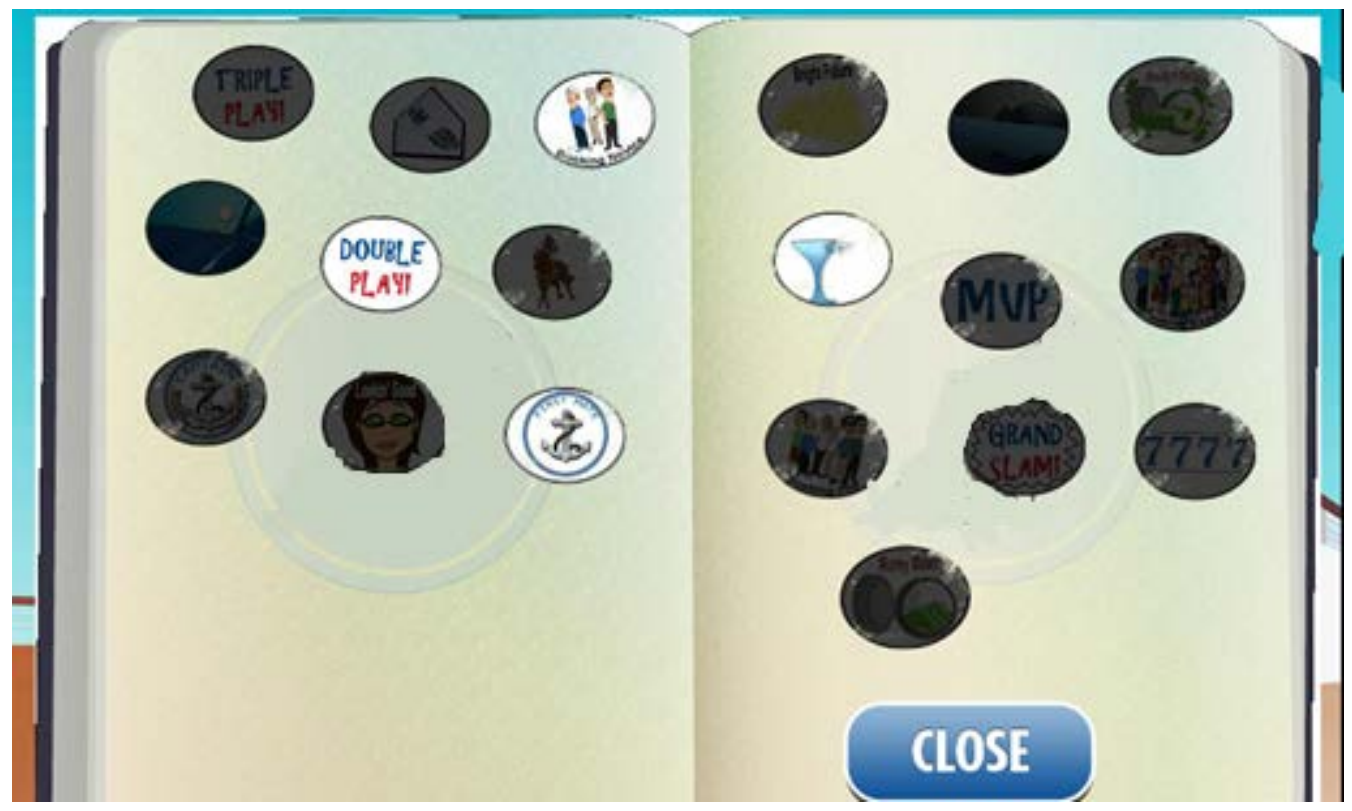

Figure 29: Achievements Screen. This figure is passport achievement screen available to each agent in the game. Adapted from Passport, In Taleo Learn, 2013, Retrieved May 28, 2013, from http://carnival.learn.com. Copyright 2013 by Taleo Learn. Reprinted with permission. 
VITA

\section{LIZETTE C. PABÓN}

\begin{tabular}{|c|c|}
\hline Place of Birth & New York, New York \\
\hline \multirow[t]{2}{*}{2003} & Bachelors of Arts in Neuroscience \\
\hline & Smith College, Northampton, MA \\
\hline \multirow[t]{2}{*}{$2005-2006$} & Graduate Assistant \\
\hline & Florida International University, Miami, Florida \\
\hline \multirow[t]{2}{*}{$2005-2006$} & Program Assistant/Course Developer \\
\hline & Florida International University, Miami, Florida \\
\hline \multirow[t]{2}{*}{$2006-2008$} & Senior Health Education Coordinator \\
\hline & Miami-Dade Area Health Education Center, Miami, Florida \\
\hline \multirow[t]{3}{*}{2007} & MPH, Health Promotion and Disease Prevention \\
\hline & Florida International University \\
\hline & Miami, Florida \\
\hline 2007 & Certified Health Education Specialist \\
\hline \multirow[t]{2}{*}{2008 - 2009} & Tobacco Prevention Specialist \\
\hline & Miami-Dade County Health Department, Miami, Florida \\
\hline \multirow[t]{2}{*}{$2009-2010$} & Specialist, Computer Applications for Educational Technology \\
\hline & Florida International University, Miami, Florida \\
\hline \multirow[t]{2}{*}{2009 - 2011} & Adjunct Professor \\
\hline & Florida International University, Miami, Florida \\
\hline \multirow[t]{2}{*}{$2010-2012$} & Senior Learning Consultant \\
\hline & AvMed Health Plans, Miami, Florida \\
\hline \multirow[t]{2}{*}{2010 - 2016} & Doctoral Candidate \\
\hline & Florida International University, Miami, Florida \\
\hline \multirow[t]{2}{*}{2012 - Present } & Instructional Design Specialist \\
\hline & Carnival Cruise Line, Miami, Florida \\
\hline
\end{tabular}




\section{PUBLICATIONS AND PRESENTATIONS}

Osterman, M., Thirunarayanan, M., Ferris, E. C., Pabon, L. C., Paul, N. \& Berger, R. (2012). Museums and Twitter: An exploratory qualitative study of how museums use Twitter for audience development and engagement. Journal of Educational Multimedia and Hypermedia, 21, 241-255.

Paul, N., Berger, R., Pabon, L., Osterman, M. \& Thirunarayanan, M. (2010). Age and sex related similarities and differences in web searching behavior: Results of four selective case studies. In J. Herrington \& C. Montgomerie (Eds.), Proceedings of EdMedia: World Conference on Educational Media and Technology 2010 (pp. 824-831). Vancouver, CA: Association for the Advancement of Computing in Education (AACE).

Thirunarayanan, M. O., Berger, R., Paul, N., Pabon, L., Osterman, M. \& Ferris, E. (2010). The use of Tweets in formal and informal educational settings. In J. Sanchez \& K. Zhang (Eds.), Proceedings of E-Learn: World Conference on ELearning in Corporate, Government, Healthcare, and Higher Education 2010 (pp. 2231-2234). Chesapeake, VA: Association for the Advancement of Computing in Education (AACE).

Zamboanga, B. L., Bean, J. L., Pietras, A. C., \& Pabon, L. C. (2005). Subjective evaluations of alcohol expectancies and their relevance to drinking game involvement in female college students. Journal of Adolescent Health, 37, 77-80. 